\title{
O Papel do Estado Nutricional na Reinfecção Pós-tratamento Antiparasitário em Crianças Residentes no Município de Santa Isabel, SP.
}

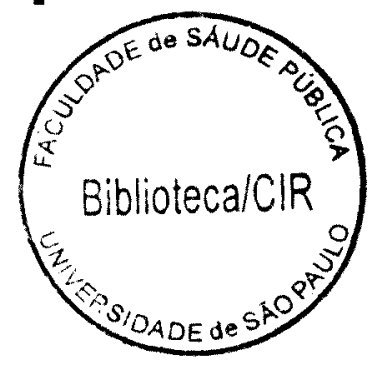

Silvia Regina Dias Medici Saldiva

Tese de Doutorado apresentada ao Departamento de Epidemiologia da Faculdade de Saúde Pública da Universidade de São Paulo para obtenção do Grau de Doutor.

Área de Concentração:

Epidemiologia

Orientador: Prof. Dr. Eduardo Massad

São Paulo 
Autorizo, exclusivamente para fins acadêmicos e científicos, a reprodução total ou parcial desta tese, por processos fotocopiadores.

Silvia Saldiva

Data: 28.10 .1999

$39204 / 2000$ (doc) 
Esta tese teve o apoio financeiro da FAPESP - Fundação de Amparo à Pesquisa do Estado de São Paulo.

Processos n ${ }^{0}: 95 / 6573-2$ e 96/7413-1. 
Paulo, Lucas e Leonardo

Meus amores eternos

José Luiz e Wilma

Meus pais 


\section{Agradecimentos}

A todas as crianças que participaram deste projeto, porque sem elas nada seria possível e, também, a todas as mães que, com paciência e determinação colaboraram durante um longo ano.

Ao Prof. Dr. Eduardo Massad, meu orientador, pela compreensão e competência demonstrada ao longo de todos estes anos. Muito obrigada por me oferecer tantas oportunidades.

Ao Dr. Heráclito Carvalho de Barbosa meu amigo e colaborador, sempre atento e disposto a me socorrer nos momentos mais difíces, e principalmente, por sua infinita paciência.

Ao Dr. Paulo Salum por sua amizade e por facilitar todos os caminhos até Santa Isabel.

Ao Dr. Paulo Cesar Dornellas do Nascimento, Secretário da Saúde de Santa Isabel, por colocar à nossa disposição toda infra-estrutura da Secretaria, com tanta consideração e estima.

À Sra. Maria Angela Sanches, Prefeita de Santa Isabel, por permitir o desenvolvimento deste projeto e ainda por ter nos recebido com tanto entusiasmo. 
À Dra. Vera Pagliusi Castilho, por ter aberto as portas da Seção de Parasitologia para este projeto, e ainda pela competência e dedicação com que providenciou todos os exames.

Às meninas da Seção de Parasitologia do Laboratório Central do Hospital das Clínicas: Dorca Lopes, Vergínia Aparecida dos Santos, Iaiko Horroiva Uemura, Margareth Kazumi Ueda, Elenice Messias do Nascimento. Gonçalves, Divina Venâncio do Espírito Santo, Valeria Aparecida Faria, Reginalda Emília Jorge, Loide Lopes, Noelia Goes Rosa Fernandes, Valquíria Antonia Luciano, que com carinho receberam a incumbência mais difícil deste projeto, ou seja, o preparo e a leitura de tantos milhares de exames

Ao Wladimir Ribeiro dos Santos pela dedicação com que digitou e conferiu todos os laudos.

Ao Prof. Dr. Paulo Silveira pela compreensão e paciência que sempre demonstrou ao me socorrer das armadilhas da informática.

Ao Roberval da Silva por sua dedicação e eficiência, e ainda por nos oferecer tanta tecnologia e apoio.

Ao Wanderlei, conhecido por "Só por Deus", que nos conduziu com tanta alegria e boa vontade a todos os lugares e "buracos"de Santa Isabel.

Ao Rob Rubens Boccia, nosso piloto de Kombi, navegador seguro neste vai-e-vem da Dutra. 
Aos motoristas Marcos, Tarcísio, Ronaldo que em algumas etapas do projeto, nos acompanharam.

Ao Valtair de Santana, Matilde Maciel, Maria Eunice Pereira meus supervisores de campo, pela inestimável ajuda, dedicação e companheirismo, com que me acompanharam neste longo período de coleta de dados.

Às minhas queridas meninas Marlene Aparecida Alves, Maria José Silva dos Santos, Selma de Miranda, Leila Batista da Silva, Elisângela Conceição de Jesus, Adriana Cristina Viana, Lucimara de Oliveira Carvallho, pela amizade, confiança, responsabilidade, bom humor (com direito a "grito de guerra") e dedicação com que enfrentaram tantos obstáculos.

Aos meus meninos Saulo Rodrigues dos Santos e Luis Gustavo Oliveira Carvalho pela dedicação e seriedade que dispensaram a este trabalho.

A Ingrid Werneck de Oliveira, nossa secretária de campo em Santa Isabel, pela competência e zêlo com que preparava todas as listas de campo.

Às senhoras Dalva dos Santos Lobo e Maria Luiza Brustolin Soares, do grupo da $3^{a}$ idade de Santa Isabel, que na fase inicial do projeto, se empenharam com energia para o bom andamento da pesquisa. 
A Rosilda Maria Vieira Rodrigues diretora da Escola de Auxilar de Enfermagem de Santa Isabel, pelo apoio e colaboração no recrutamento dos estudantes, ajuda imprescindível.

A Maria José, enfermeira e professora do Centro de Saúde Ilário Dassiê pela dedicação com que abraçou a nossa causa, excercendo papel importante na coordenação dos auxiliares de enfermagem.

A todos os estudantes da Escola de Auxiliar Enfermagem de Santa Isabel, que apesar das intemperies, lamas, ladeiras e outros obstáculos, enfrentaram com otimismo e responsabilidade as fases de tratamento das crianças. Entre eles, queria principalmente agradecer o pessoal de Igaratá, que mesmo após o plantão noturno, ainda tinha disposição em nos ajudar.

A Alexandra Rufino, que no início do projeto tanto me ajudou com compras de materiais, etiquetas e preparo do campo.

Ao Professor Carlos Augusto Monteiro pelo empréstimo dos antropômetros e estadiômetros.

Ao Volney Lisboa Conde, pela simpatia com que me recebeu sempre que eu precisei.

À Prof ${ }^{a}$. Dra. Maria do Rosário Dias de Oliveira Latorre por me apresentar o "SPSS" e pelo carinho com que me recebeu.

À Prof ${ }^{a}$. Dra. Carmem Diva Saldiva por me apresentar os estatísticos. 
Aos estatísticos Prof. Dr. Antônio Carlos Pedroso de Lima e Lilian Lima , pelas sugestões feitas durante as análises estatísticas.

A Maria Lúcia de Faria Ferraz, bibliotecária da Faculdade de Saúde Pública, por sua atenção e competência na revisão bibliográfica.

A Tânia Maria Queiroz Reis Boccia, pela digitação dos laudos no início da pesquisa.

A Iracene Aparecida Boccia Fichamnn, pela disposição e eficiência com que providenciou toda a documentação junto a FAPESP, e ainda, pelo carinho e respeito.

Ao Flamínio Fichmann por ter me enviado os mapas geográficos.

Ao Rubens Boccia pelas fotos e slides de Santa Isabel.

Ao Ricardo de Leonardo, Marcelo Salavee e Paulo Simionato, pelo suporte de estrutura e manutenção em informática.

A Vilma Duarte Sanches, nossa querida secretária, pela simpatia, competência e carinho.

Aos meus irmãos: José Luiz, Ligia e Mônica.

À Dra. Ana Silvia Barreiro Silveira pela amizade e carinho.

A Maria Edileuza dos Santos, meu anjo da guarda, que segurou todas as barras, meu eterno agradecimento. 
Aos colegas da Disciplina de Informática Médica.

A todos aqueles que diretamente ou indiretamente contribuíram na execução deste projeto. 


\section{Resumo}

Saldiva, SRDM. Papel do estado nutricional na reinfecção pós-tratamento antiparasitário em crianças residentes em 3 bairros do município de Santa Isabel,SP. São Paulo, 1999. [ Tese de Doutorado - Faculdade de Saúde Pública da Universidade de São Paulo].

O presente trabalho têm como objetivo avaliar o papel do estado nutricional na infecção ou reinfecção por parasitas intestinais após tratamento quimioterápico em crianças de 1 a 10 anos de idade. O estudo foi planejado como epidemiológico longitudinal (coorte prospectiva) com acompanhamento bimensal da população alvo pelo período de 1 ano. O trabalho foi desenvolvido em 3 bairros com características semi-urbanas do Município de Santa Isabel: Jardim Novo Éden, Jardim das Acácias e Jardim Eldorado. O município de Santa Isabel está a $65 \mathrm{Km}$ de distância de São Paulo. O início do trabalho foi em outubro de 1997. Todas as residências dos 3 bairros foram visitadas e as crianças na faixa etária escolhida foram convidadas a participar do estudo. Tivemos 58 crianças em que os pais se recusaram a participar. Todas as crianças que participaram do estudo tiveram a autorização dos pais com a assinatura do consentimento pósinformado. O total de crianças estudadas foi de 759. Foram aplicados questionários sobre a saúde da criança, tomada de medidas de peso e altura, recolhidas 3 amostras de fezes. Após o resultado do primeiro exame de fezes todas as crianças receberam tratamento com Panfugan (mebendazol) com reforço após 15 dias e comprovação da cura através de novo exame protoparasitológico. As crianças que apresentaram positividade para Giardia lamblia e Entamoeba histolytica receberam Secnidal (secnidazol). Os períodos de coletas de dados após o tratamento antiparasitário foram: 12 a 17 de Janeiro, 23 de Março a 07 de Abril, 24 de Maio a 9 Junho, 06 a 12 de Agosto, 19 a 27 de Outubro no ano de 1998. Em uma sub-amostra da população estudada foram preenchidos questões sobre as condições sócio-econômica e cultural das familias, e ainda foi aplicado o Recordatório 24 horas para conhecermos o consumo alimentar das crianças. Os métodos utilizados na identificação dos ovos e larvas dos parasitas foram: Hoffman e col., Rugai e col., Faust e col. e para a contagem de ovos foi utilizado o método de Kato-Katz. Para avaliar o perfil nutricional das crianças foi 
utilizado o padrão de referência do National Center Health Statistics (NCHS) e os "scores" de desvio padrão (Zscores) para os índices de peso para altura (WHZ) e altura para idade (HAZ). As análises estatísticas univariadas foram realizadas por meio do teste do qui-quadrado, e para as análises de "sobrevida" foi utilizado o modelo de riscos proporcionais de Cox.

Os resultados mostraram que a prevalência inicial de helmintos foi de 33,6\% (255), e os parasitas mais prevalentes foram Ascaris lumbricoides 18,9\%(143) e Trichuris trichiura $16,9 \%$ (128). Foi encontrada uma prevalência de $8 \%$ (61) de desnutrição infantil. A infecção concomitante de Ascaris e Trichuris foi observada em 26\%(11) dos desnutridos, mostrando uma associação positiva entre as duas variáveis. Após o tratamento antiparasitário as crianças desnutridas infectaram-se numa proporção maior que as crianças eutróficas. Os resultados obtidos através do modelo de Cox mostraram que os desnutridos têm um risco de infecção por helmintos de $\boldsymbol{R} \boldsymbol{R}=1,726 \boldsymbol{p}=0,0326 \mathrm{e}$ um risco para reinfecção de $\boldsymbol{R} \boldsymbol{R}=2,2921 \boldsymbol{p}=0,0029$, mesmo controlando este risco com a idade da criança e o local de moradia. Estes resultados indicam que as crianças desnutridas são mais susceptíveis a infecção e reinfecção por helmintos.

Descritores: Helmintíases, Ascaris lumbricoides, Trichuris trichiura, Estado nutricional, Crianças com idade entre 1 a 10 anos. 


\section{Summary}

Saldiva, SRDM. Papel do estado nutricional na reinfecção pós-tratamento antiparasitário em crianças residentes em 3 bairros do município de Santa Isabel,SP. [The role of nutritional status in helminthic infections in school children living in Santa Isabel, São Paulo, Brazil]. São Paulo, 1999. [ Tese de Doutorado Faculdade de Saúde Pública da Universidade de São Paulo].

This work was designed to verify the effects of nutritional status on the infection or reinfection of children ( 1 to 10 years of age) previously treated for helmints. The study desing was prospective cohort, with evaluation every 2 months. The investigation was carried out in 3 semi-urban locations - Jardim Novo Éden, Jardim das Acácias e Jardim Eldorado, belonging to the municipality of Santa Isabel, $65 \mathrm{~km}$ far from São Paulo. The study started in October 1997. All residences of the 3 locations were visited and children within the age range of interested were invited to join the study. Only 58 children were not enrolled, and the population investigated comprised 759 individuals, after obtaining the informed consent agreed upon by their parents. A questionnaire about children's health, measurements of height and weight and 3 stool samples were the information gathered at the first approach. After the results of the stool examination, children were treated with Panfugan (mebendazole), with a boost given after 15 days. The value of treatment was confirmed by a second stool examination. Children that presented infection by Giardia lamblia and/or Entamoeba histolytica received Secnidal (secnidazole). After this, new measurements were taken in the following periods: 12 to 17 of January; 23 of March to 7 of April; 24 of May to 9 of June; 6 to 12 of August; and 19 to 27 of October of 1998. A sub-sample of the studied population was investigated about their socio-economic conditions, educational background; in addition, a 24-hour record about food intake was also obtained. The nutritional status was evaluated by means of Z-scores of the indices of weigh for height and height for age. Statistical analyses were done by means of the chi-square statisticis and survival analysis using multivariated Cox proportional hazards models.

The results disclosed that the prevalence of helminths was $33.6 \%$ (255), and the most prevalent parasites were Ascaris lumbricoides (18.9\% - 143) and Trichuris trichiura 
(16.9\% - 128). Malnutrition was found in $8 \%(61)$ of the studied children. The simultaneous infection by Ascaris and Trichirus was observed in $26 \%$ (11) of malnutrition children, disclosing a positive and significant association between these two conditions. After treatment, malnutrition children got infected in a greater proportion than those without malnutrition. The coefficients of the Cox proportional hazards models indicated that malnourished children have a greater risk for helminthic infection (RR 1.726) and for re-infection (RR 2.29), after controlling for age and housing. The results indicate that malnutrition children are at a greater risk to develop infection and re-infection by helminths.

Descriptors: Helminthic infections, Ascaris lumbricoides, Trichuris trichiura, Nutritional health, Pre-School and School children 


\section{Índice}

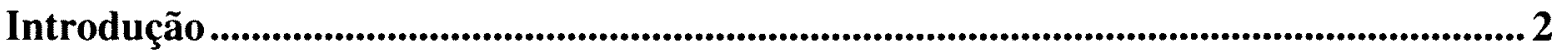

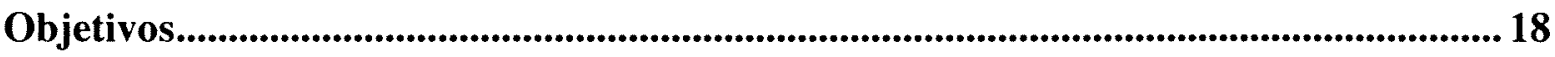

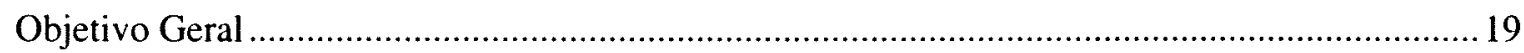

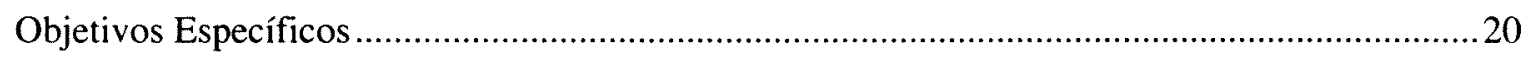

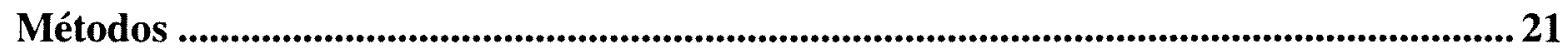

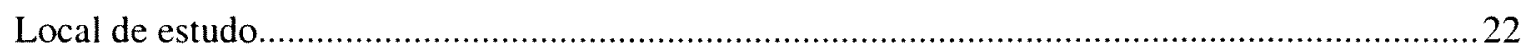

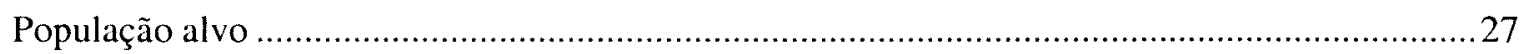

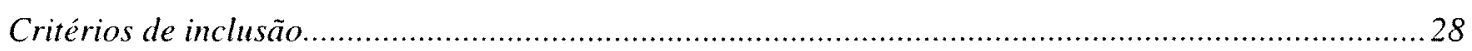

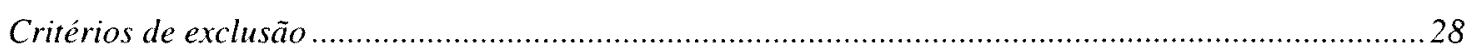

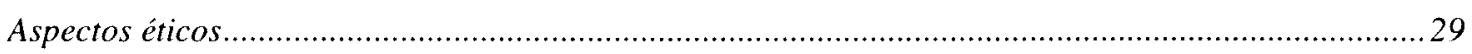

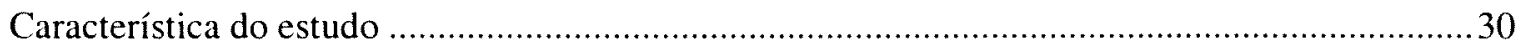

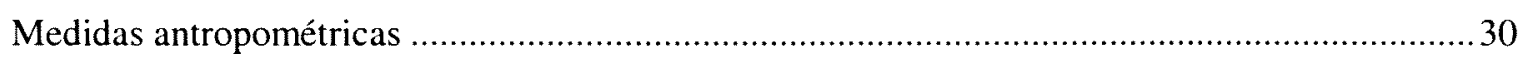

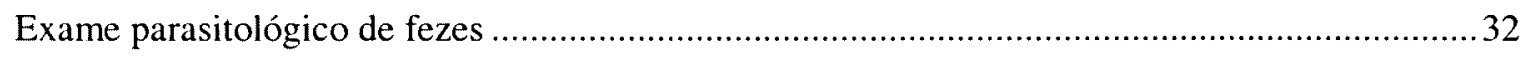

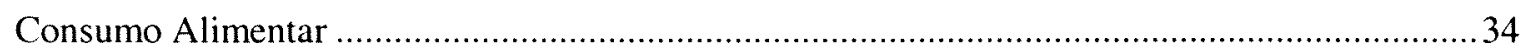

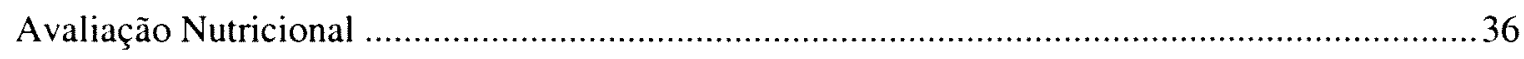

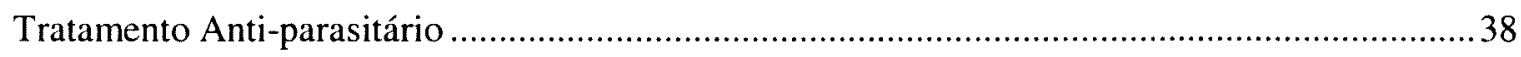

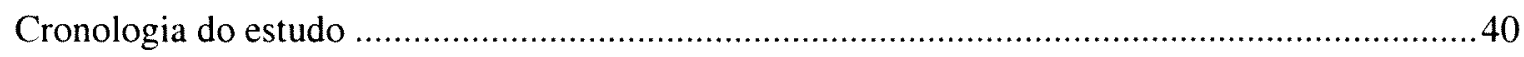

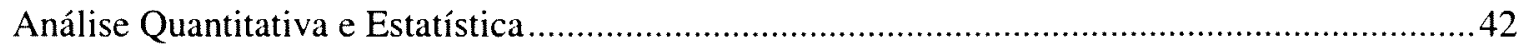

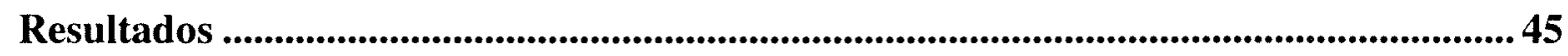

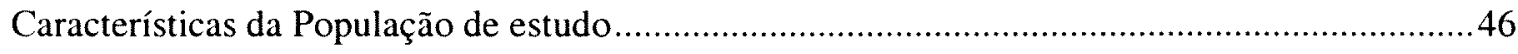

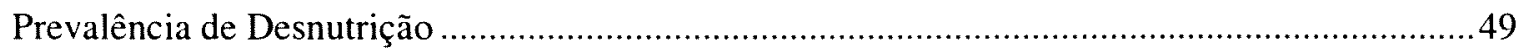

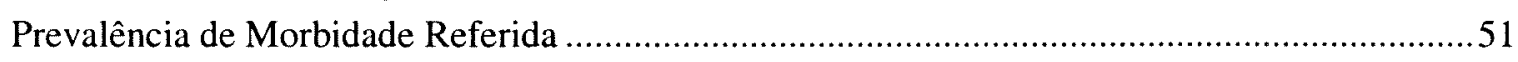

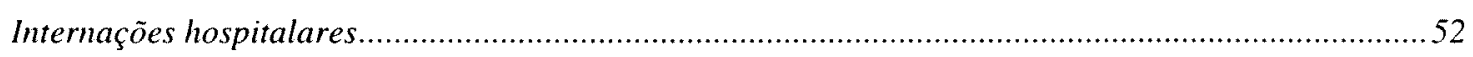

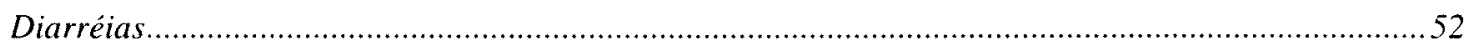

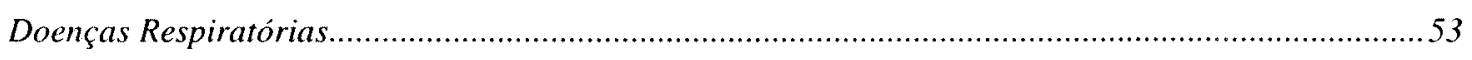

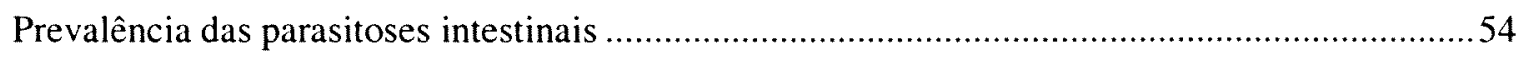

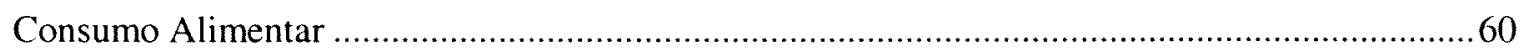

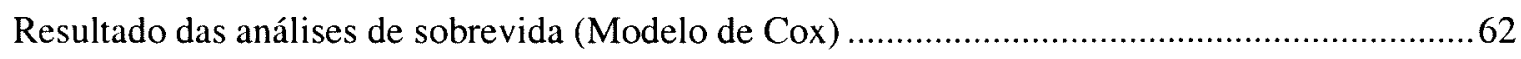

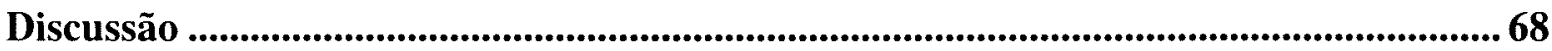

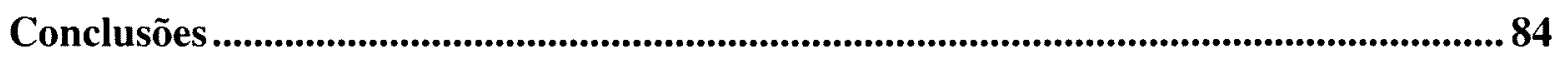

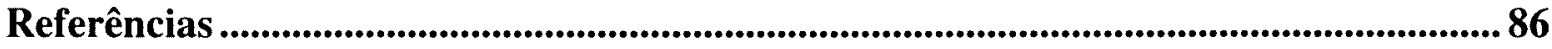

Anexos........................................................................................ Erro! Indicador não definido.

Anexo 1 - Termo de consentimento pós-informado

Anexo 2 - Ficha individual

Anexo 3 - Ficha social

Anexo 4 - Recordatório 24 horas 
Infecções por helmintos representam uma das infecções mais comuns em humanos, com uma distribuição global com mais de 1471 milhões de casos, indicando que ela afeta mais de um quarto da população mundial (Chan e col. 1994a). Só nos países do Terceiro Mundo afetam aproximadamente 800 milhões de pessoas (Simeon,1995). Ascaris lumbricoides e Trichuris trichiura são os parasitas mais prevalentes em crianças em idade escolar, que podem apresentar infecções de grande intensidade (Bundy e col.,1987). Uma nova estimativa de risco para infecção de Ascaris mostra um total de 59 milhões de pessoas com risco de déficit de saúde decorrente de infecção, dos quais 1,5 milhão de crianças apresenta um risco permanente de déficit de saúde (de Silva e col., 1997a).

No Brasil, desde a década de 40, muitos trabalhos tentam dimensionar a prevalência das parasitoses intestinais. No entanto, estes trabalhos refletem apenas a realidade de pequenas localidades, tornando-se difícil um diagnóstico abrangente da situação do país (Waldman, 1995). No Estado de São Paulo, alguns levantamentos feitos por Chieffi e col. (1982) sobre os resultados de exames parasitológicos realizados nas décadas de 60 e 70 pela clientela das unidades sanitárias da Secretaria Estadual de Saúde, mostraram uma diminuição na freqüência de exames positivos para ascaridíase tanto no interior do estado como na região metropolitana. A prevalência de ascaridíase no interior do Estado de São Paulo em 1979 era de pouco menos de $20 \%$ e na região metropolitana de pouco mais de 20\% (Waldman,1995).

Segundo a Organização Mundial de Saúde (WHO,1981), áreas endêmicas de infecção por Ascaris apresentam condições favoráveis para 
reinfecção, especialmente em crianças, por diversas razões: deficiência de higiene pessoal, estado nutricional comprometido, más condições sanitárias, baixo desenvolvimento de imunidade do homem, assim como exposição ao grande número de ovos descarregados diariamente. A taxa de ovos descarregados por dia no solo é ao redor de 200.000 ovos por fêmea adulta. Esta grande oviposição é feita durante um a dois anos e a sobrevida destes ovos no solo é de mais de um ano (Muller,1975).

Os helmintos apresentam grande diversidade em sua estrutura, fisiologia e comportamento. Esta diversidade é consequiência das suas múltiplas adaptações para um adequado ciclo de vida no hospedeiro. (Whitfield, 1996).

A ingestão de ovos inicia, na maioria dos casos, o ciclo de vida dos helmintos no seus hospedeiros. Exemplos característicos deste processo são a ascaridíase e tricuríase, onde os ovos são ingeridos de forma direta (com os alimentos ou pela água) ou indiretamente pelas moscas, por condições de higiene e saneamento básico insatisfatórios. O Ascaris lumbricoides tem a propriedade de atravessar a mucosa, visto que, após sua ingestão, o ovo abre-se no duodeno e a larva penetra na mucosa, dando início à fase de migração tissular (Miranda e col., 1997).

Em outras situações, pode ocorrer infeção por outros mecanismos. Nos ancilostomídeos, a continuidade do ciclo é garantida pelas larvas rabditóides geradas a partir de ovos embrionados, que evoluem para larvas filarióides infectantes e penetram através da pele (Miranda e col., 1997). 
O ciclo do Enterobius vermicularis inicia quando os ovos embrionados são ingeridos ou inalados pelo hospedeiro e desenvolvem-se até a fase adulta no intestino. As fêmeas, após fecundadas, migram para o reto e ânus, onde depositam seus ovos (Miranda e col., 1997).

O Strongyloides stercoralis possui ciclo bastante complexo, envolvendo uma fase onde pode ocorrer um ciclo direto ou assexuado e outra fase onde ocorre um ciclo indireto ou sexuado. As larvas rabditóides, eliminadas junto com as fezes podem evoluir no solo sob uma forma infectante para o hospedeiro, ou, alternativamente, podem dar origem a formas adultas (macho e fêmea), que terão vida livre. Há possibilidade de ocorrer um ciclo sem uso do solo para atingir o homem - a auto-infecção externa- na qual as larvas rabditóides evoluem para filarióides nas margens do ânus, onde penetram, atingem os vasos sanguíneos. Após o desenvolvimento de um ciclo pulmonar, estas larvas podem ser eliminadas pelo transporte mucociliar e ser deglutidas, alcançando novamente o intestino delgado. A auto-infecção interna ocorre quando essa transformação se dá ainda na luz intestinal, iniciando sucessivos ciclos, responsáveis por quadros de prolongado parasitismo (Miranda e col., 1997).

A ação patogênica que os helmintos exercem no ser humano depende de fatores relacionados ao parasita, ao hospedeiro e meio ambiente. Evidentemente, a gravidade da manifestação das parasitoses é altamente dependente da intensidade da infecção. Outros fatores relacionados ao parasita são também significativos para determinar a gravidade da doença, tais como a espécie envolvida e a sua patogenicidade, as associações parasitárias, e o sítio de 
localização. No entanto, fatores pertinentes ao hospedeiro também são significativos na determinação dos efeitos patológicos das parasitoses. Entre estes é importante ressaltar o grau de nutrição e a resistência do hospedeiro (Cook, 1986).

$\mathrm{Na}$ realidade, os fatores acima apontados indicam que as infecções por parasitas podem variar de situações subclínicas à forma mais graves, e desta maneira, determinar doença fatal.

Muitos estudos apontam para a diferença entre a prevalência de infecção e prevalência de doença, que resultam de duas características gerais de infecção por helmintos. Primeiro, muitas espécies de helmintos não se multiplicam dentro dos seus hospedeiros, sendo que os vermes são adquiridos no meio ambiente por exposição contínua aos estágios infectantes dos parasitas. Infecções com poucos parasitas são usualmente assintomáticas, sendo que a probabilidade de manifestação da doença aumenta proporcionalmente com o aumento da carga parasitária. Outro fator de importância é a maneira pela qual a população de helmintos é distribuída na população de hospedeiros. Em áreas de grande prevalência, é muito comum que aproximadamente $70 \%$ dos helmintos estejam albergados em torno de $15 \%$ de toda população infectada, sendo que a maioria dos portadores tendem a ser levemente infectados e não desenvolvem doença (Bundy e col. 1992).

As razões pelas quais os parasitas são agregados na minoria da população hospedeira não são totalmente conhecidas, mas podem estar relacionadas ao comportamento do hospedeiro, à distribuição desigual dos 
estágios infectantes no meio ambiente, ou ainda na diferença de habilidade da resposta imune do hospedeiro (Hall, 1992). Em trabalho recente, Kightlinger e col. (1996) relataram que, em um estudo realizado em Madagascar, a intensidade de agregação parasitária não parece depender do estado nutricional do hospedeiro

Estas características gerais da infecção por helmintos sugerem que a morbidade causada pelos parasitas pode ser controlada através de tratamento quimioterápico somente nos indivíduos maciçamente infectados na comunidade. Esta concentração preferencial da maioria dos parasitas em uma fração relativamente pequena da população infectada favoreceria o controle quimioterápico da infecção, dado que o tratamento de uma subpopulação poderia reduzir significativamente a carga parasitária de uma comunidade (Ruiz e col., 1996). Outro estudo desenvolvido em Bangladesh por Hall e col. (1992) sobre intensidade de reinfecção com Ascaris lumbricoides, mostrou que o tratamento anti-parasitário tem um efeito muito maior na intensidade de infecção do que na prevalência, e ainda que o tratamento quimioterápico em massa periodicamente é muito mais efetivo como medida de controle de morbidade do que o tratamento seletivo dos indivíduos maciçamente infectados. Entretanto, essa questão é ainda controversa e estudos futuros poderão contribuir para a definição de uma estratégia ótima de intervenção. 
Além dos aspectos acima expostos, existem alguns pontos relevantes da infecção por Ascaris, Trichuris e Ancilostomídeos que são significativos do ponto de vista da sua distribuição em comunidades endêmicas que podem ser resumidos da seguinte forma (Anderson,1986):

- Os parasitas comportam-se de forma diferente para os diversos estratos da comunidade, assim como para as diferentes faixas etárias e entre os sexos. Em outras palavras, crianças tendem a apresentar maior prevalência de infecção por Ascaris e Trichuris, ao passo que a prevalência de Ancilostomídeos é maior em adultos. Por outro lado, crianças do sexo masculino tendem a ter maior prevalência de parasitas quando comparadas com meninas vivendo no mesmo ambiente e com nível sócio-econômico semelhante.

- Alguns dos aspectos acima descritos para prevalência também ocorrem quando se avalia a intensidade de infecção. Existem variações na média de intensidade da infecção de acordo com a idade, ou seja o pico de intensidade de infecção, para alguns parasitas como Ascaris e Trichuris, está mais relacionado às crianças do que aos adolescentes e adultos (Anderson \& May, 1985).

- A fecundidade do verme, em geral, tende a declinar quando a carga parasitária do hospedeiro tende a aumentar, ou seja, quando o hospedeiro alberga muitos parasitas as fêmeas diminuem a oviposição. Esta dependência da densidade foi relatada para parasitas do tipo Ancilostomideos, Ascaris e Trichuris. 
- A reinfecção após o tratamento quimioterápico tende a ser rápida, e depende de uma variedade de fatores relacionados às características do helminto e dos hospedeiros (Anderson \& Medley,1985).

A alta intensidade de infecção é geralmente observada em crianças em idade escolar que contribuem mais para a transmissão parasitária do que os aspectos do comportamento humano relativos a falta de higiene. As crianças adquirem mais infecção e contaminam mais o ambiente do que o adulto (Chan e col., 1994b).

A presença de parasitas intestinais representa um fator agravante da desnutrição, seja pela diarréia crônica, seja pela competição pelo alimento ingerido (Gupta, 1980; Blumenthal \& Schutz,1976; Saldiva e col.,1999), contribuindo para a piora das condições de saúde da população. Nos países chamados de Terceiro Mundo o papel patogênico das parasitoses intestinais faz-se sentir com maior intensidade pela existência de amplos segmentos populacionais vivendo em áreas sem saneamento básico, sob condições habitacionais precárias e submetidos a condições alimentares deficientes (Waldman e col., 1995).

A magnitude do impacto das parasitoses intestinais sobre a saúde humana depende do tipo de efeito que é utilizado na sua avaliação. Uma das consequiências onde a relação causa - efeito está bem determinada é a anemia ferropriva, especialmente nas infecções por Ancilostoma e Necator. Estes parasitas interferem diretamente com a eficiência da absorção de ferro no trato gastrointestinal, bem como aumentam a perda de ferro por meio de sangramento oculto ocasionado pelas ulcerações intestinais (Crompton e col. 1993). Embora a 
anemia ferropriva conseqüente à infecção pelos parasitas acima seja mais associada a adultos, existem evidências provindas de trabalhos de campo na África que indicam que infecções por Ancilostoma e Necator podem ser responsáveis por anemia em crianças.

Ao contrário dos parasitas descritos acima, as infecções por Ascaris e Trichuris são consideradas como causadoras de poucas repercussões clínicas. No entanto, existe atualmente um conjunto de informações significativas relacionando a presença destes parasitas com retardo do desenvolvimento somático e desnutrição (Thein-Hlaing e col., 1991, Stephenson e col., 1993 a,b).

Um esquema representativo dos mecanismos pelos quais os parasitas podem influenciar o estado nutricional do hospedeiro foi apresentado por Lunn e Northrop-Clewes (1992):

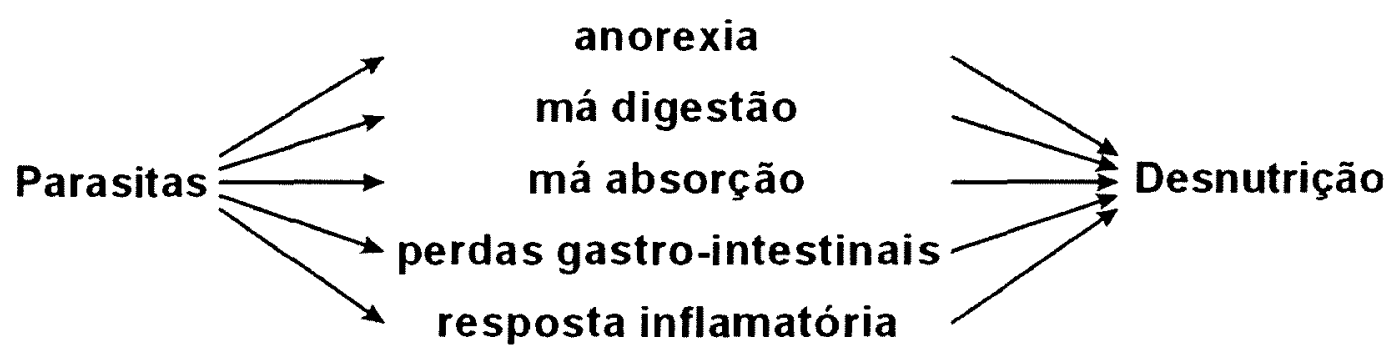

Figura 1 - Mecanismos das interações parasita - hospedeiro (modificado de Lunn e col., 1993).

Além dos prejuízos ao desenvolvimento somático e estado nutricional, mais recentemente as infecções parasitárias têm sido associadas com distúrbios cognitivos em crianças (Simeon e col., 1995 e Watkins e col., 1997). Inicialmente, embora presente, a caracterização precisa do papel das infecções parasitárias 
como fator causal das alterações de desenvolvimento e aprendizado não pode ser isolada do papel dos fatores sócio-econômicos. Posteriormente, estudos de intervenção puderam avaliar melhor o papel das parasitoses como causadoras de problemas de cognição. A síndrome diarréica provocada pela infecção pelo Trichuris trichiura foi associada com alterações do desenvolvimento intelectual de crianças jamaicanas em um estudo do tipo caso-controle (Callendar e col., 1992). Este achado foi confirmado por outro estudo de intervenção do tipo duplo cego com utilização de placebo (Nokes e col., 1992).

Como dito anteriormente, as infecções parasitárias apresentam, na grande maioria dos casos, uma evolução clínica oligosintomática e relativamente benigna. No entanto, nas suas formas mais graves, existe a possibilidade de morte diretamente causada por parasitoses intestinais. Nos casos de infecção maciça por Ascaris e/ou Trichuris, podem ocorrer formas graves, com desenvolvimento de quadros obstrutivos de intestinos ou vias biliares, apendicites, peritonites, as quais, em alguns casos, pode ser fatal (WHO,1987). Embora este tipo de complicação seja relativamente raro, deve-se sempre ter em perspectiva a grande prevalência das parasitoses no mundo, fazendo com que, mesmo uma complicação pouco freqüente possa ser responsável por um número significativo de mortes. A Organização Mundial da Saúde estima que, anualmente, 65.000 mortes sejam provocadas por parasitas do tipo do Ancilostoma e Necator, ao passo que 10.000 crianças morram por ano como conseqüência pelo Ascaris lumbricoides. 
Uma das alternativas para reduzir a gravidade do quadro acima descrito seria o tratamento maciço da população infectada, visando diminuir a transmissibilidade das enteroparasitoses. No entanto, o planejamento desta intervenção quimioterápica depende da determinação da taxa da reinfecção parasitária na população exposta, pois dela dependem as estratégias de controle das doenças parasitárias. Assim sendo, diferentes estudos têm demonstrado uma alta taxa de reinfecção pelos enteroparasitas em populações submetidas a quimioterapia de massa, sendo que a prevalência dos mesmos atinge os níveis prétratamento em períodos de tempo não superiores a 1 ano (Anderson, 1982, Albonico e col., 1995). Os mecanismos que determinam o tempo de reinfecção são complexos, devendo ser considerada uma multiplicidade de fatores, tais como os hábitos culturais e alimentares, condições de saneamento básico e estrutura sócio-econômica da população.

Do ponto de vista teórico, as condições nutricionais, com a sua consequiente modulação do estado imunitário do hospedeiro, podem também se constituir em um aspecto determinante da eficiência de reinfecção. Tanto a desnutrição infantil, como conseqüência direta da fome, ou como produto da interação nutrição - infecção (mais comum nos países em desenvolvimento) provoca alterações na integridade da pele e mucosas, hipocloridria e anormalidades na flora intestinal. Crianças com desnutrição grave podem exibir diminuição nas células linfóides, prejuízo nas funções linfocitárias, e ainda diminuição na síntese de secreção de imunoglobulinas (Chandra e col., 1977 e DuPont e col., 1980). Experimentos com crianças desnutridas mostraram um aumento da gravidade, cronicidade e mortalidade devidas às infecções. A duração 
da doença e o estado de portador de certos agentes é geralmente mais longo em indivíduos desnutridos quando comparados com indivíduos eutróficos (Scrimshaw e col., 1959 e Mata, 1978).

Com uma privação alimentar grave, o hospedeiro depleta suas reservas orgânicas, o que pode inclusive levar a estados infecciosos subclínicos. Com a recuperação nutricional, estes indivíduos que tiveram jejum prolongado, passam a desenvolver manifestação clínica às infecções agudas (Murray e col., 1977). Infecções agudas geralmente aumentam a imunidade do hospedeiro contra alguns agentes, salvo exceções, como no caso do sarampo, que induz comumente a um imunodeficiência secundária (Targett, 1980).

Infecção e nutrição têm implicações importantes em Saúde Pública devido ao aumento de sintomas, duração e precipitação de desnutrição aguda, assim como o aumento da mortalidade devido aos dois processos (Scrimshaw e col., 1959; Mata, 1978; Chen e col., 1980). Investigações de interações entre nutrição e função imune têm sido conduzidas em humanos e em animais. Porém, é preciso reconhecer que em humanos a avaliação dos efeitos da desnutrição é mais complexa do que em modelos experimentais de deficiência em animais. Por exemplo, desnutrição em humanos raramente é de um único nutriente. Ela é geralmente complicada por outros fatores de perdas como a infecção, e desenvolve-se irregularmente no tempo, ao contrário do equilíbrio e do controle do processo imposto pelo modelo experimental. Todos estes fatores podem alterar o aparente impacto imunológico de mudanças no estado nutricional em humanos. 
Embora a solução do problema acima exposto seja a melhoria das condições sanitárias do meio ambiente e da higiene das pessoas, medidas de quimioterapia de massa periódicas são justificáveis para o controle da infecção e suas complicações, tanto para diminuir a carga parasitária nas pessoas infectadas, como para diminuir a morbidade associada a ela (WHO,1967; WHO, 1987; Davis, 1989).

As novas drogas testadas para o tratamento de infecções por helmintos são simples de usar, seguras, efetivas, relativamente de custo baixo e têm um amplo espectro de atividade. Albendazol e mebendazol são as drogas mais efetivas contra ascaridíases, trichuríases e ancilostomíases. A dose única recomendada pela WHO, 1987 de $400 \mathrm{mg}$ de albendazol ou $500 \mathrm{mg}$ de mebendazol pode não trazer uma cura completa, especialmente em infecções maciças, mas mostrou uma redução da carga parasitária significativa, e assim reduzindo o risco de morbidade. O uso tanto do albendazol quanto do mebendazol para tratamento de parasitas intestinais não apresenta efeitos colaterais. O custo das drogas varia entre US\$ 0,02 a US\$ 0,2 por dose (Bundy e col., 1998). Uma análise de custo do programa anual de tratamento de escolares em Gana e Tanzânia, mostrou que o custo foi inferior a US $\$ 1,00$ por criança tratada, mesmo utilizando-se duas drogas: mebendazol ou albendazol e praziquantel segundo a Partnership for Child Development, 1997.

Quando se propõe um esquema de tratamento de massa da população, há que se levar em conta a possibilidade de desenvolvimento de resistência por parte dos parasitas. Seria extremamente grave a situação onde os parasitas 
intestinais desenvolvessem resistência aos quimioterápicos de uma forma análoga à aquela das bactérias, especialmente no contexto hospitalar. Felizmente, este fenômeno - a resistência dos parasitas à ação das drogas anti - helmintícas não foi ainda observado em humanos. No entanto, há que se notar que o fenômeno de resistência a algumas drogas, como por exemplo, levamisole, já foi relatado na literatura veterinária (de Silva e col.,1997b). Este é um aspecto que deve ser continuamente monitorado quando se propõe a aplicação maciça de drogas anti parasitárias com a finalidade de tratamento populacional.

O Japão é o maior exemplo de sucesso no controle da prevalência de infecção parasitária após a Segunda Guerra Mundial. De acordo com as estatísticas a prevalência do parasitismo no Japão em 1949 era de $73 \%$, porém em algumas regiões atingia 80 a $90 \%$; a partir daí foi desenvolvido um programa nacional de controle de infecções de extensas proporção fazendo com que a prevalência fosse reduzida para menos que $1 \% \mathrm{em} 1990$.

A redução da prevalência das parasitoses no Japão foi eloquiente a ponto ser motivo de citação de várias publicações a este respeito. $O$ impressionante esforço empreendido por este país, envolveu não somente a quimioterapia de massa, mas, principalmente, modificou costumes sanitários de risco e, ao mesmo tempo, desenvolveu uma política nacional de melhoria dos serviços de água e esgotos. Para conseguir o objetivo proposto, o governo japonês realizou uma parceria com as instituições médicas, universitárias e da sociedade civil, compreendendo que uma das vertentes mais importantes da redução das 
parasitoses era aquela representada pela educação sanitária da população, começando pelos escolares.

Infelizmente, no Brasil, as condições para um esforço similar ao acima descrito ainda não estão disponíveis. Não é objetivo do presente trabalho realizar uma análise detalhada das políticas e medidas sanitárias necessárias para a erradicação das parasitoses no Brasil. No entanto, é importante que se conheça algumas variáveis importantes deste "quebra-cabeças", a começar pela definição do custo local da quimioterapia. Só para efeito de comparação, o preço do mebendazol vendido em drogarias ou farmácias é da ordem de US\$2,00 por dose, significativamente superior ao relatado nos estudos internacionais acima relatados.

Outros aspectos importantes a serem definidos passam pela exeqüibilidade de um tratamento quimioterápico na vigência de condições de educação e motivação da população bastante diversos, com acentuadas diferenças regionais ao longo do território nacional. O aspecto de motivação ainda é importante quando se visa modificar hábitos de higiene arraigados na população há longos períodos de tempo, que certamente demandarão um esforço continuado de colaboração entre os sistemas de saúde e de educação.

Mais complicado ainda é o delineamento de uma política de investimentos em medidas de saneamento básico de grande alcance que só podem ser empreendidas na esfera dos governos municipais e/ou estaduais.

Dada a abrangência do tema, foi necessária a definição de um direcionamento mais objetivo para o presente estudo. Este trabalho pretende contribuir para o esclarecimento desta questão, partindo da hipótese de que a 
desnutrição aumenta a suscetibilidade à infecção por enteroparasitas em crianças de idade escolar e pré- escolar.

O presente estudo foi desenvolvido no intuito de dar continuidade a algumas hipóteses levantadas no estudo transversal realizado em 1994, no município de São Miguel Arcanjo, para se conhecer a associação de desnutrição infantil e a presença de parasitas intestinais (Saldiva, 1995).

A presença de desnutrição crônica foi significativamente associada com indicadores de baixa renda, consumo protéico inadequado e poliparasitismo, especialmente a associação Ascaris lumbricoides + Trichuris trichiura, que possui maior poder de associação com a presença de desnutrição crônica do que cada um destes parasitas individualmente. A associação acima referida possui também correlação mais significativa com desnutrição do que poliparasitismo simples, ou seja, levando-se em conta qualquer combinação de parasitas (Saldiva e col.,1999). 


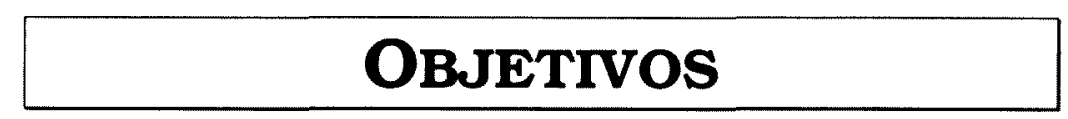




\section{Objetivo Geral}

O presente estudo têm como objetivo geral determinar o papel do estado nutricional na reinfecção por parasitas intestinais após quimioterapia de massa em crianças de 1 a 10 anos de idade residentes em 3 bairros com características semi-urbanas do Município de Santa Isabel, SP, acompanhadas pelo período de 1 ano. 


\section{Objetivos Especificos}

1. Determinar a prevalência de infecção do Ascaris lumbricoides e Trichuris trichiura de uma população vivendo em bairros com características semiurbanas do Município de Santa Isabel, SP;

2. Verificar a intensidade de infecção por Ascaris lumbricoides e Trichuris trichiura na população de estudo.

3. Verificar a prevalência de desnutrição na mesma população, através de indicadores antropométricos;

4. Quantificar o consumo alimentar da população de estudo;

5. Avaliar infecção por estes parasitas após quimioterapia na população de estudo;

6. Calcular a taxa de reinfecção destes parasitas em crianças eutróficas em comparação com crianças desnutridas, avaliados por indicadores antropométricos;

7. Calcular o risco relativo de reinfecção das crianças desnutridas em relação às crianças eutróficas. 


\section{Local de estudo}

O local escolhido para a realização deste estudo foi o município de Santa Isabel. Esta escolha deveu-se principalmente a 3 fatores: - informações obtidas junto à Secretaria Municipal de Saúde, que relatavam a presença de áreas com alta prevalência de enteroparasitoses; disponibilidade do Município em auxiliar o projeto, e finalmente a sua relativa proximidade a São Paulo que facilitava o desenvolvimento operacional da pesquisa.

Santa Isabel está localizado próximo ao município de Guarulhos, a 65 km de distância de São Paulo, capital.

O estudo foi desenvolvido em 3 bairros situados na periferia do Município de Santa Isabel, indicados pela Secretaria Municipal de Saúde pelo fato de serem áreas sem estrutura de apoio à saúde e com condições ambientais e de saneamento precárias. 


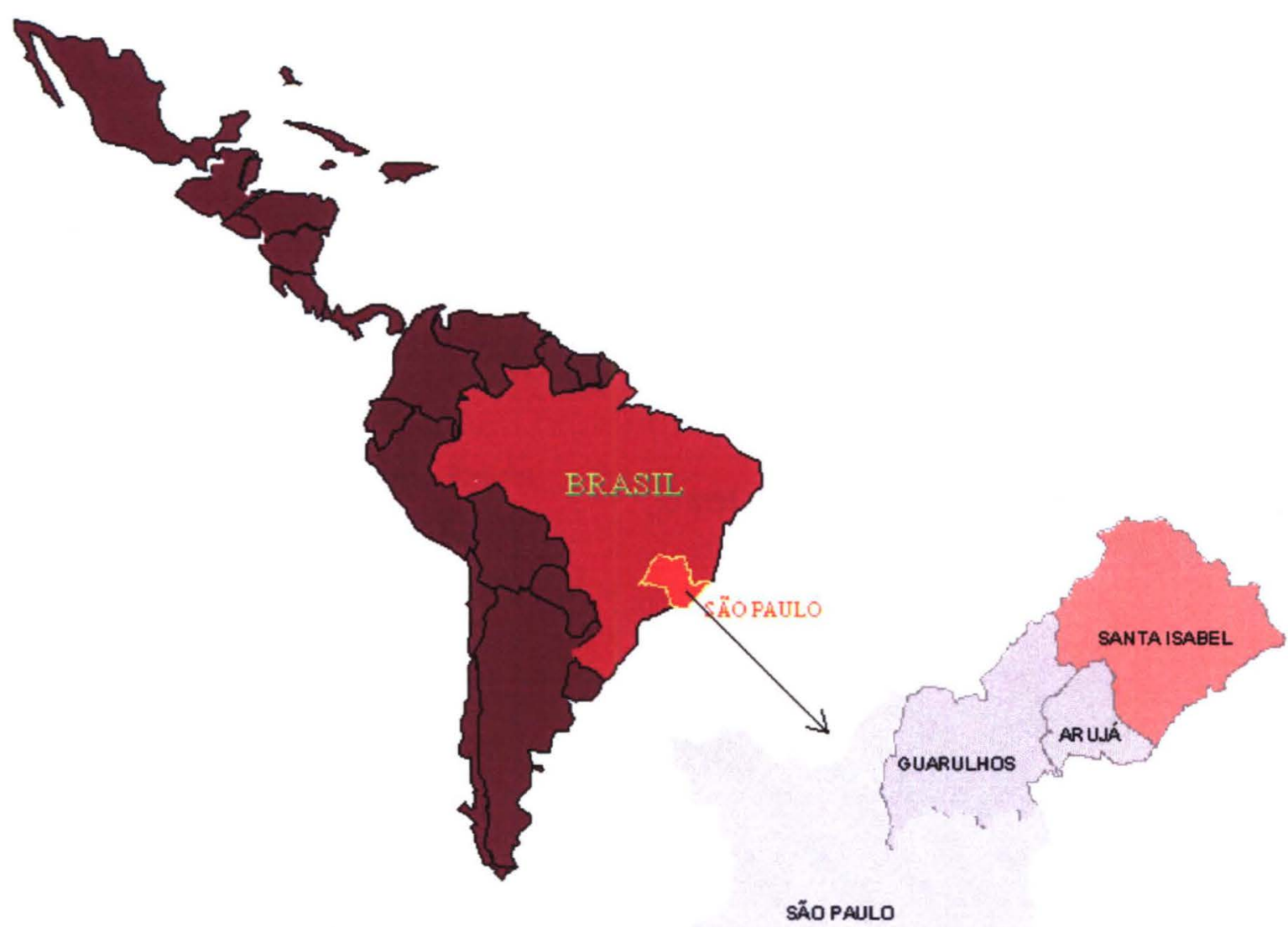

CAPITAL

Figura 2 - Localização do Município de Santa Isabel em relação à capital do Estado de São Paulo. 


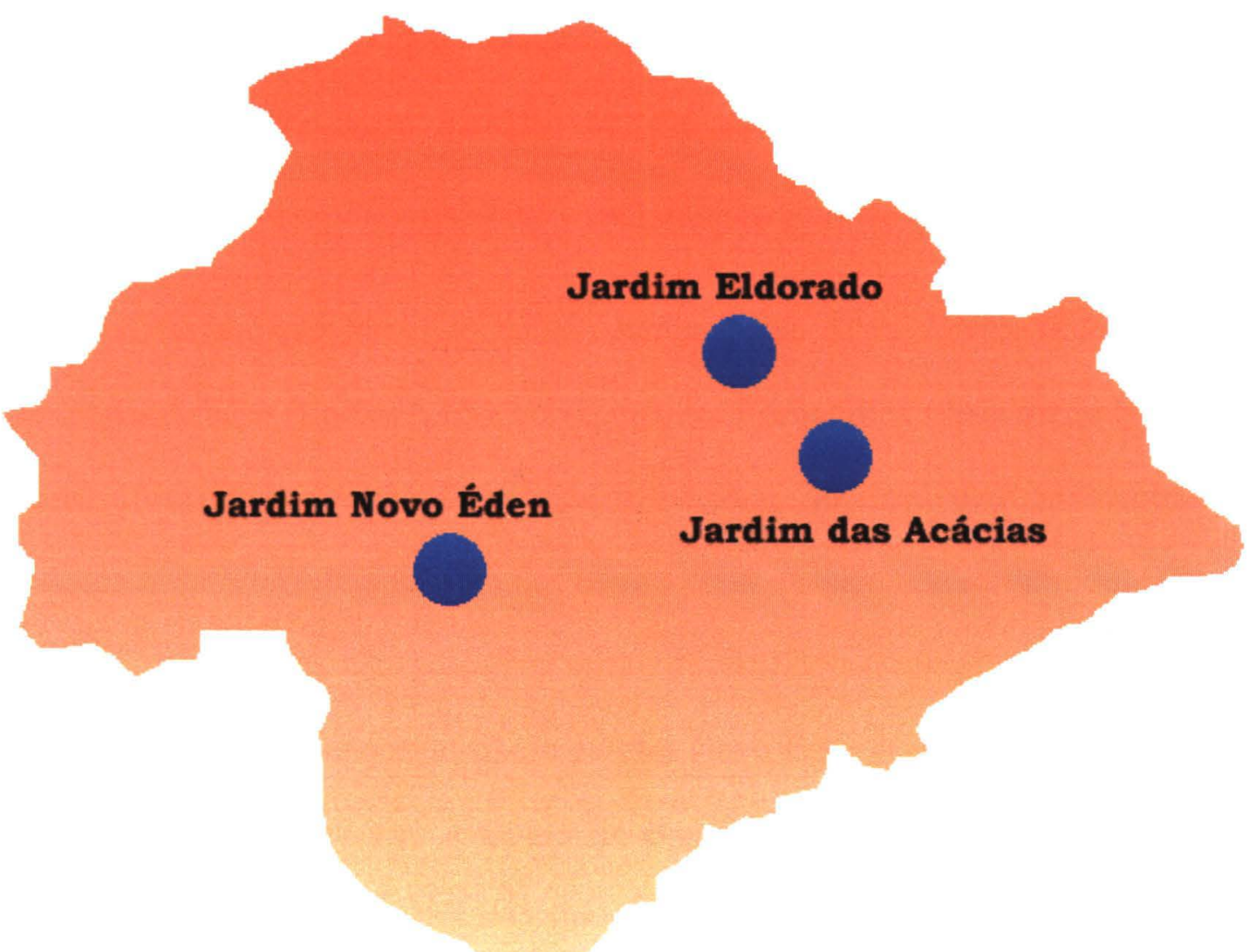

Figura 3 - Mapa do município de Santa Isabel com a localização dos 3 Bairros estudados.

A taxa de mortalidade infantil no município em 1997 foi de 24,92 mortes por 1000 nascidos vivos (SEADE,1997). Possui apenas um hospital com 76 leitos e oito unidades ambulatoriais.

Sua economia, segundo o Censo Cultural de São Paulo, em 1990 era baseado na pecuária e agricultura, mais especificamente na produção de hortifrutigranjeiros. Segundo o Censo Agropecuário de 1995 - 1996 o número de estabelecimentos por grupo de atividades econômica era: Lavoura temporária $=5$; Horticultura $=30$, Lavoura permanente $=25 ;$ Pecuária $=138 ;$ Produção mista $=2$; Pesca $=13$ e de Silvicultura e exploração florestal = 5 (IBGE,1996). 
O saneamento básico em porcentagem de nível de atendimento era em 1991, segundo a Fundação SEADE, 81,14\% para o abastecimento de água; $71,16 \%$ para esgoto sanitário, e $86,42 \%$ para a coleta de lixo.

Foram escolhidos os bairros Jardim Novo Éden, Jardim Eldorado e Jardim das Acácias (figuras 3,4,5), pela localização geográfica adjacente ao centro urbano. Distavam do centro urbano cerca de 5 a $8 \mathrm{~km}$. Durante o período de coleta de dados as características urbanas dos bairros eram distintas. Os Jardim Eldorado e Jardim das Acácias não possuíam infra-estrutura de saneamento básico nem calçamento nas ruas, enquanto que o Jardim Novo Éden possuía água e manta asfáltica nas ruas, mas sem estrutura de esgoto e sem calçadas. No final do projeto, em setembro de 1998 havia sido iniciado a colocação de manta asfáltica nas ruas principais do Jardim Eldorado e do Jardim das Acácias.

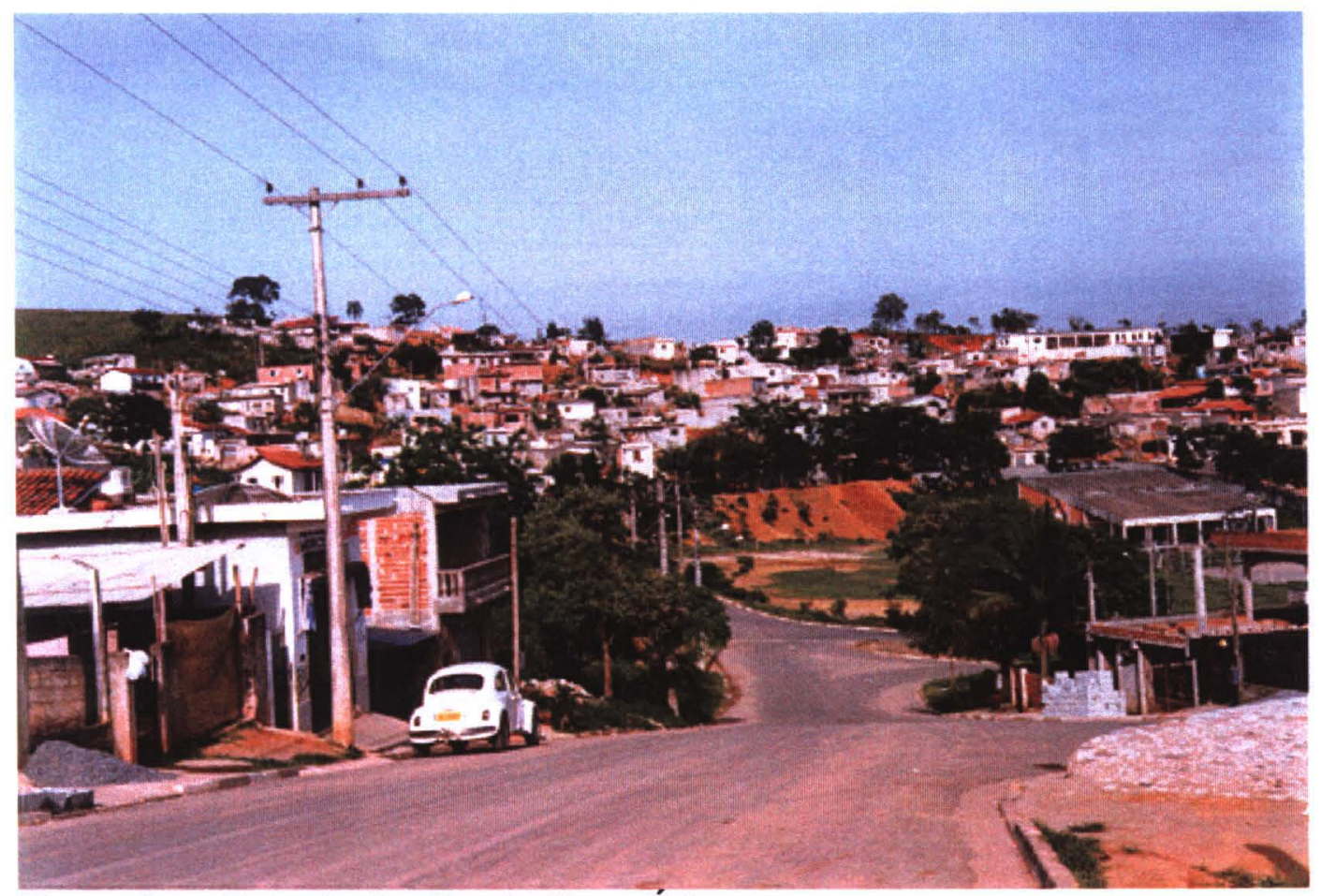

Figura 4 - Foto do Jardim do Novo Éden 


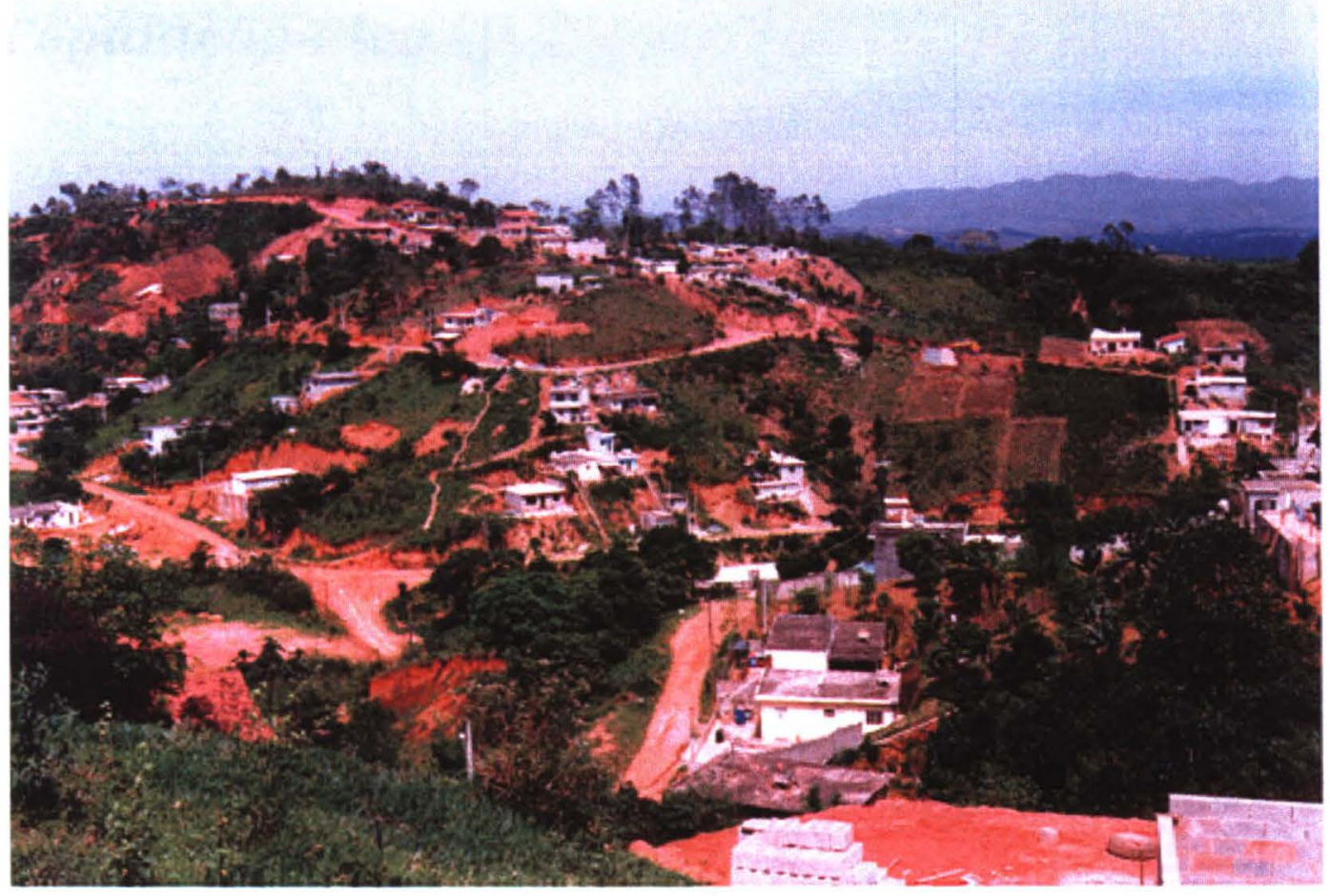

Figura 5 - Foto do Jardim do Eldorado

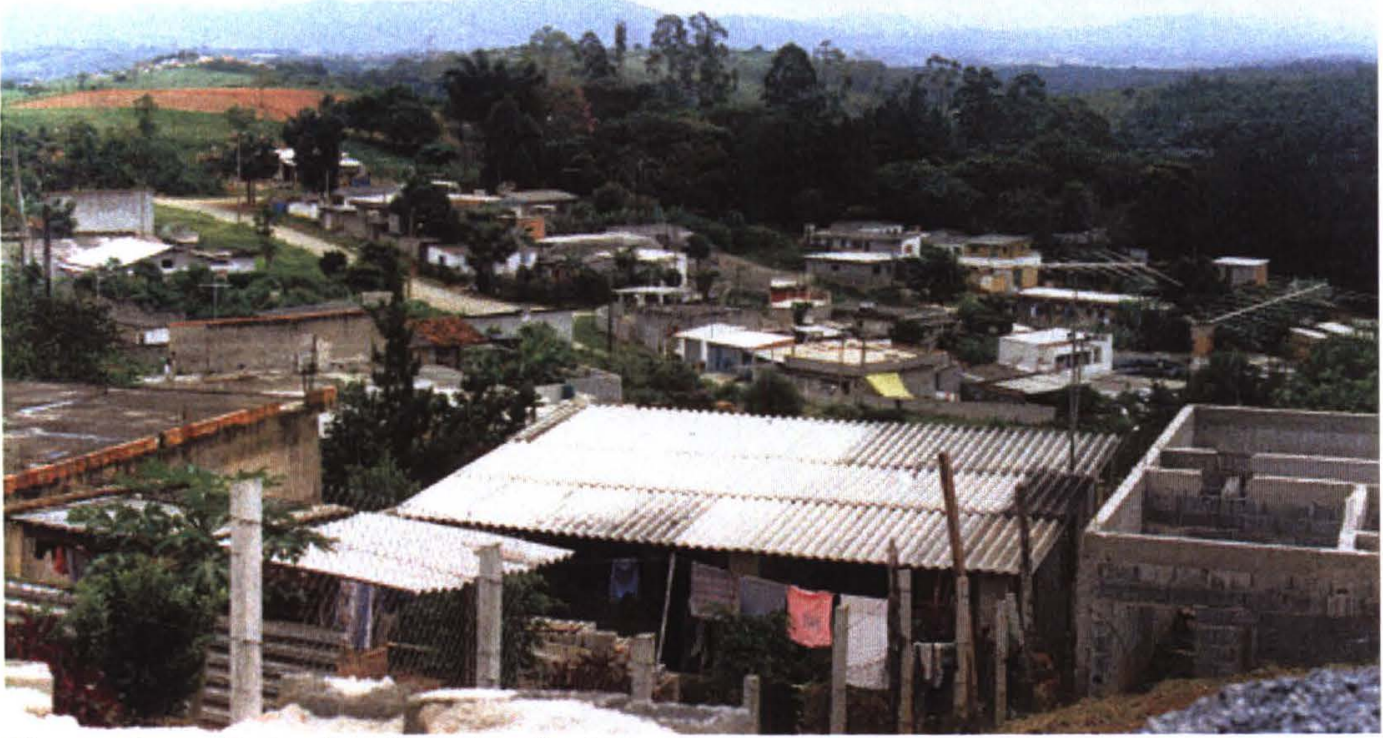

Figura 6 - Foto Jardim das Acácias 


\section{População alvo}

O total da população residente no município de Santa Isabel segundo o Instituto Brasileiro de Geografia e Estatística (IBGE,1996) é de 41.367 sendo 21.032 homens e 20.335 mulheres. A densidade populacional é de $116,347 \mathrm{hab} / \mathrm{Km}^{2}$ (SEADE, 1997).

Todos os domicílios dos três bairros foram visitados na procura de crianças na faixa etária 1 a 10 anos de idade. Houve recusa de participação na pesquisa em 5 domicílios do Jardim das Acácias ( 7 crianças); 7 domicílios no Jardim Eldorado (17 crianças) e 19 domicílios do Jardim Novo Éden (34 crianças), perfazendo um total de 58 crianças.

A idade considerada foi confirmada através da certidão de nascimento, levando-se em conta dia, mês e ano de nascimento para a distribuição etária da população.

Informações sobre a criança, exame antropométrico e ocorrências de doenças, que poderiam afetar o estado nutricional da população foram anotadas em formulário destinado a esse fim (anexo 2).

Foi aplicado questionário padronizado (anexo 3) contendo informações sobre as condições sócio - econômicas, de moradia, de ocupação e escolaridade dos pais. Esta amostra foi sorteada aleatoriamente antes da seleção dos casos. O questionário foi aplicado no cadastramento das crianças, e foram estudados 125 domicílios, que representam 35\% dos domicílios estudados. 


\section{Critérios de inclusão}

Foram incluídas no estudo todas as crianças de 1 a 10 anos residentes nos 3 bairros estudados, cujos os responsáveis autorizaram a participar do estudo. O número total de crianças foi de 851 .

Crianças que receberam tratamento anti-parasitário completo, assim como a confirmação de cura através da negativação do exame protoparasitológico.

\section{Critérios de exclusão}

Menores de 12 meses, por representarem uma faixa etária com baixa prevalência de enteroparasitas e por não ser recomendado o tratamento antiparasitário (3);

Crianças que não conseguiram entregar nenhuma amostra de fezes $(25)$;

Crianças que foram resistentes a 2 tratamentos antiparasitários (4);

Portadoras de doenças que poderiam comprometer seu estado nutricional como paralisia infantil ou câncer em tratamento (2). 
O total de domicílios por bairro e o total de domicílios com crianças na faixa etária estudada encontra-se na tabela 1 :

Tabela 1- Número total de domicílios e número de domicílios incluídos no estudo, por bairro do Município de Santa Isabel, São Paulo, 1997.

\begin{tabular}{c|c|c}
\hline BAIRROS & TOTAL DE DOMICÍLIOS & $\begin{array}{c}\text { DOMICÍLIOS } \\
\text { ESTUDADOS }\end{array}$ \\
\hline Jardim das Acácias & 163 & 61 \\
Jardim Eldorado & 443 & 139 \\
Jardim Novo Éden & 448 & 153 \\
\hline
\end{tabular}

Foram estudadas 759 crianças, sendo que distribuídas pelos bairros da seguinte forma: Jardim das Acácias: 113, Jardim Eldorado: 301 e Jardim Novo Éden: 345.

\section{Aspectos éticos}

A participação destas crianças foi possível após conscientização dos responsáveis sobre o objetivo do projeto e a assinatura dos mesmos no termo de consentimento pós-informado (anexo 1), de acordo com a Resolução $n^{0} 1$ de 13/06/1988 da Comissão Nacional de Saúde. O projeto foi submetido e aprovado pela Comissão de Ética em Pesquisa do Hospital das Clínicas da Faculdade de Medicina da Universidade de São Paulo.

Todas as crianças receberam o resultado do exame protoparasitológico e tratamento quando o resultado do exame foi positivo para os parasitas patogênicos. As crianças que tiveram resultado positivo para Giardia lamblia e ou 
E. histolytica, receberam Secnidal (secnidazol) e continuaram no estudo. Aquelas que tiveram resultado positivo para helmintos receberam tratamento completo de Panfugan (mebendazol), ou Cestox (praziquantel) ou ainda Thiaben (tiabendazol) e tiveram alta do estudo.

\section{Caracteristica do estudo}

O estudo realizado foi planejado como epidemiológico longitudinal (coorte prospectiva) com acompanhamento bimensal da população alvo pelo período de 10 meses.

Este estudo se inicia em dezembro de 1997 quando da confirmação da ausência de parasitas patogênicos nos exames protoparasitológicos.

\section{Medidas antropométricas}

Medidas de peso e altura foram efetuadas em toda população de estudo, de acordo com os procedimentos técnicos recomendados pela OMS,1983. A altura foi medida em $\mathrm{cm}$ e o peso em $\mathrm{Kg}$.

Para a tomada de peso a criança era colocada no centro da plataforma da balança com o mínimo de roupa possível e sem sapatos, não se apoiando em nenhum objeto ou parede próxima, (Gordon, Chumlea e Roche, 1988). Uma entrevistadora fazia a leitura do peso e a outra anotava no local previsto da ficha individual de cada criança. Para as crianças menores de 2 anos ou para aquelas 
que não conseguiam ficar em pé sozinhas, a mãe subia na balança com a criança no colo, anotava-se o peso total na ficha e em seguida a mãe subia na balança sozinha e anotava-se o peso da mãe, estimando o peso da criança por subtração.

As três balanças portáteis utilizadas para a tomada de peso das crianças eram digitais da marca Soehnle modelo 7504 com intervalo de 0 a 150 $\mathrm{kg}$, com intervalos de $0,1 \mathrm{~kg}$.

A tomada da altura para crianças acima de 2 anos foi efetuada com um antropômetro portátil da marca "Microtoise", subdividido em $0,1 \mathrm{~cm}$, que foi afixado em uma haste vertical de madeira, divididas em 4 partes e quando encaixadas todas as partes ficava com 2 metros de comprimento, tendo uma base onde a criança ficava em pé. $\mathrm{O}$ antropômetro era colocado num local plano. Em seguida a criança era colocada no centro da base sem sapatos, pés paralelos, com os calcanhares, nádegas, ombros e a cabeça em posição ereta. No topo superior da haste o antropômetro descia suavemente até o ápice da cabeça, depois de afastado o cabelo da criança, (Gordon, Chumlea e Roche, 1988). Uma entrevistadora fazia leitura da altura e a outra anotava no local indicado da ficha individual.

Quando a criança não conseguia ficar em pé, foi utilizado um estadiômetro de madeira com os lados perpendiculares e fita métrica colocada nos dois lados do vértice, onde a criança era colocada deitada, com a cabeça firmemente apoiada no topo do estadiômetro, mantida a cabeça reta. Os joelhos eram seguros e os pés em ângulo reto com as pernas. A haste era deslocada até o contato firme com os calcanhares da criança para a leitura do comprimento (Gordon, Chumlea e Roche, 1988). 


\section{Exame parasitológico de fezes}

A metodologia abaixo descrita foi aplicada em todas as etapas do estudo, desde a seleção dos casos.

Foram solicitadas 3 amostras de fezes de cada criança em dias consecutivos para análise. Após a entrevista, era entregue à mãe 3 frascos vazios contendo o número da criança e seu primeiro nome, para a coleta de fezes. A mãe era orientada para o procedimento de coleta.

A orientação dada às mães sobre o procedimento de coleta de fezes foi para que as crianças defecassem em um piniquinho ou jornal, recolhendo-se as fezes com uma espátula. O material deveria ser depositado no frasco correspondente ao nome e ao número de cada criança.

As fezes deveriam ser colhidas em 3 dias consecutivos e conservadas em geladeira, pois no quarto dia de manhã as equipes passavam para recolher as amostras. Quando a crianças não conseguiam entregar todas as amostras, ou ainda nenhuma amostra, as equipes orientavam a mãe para fazer a coleta de amostra para o dia seguinte. Este procedimento foi feito pelo menos por mais 5 dias, para que a criança tivesse pelo menos 1 amostra de fezes analisada.

Os frascos contendo amostras eram recolhidos nos domicílios de manhã, acondicionados em caixas térmicas com gelo reciclado (gelox), lacradas, identificadas e trazidas para São Paulo por volta das 14:00 horas, para análise no Serviço de Parasitologia do Laboratório Central do Hospital das Clínicas da Universidade de São Paulo. 
No Serviço de Parasitologia, as amostras de fezes eram preparadas imediatamente quando de sua chegada. A leitura era realizada no dia seguinte da entrega pela manhã. As técnicas utilizadas para determinar a presença e intensidade de infecção dos parasitas intestinais foram os métodos de Hoffman, Rugai, Faust, (Amato Neto \& Corrêa, 1991) e Kato-Katz (WHO,1991). A utilização destes métodos foi definidas pelo Serviço de Parasitologia do Laboratório Central do Hospital das Clínicas que os utiliza na sua rotina de atendimento.

O método de Hoffman, Pons \& Janer (1934) é fundamentado na sedimentação espontânea, sendo uma técnica bastante utilizada na identificação de ovos e cistos pela sua facilidade, simplicidade e custo baixo.

O método de Rugai e col. (1954) também baseia-se no hidrotermotropismo de larvas de nematódeos, constituindo técnica voltada especialmente para o diagnóstico da estrongiloidáse.

O método de Faust e col. (1939) baseia-se no princípio da centrífugoflutuação em sulfato de zinco e é particularmente sensível para a identificação de cistos de protozoários e de ovos ou larvas de helmintos.

O método de Kato-Katz (1972) consiste no exame de um esfregaço espesso de fezes, sob uma lamínula de celofane embebido em glicerina. Destinase à contagem de ovos de helmintos.

Foram consideradas infectadas todas as crianças que tiveram exame protoparasitológico positivo para helmintos após o tratamento em massa realizado 
na seleção dos casos. As crianças reinfectadas são um sub-grupo das crianças infectadas, que possuíam exame positivo para helmintos na seleção dos casos em outubro/novembro de 1997. Aquelas consideradas como infecção "nova" representam outro sub-grupo das crianças infectadas com resultado negativo na seleção dos casos.

A intensidade de infecção foi considerada leve, moderada ou intensa conforme a quantidade de ovos encontrada em 1 grama de fezes. Para a realização desta técnica a amostra de fezes necessita estar em quantidade suficiente e com consistência pastosa. No período da seleção dos casos, outubro/novembro/97, tivemos perda de $27 \%$ das crianças com exame positivo para Ascaris e Trichuris, por se tratarem de amostras inadequadas, a maioria das vezes por fezes liquefeitas $(90 \%)$.

Os critérios para classificar a intensidade de infecção foram baseados na definição da WHO, 1987 e são apresentados na tabela 3.

Tabela 3 - Classificação da intensidade de infecção de acordo com a quantidade de ovos encontrados por grama de fezes.

\begin{tabular}{c|c|c|c}
\hline Parasitas & Leve & Moderada & Intensa \\
\hline Ascaris lumbricoides & $<5.000$ & $5.000-50.000$ & $>50.000$ \\
Trichuris trichiura & $<=1.000$ & $>1.000-10.000$ & $>10.000$ \\
\hline
\end{tabular}

\section{Consumo Alimentar}

Para conhecermos o consumo alimentar da população em estudo foi utilizado o método do Recordatório de 24 horas (Medlin, 1988 e 
Bloemberg, 1989) (anexo 4) que foi aplicado nas crianças desnutridas e em uma sub-amostra sorteada de crianças eutróficas pareadas de acordo com o sexo e idade.

O recordatório foi aplicado em janeiro de 1998 em 58 crianças desnutridas e 63 eutróficas. As entrevistadoras receberam a lista das crianças sorteadas com nome, endereço, bairro e o número da equipe responsável pela entrevista. As entrevistadoras foram selecionadas dentre os membros da equipe e treinadas para o procedimento com supervisão da pesquisadora.

O consumo alimentar foi estimado através de entrevista com a mãe ou com o responsável pela alimentação da criança. Na maioria das vezes foi a mãe quem respondeu, quase sempre com a presença das crianças, que ajudaram bastante no esclarecimento das quantidades e do tamanho das porções.

Com a ajuda da entrevistadora, o responsável relatava o horário, quais alimentos e a quantidade que a criança tinha consumido em cada uma das refeições do dia anterior. Essa informação foi anotada numa ficha específica. Quando se tratava de preparações, as receitas eram anotadas no verso da ficha. As quantidades consumidas pela criança eram anotadas em medidas caseiras.

A transformação dos alimentos ingeridos em calorias e nutrientes foi feita através do programa Virtual Nutri (Philippi, 1996).

A adequação nutricional das dietas foi analisada em relação a energia e proteína. A escolha desses elementos decorre da sua relação com as deficiências 
nutricionais de maior relevância epidemiológica em nosso meio (Batista Filho, 1985 e Shrimpton, 1986).

As adequações energéticas e protéica das dietas foram analisadas tendo por base os valores de referência propostos pelo National Research Council (RDA), 1989. Foram consideradas dietas adequadas àquelas que atingiram 100\% da recomendação preconizadas.

\section{Avaliação Nutricional}

A avaliação nutricional foi determinada através dos parâmetros antropométricos, idade, peso e altura para crianças e adolescentes. O padrão de referência utilizado foi o NCHS/OMS (Hamil e col. 1979)(Dibley e col.,1987a), sendo o seu uso recomendado pela Organização Mundial da Saúde (WHO, 1986). O programa utilizado para os cálculos foi o EPINUT do EPI INFO versão 6.04, (CDC, 1997).

$\mathrm{Na}$ análise realizada pelo programa EPINUT modificamos os pontos de corte dos índices estudados para um melhor ajuste dos dados. Os valores foram os seguintes:

$$
\begin{array}{ll}
\text { WHZ }<-5.00 \text { ou }>5.00 & \text { WAZ }<-4.00 \text { ou }>5.00 \\
\text { HAZ }<-5.00 \text { ou }>3.00 & \text { HAZ e WHZ }<-3.09 \text { ou }>3.09
\end{array}
$$


Estes pontos de corte são usados para que o programa possa "sinalizar" os registros com problemas de medida.

Para estabelecer o perfil de crescimento da população infantil foram utilizados os "scores" de desvio padrão (Z scores) para os índices peso para altura (WHZ) e altura para idade (HAZ), calculados de acordo com a O.M.S. (WHO, 1986 e Dibley, 1987b). Dependendo de seu WHZ e HAZ, o estado nutricional da criança foi classificado como:

\section{Estado Nutricional}

Normal

Déficit de peso para altura ou magreza excessiva (wasting)

Déficit de altura para idade ou nanismo (stunting)

Déficit de altura/idade e peso/altura associados

\section{WHZ HAZ}

$$
>-2.0 \quad>-2.0
$$

$<=-2.0$

$>-2.0$

$$
>-2.0<=-2.0
$$

$$
<=-2.0 \quad<=-2.0
$$

A magreza excessiva é indicativa de um déficit de massa muscular ou de tecido gorduroso em relação ao esperado para uma criança de mesma altura ou comprimento, e pode ser resultado tanto de uma perda de peso quanto da falta de ganho de peso atual. $O$ nanismo significa retardamento do crescimento esquelético, representando as conseqüências acumuladas do retardo no crescimento (Weisell, 1982; e Dibley, 1987b).

Para as crianças de 10 anos de idade utilizou-se o índice de altura para a idade conforme recomendação da FAO/WHO/UNO Expert Consultation, 1986. 
Apenas com o intuito de se analisar o efeito das variáveis preditivas do estudo, todas as crianças que foram classificadas como "stunting" ou "wasting" foram denominadas como desnutridas, e aquelas que tiveram a classificação "normal" como eutróficas.

\section{Tratamento Anti-parasitário}

Para a realização do tratamento anti-parasitário, foi analisado o sabor dos medicamentos disponíveis no mercado, para que ele fosse agradável às crianças e assim não houvesse rejeição. Desta forma, foi administrado Panfugan (mebendazol) do laboratório Byk, apresentado em frascos de 40ml de suspensão $(100 \mathrm{mg} / \mathrm{ml})$, no sabor de morango, na dosagem de 1 medida $(5 \mathrm{ml}) 2$ vezes ao dia, durante 3 dias consecutivos, para todas as crianças do estudo, independentemente do resultado do exame.

O tratamento foi supervisionado e acompanhado diretamente pelo pessoal da equipe, garantindo desta maneira a eficácia do tratamento. Este tratamento consistia em visitas domiciliares diárias (3 dias consecutivos) para: a administração da primeira dose do dia, orientação para a segunda dose do dia, e checagem (quando procedente, isto é, a partir da segunda visita) da quantidade de remédio no frasco indicativo de sua administração pela mãe ou responsável.

Para as crianças que tiveram exame positivo para Hymenolepis nana foi administrado Cestox (praziquantel) do laboratório Merck em comprimidos, na quantidade de $25 \mathrm{mg} / \mathrm{kg}$ de peso; para aquelas que tiveram exame positivo para 
Strongyloides stercoralis, foi administrado Thiaben (tiabendazol) do laboratório Uci-farma em vidro com $40 \mathrm{ml}$ de suspensão, na quantidade de $50 \mathrm{mg} / \mathrm{kg}$ de peso.

Embora não houvesse interesse em se avaliar a infecção por protozoários, por uma questão de ética, foi administrado Secnidal (secnidazol) do laboratório Rhodia-Farma em frascos com $15 \mathrm{ml}$ ou $30 \mathrm{ml}$, na quantidade de $1 \mathrm{ml} / \mathrm{kg}$ de peso, em dose única para as crianças que tiveram exame positivo para Entamoeba histolytica e Giardia lamblia.

Em novembro, nos dias 14,15 e 16 , foi realizado o tratamento antiparasitário para todas as crianças do estudo e nos dias 28,29 e 30 de novembro, foi realizado o reforço do tratamento de Panfugan (mebendazol) para todas as crianças.

Nestes dois períodos de tratamento obtivemos a colaboração de cerca de 40 estudantes da Escola de Auxiliar de Enfermagem de Santa Isabel, sob supervisão de uma professora, que também exerce o cargo na Unidade de Saúde Hilário Dassiê, e ainda alguns funcionários de outra Unidade de Saúde. Também foi cedido pelo Secretário Municipal da Saúde do município de Santa Isabel veículo para o transporte dos mesmos, como colaboração da Prefeitura.

Em dezembro, nos dias 8 e 9 , foi realizada a coleta de material por 3 dias consecutivos de todas as crianças do estudo para o exame protoparasitológico, para controle do tratamento. Foram aceitas as crianças que entregaram pelo menos 1 amostra de fezes. 
Após completado o ciclo de tratamento, 10 crianças que mantiveram exame positivo para helmintos (10) e 26 positivas para protozoários tiveram ciclo de tratamento repetido.

\section{Cronologia do estudo}

Em agosto de 1997 foi realizada a seleção de entrevistadores para o desenvolvimento do trabalho de campo. Estes entrevistadores foram selecionados entre estudantes do $2^{0}$ grau da Escola do BNH de Santa Isabel. Deste grupo selecionamos 7 alunos. Além destes, tivemos 2 senhoras do grupo de $3^{\mathrm{a}}$ idade (que permaneceram com o grupo somente na primeira fase do trabalho, sendo substituídas por outros dois estudantes do segundo grau nas fases seguintes) e 1 aluna do curso de Técnica Dietética de Nutrição de Mogi das Cruzes. Tivemos ainda 3 supervisores de campo que a Disciplina de Informática Médica da Faculdade de Medicina da USP disponibilizou para o projeto.

Em setembro os entrevistadores e os supervisores de campo receberam treinamento para abordagem no domicílio, preenchimento de formulários, assim como todo o procedimento técnico para a tomada das medidas antropométricas. Estes procedimentos foram detalhados no Manual de Treinamento, que foi mantido com os entrevistadores durante todo o trabalho de campo.

Os entrevistadores foram divididos em 3 equipes de trabalhos para a realização das entrevistas e para a coleta de material. O número e a composição de 
cada equipe foram mantidos durante todo o projeto, para que as mesmas fizessem sempre o mesmo trajeto e assim ficassem familiarizadas com as crianças e as mães e vice-versa.

A coleta de dados foi realizada no período de 15 de outubro de 1997 a 07 de novembro de 1998.

Para o desenvolvimento deste projeto, tivemos duas Peruas Kombi para transporte dos pesquisadores, entrevistadores e de material para exame, sendo que uma perua foi cedida pela Disciplina de Informática Médica e a outra foi alugada em Santa Isabel. Durante todo o projeto a perua da Disciplina de Informática Médica fazia o percurso São Paulo - Santa Isabel - São Paulo. Também foram utilizados em campo aparelhos de comunicação para que todas as equipes, os supervisores, as peruas e a pesquisadora estivessem em contato permanente para a solução dos problemas ou mesmo de acesso.

Os períodos de coletas de dados após o tratamento antiparasitário foram: -12 a 17 de Janeiro de 1998, - 23 de Março a 07 de Abril, - 24 de Maio a 9 Junho, - 06 a 12 de Agosto, - 19 a 27 de Outubro.

Em todas as etapas acima definidas, foram feitas medidas de peso e altura, aplicação da ficha individual onde foram anotados dados sobre a saúde da criança no período, assim como coleta de material de 3 dias consecutivos para exame protoparasitológico e tratamento dos positivos.

Em janeiro de 1998 foi também aplicado o Recordatório 24 horas em 58 crianças desnutridas e em 63 crianças eutróficas, pareadas por idade e sexo. 
Para podermos analisar a infecção ou reinfecção dos parasitas intestinais, entre dois grupos de crianças classificadas de acordo com o seu estado nutricional foi utilizado o modelo de regressão de Cox através do programa SPSS - 9.0, versão para Windows, 1999. Este modelo é o que melhor se aplica em estudos longitudinais, pois permite a análise de dados onde a resposta medida é o tempo até a ocorrência de um evento de interesse, ajustado por covariáveis.

O modelo de regressão proposto por Cox é usado para determinar a influência de variáveis preditivas na variável dependente. As variáveis preditivas são chamadas de covariáveis. Este modelo usa a função de risco, para estimar o risco relativo de um evento acontecer, neste caso a infecção ou reinfecção por parasitas intestinais, num intervalo de tempo. A função de risco, $\boldsymbol{h}(t)$, exprime uma taxa que corresponde à densidade de incidência (Kleinbaum, 1996).

A expectativa de um indivíduo permanecer na condição "não infectado" num determinado intervalo de tempo é conhecida como a função de sobrevida, $\boldsymbol{S}(\boldsymbol{t})$ definida como a proporção de casos que "sobreviveram" na condição não infectado neste intervalo de tempo. A variável sobrevida obedece ao modelo linear:

$$
\frac{d S(t)}{d t}=-h(t) S(t)
$$

Onde $\boldsymbol{h}(\boldsymbol{t})$ é a densidade de incidência, ou "harzad", para o evento (infecção no caso). 
A solução da equação (1) é:

$$
S(t)=S(0) \exp \left[-\int_{0}^{t} h\left(t^{\prime}\right) d t^{\prime}\right]
$$

Chamando de função de risco acumulado:

$$
H(t)=\int_{0}^{t} h\left(t^{\prime}\right) d t^{\prime}
$$

obtemos:

$$
H(t)=-\ln (S(t))
$$

Um modelo simples comparando condição e não condição pode ser escrita da seguinte forma:

$$
h(t)=\left[h_{0}(t)\right] e^{(B X)}
$$

onde $X$ é uma covariável dicotômica que têm o valor 0 para controle ou não condição (não infectado) e valor 1 para a condição, ou seja infectado ou reinfectado. $\boldsymbol{B}$ é o coeficiente de regressão, $\boldsymbol{e}$ é a base do logarítimo natural (cerca de 2,718), e $h_{0}(t)$ é a função de base de risco. O risco esperado da ocorrência do evento positivo para um caso particular com a condição $\boldsymbol{X}$ é igual ao risco da mesma ocorrência sem a condição $\boldsymbol{X}$ multiplicada pela quantidade $\boldsymbol{e}$ elevada a força $(\boldsymbol{B} \boldsymbol{X})$. 


\section{Caracteristicas da População de estudo}

A população estudada foi composta da seguinte maneira 49\% (373) do sexo feminino, e $51 \%$ (386) do sexo masculino. A distribuição etária por faixa de idade encontra-se na tabela 4.

Tabela 4 - Distribuição etária em anos das crianças estudadas de 3 bairros do município de Santa Isabel - SP, 1997.

\begin{tabular}{c|c|c}
\hline Idade (anos) & Frequiência & Porcentagem \\
\hline \hline 01 & 33 & 4,3 \\
02 & 71 & 9,4 \\
03 & 63 & 8,3 \\
04 & 70 & 9,2 \\
05 & 87 & 11,5 \\
06 & 79 & 10,4 \\
07 & 88 & 11,6 \\
08 & 78 & 10,3 \\
09 & 81 & 10,7 \\
10 & 109 & 14,3 \\
\hline TOTAL & 759 & 100 \\
\hline
\end{tabular}

No início do estudo $58,6 \%$ (451) freqüentavam escola ou creche, dos quais $97,8 \%$ (440) permaneciam meio período, e 96,7\% (435) recebiam apenas uma refeição na escola.

A quantidade de crianças dentro dos domicílios na sub-amostra da população estudada encontra-se na tabela 5 , sendo que a média de pessoas no domicílio foi de 5,4 pessoas. 
Tabela 5 - Distribuição do número de crianças por domicílio, em uma amostra da população estudada nas 3 localidades de Santa Isabel, 1997.

\begin{tabular}{c|c|c}
\hline $\begin{array}{c}\text { Número de crianças } \\
\text { por domicílio }\end{array}$ & Freqüência & Porcentagem \\
\hline 01 & 59 & 47,2 \\
02 & 49 & 39,2 \\
03 & 12 & 9,6 \\
04 & 04 & 3,2 \\
05 & 01 & 0,8 \\
\hline Total & 125 & 100 \\
\hline
\end{tabular}

Em relação à entrevista tivemos que $90,6 \%$ dos informantes eram os pais da criança ( $84 \%$ a mãe, e $6,6 \%$ o pai).

A média da renda per capita mensal foi de $\mathrm{R} \$ 112,7$ com variação entre $\mathrm{R} \$ 14,4$ a $\mathrm{R} \$ 475,00$.

Em relação às mães, temos que $70 \%$ eram casadas, com idade variando de 17 a 49 anos e média de 30,6 anos. A análise da escolaridade mostrou que $12,7 \%$ (48) não sabiam ler, $14 \%$ (53) não sabiam escrever e 13,2\% (50) nunca freqüentaram escola.

Analisando a atividade profissional das mães temos que $74 \%$ (93) não estavam empregadas, sendo que destas $86 \%$ (80) eram donas de casa, 9,6\% (9) estavam desempregadas e 4,3\% (4) eram aposentadas. Em relação às mães que estavam empregadas, vimos que: $51 \%$ (17) tinham vínculo empregatício e $30 \%$ (10) eram empregadas domésticas. Das 17 mães empregadas com vínculo, 13 não recebiam nenhum benefício, apenas uma mãe recebia cesta básica, e duas mães recebiam vale refeição e cesta básica. 
As informações sobre o chefe de família, temos que, a idade deles variou de 19 a 67 anos com uma média de 36 anos. Em relação à escolaridade, $7,6 \%$ não sabiam ler e escrever, e $12,7 \%$ nunca freqüentaram escola.

O nível de desemprego dos chefes de família neste período foi de 13,6\% (16). Dos empregados (102) temos que 69,6\% (71) possuíam vínculo empregatício, $16,6 \%$ (17) tinham estabelecimento comercial e $13,7 \%$ (13) trabalhavam por conta própria, prestando serviços em casa de clientes. Entre os pais que tinham vínculo empregatício apenas $38 \%$ (27) recebiam cesta básica e a média de duração da cesta foi de 2 semanas. Todas as famílias entrevistadas não recebiam ajuda filantrópica ou institucional.

Os dados referentes ao meio ambiente das famílias estudadas indicam que, $64,3 \%$ (81) das residência estavam localizadas em ruas e calçadas sem pavimentação, $20,6 \%$ (26) possuíam esgoto a céu aberto e $40 \%$ possuíam fossas negras. A coleta de lixo era feita regularmente em $93 \%$ dos domicílios.

Em relação às características dos domicílios encontramos que $79,5 \%$ (101) possuíam revestimento nas paredes, $53,5 \%$ tinham piso de cerâmica, $43,1 \%$ possuíam 4 cômodos, $50 \%$ com 1 dormitório, $89,7 \%$ possuíam cozinha separada dos outros cômodos, $94 \%$ possuíam chuveiro dentro do domicílio, $96 \%$ tinham privada com descarga de água.

Os dados referentes ao hábito de dormir das crianças mostrou que $45 \%$ das crianças dividiam o quarto com mais de 4 pessoas, e que $23 \%$ das crianças dividiam a mesma cama com outras pessoas. As características do quarto 
das crianças indicava que em $97 \%$ deles o piso era cimentado ou de cerâmica, e que em $28,3 \%$ havia umidade permanente nas paredes.

\section{Prevalência de Desnutrição}

Os resultados mostraram que a prevalência de desnutrição foi de $8 \%$ (61), dos quais 5,5\% (42) eram de casos de déficit de altura para idade, 2,3\% (17) eram de crianças com déficit de peso para altura, e $0,26 \%$ (2) apresentavam as duas formas de déficit.

Analisando a desnutrição em relação à idade das crianças, temos que, entre as crianças menores de 5 anos (292) a prevalência de desnutrição foi de $10 \%$ (29), entre as crianças acima desta idade $(n=476)$, a taxa de desnutrição foi de $7,1 \%(34)$

Quando analisamos a desnutrição infantil com o grau de instrução materna em uma sub-amostra da população $(n=378)$, não foi encontrada associação estatística entre a desnutrição infantil e analfabetismo da mãe. Também não foi encontrada associação estatística entre desnutrição infantil e renda per capita e local de residência. 


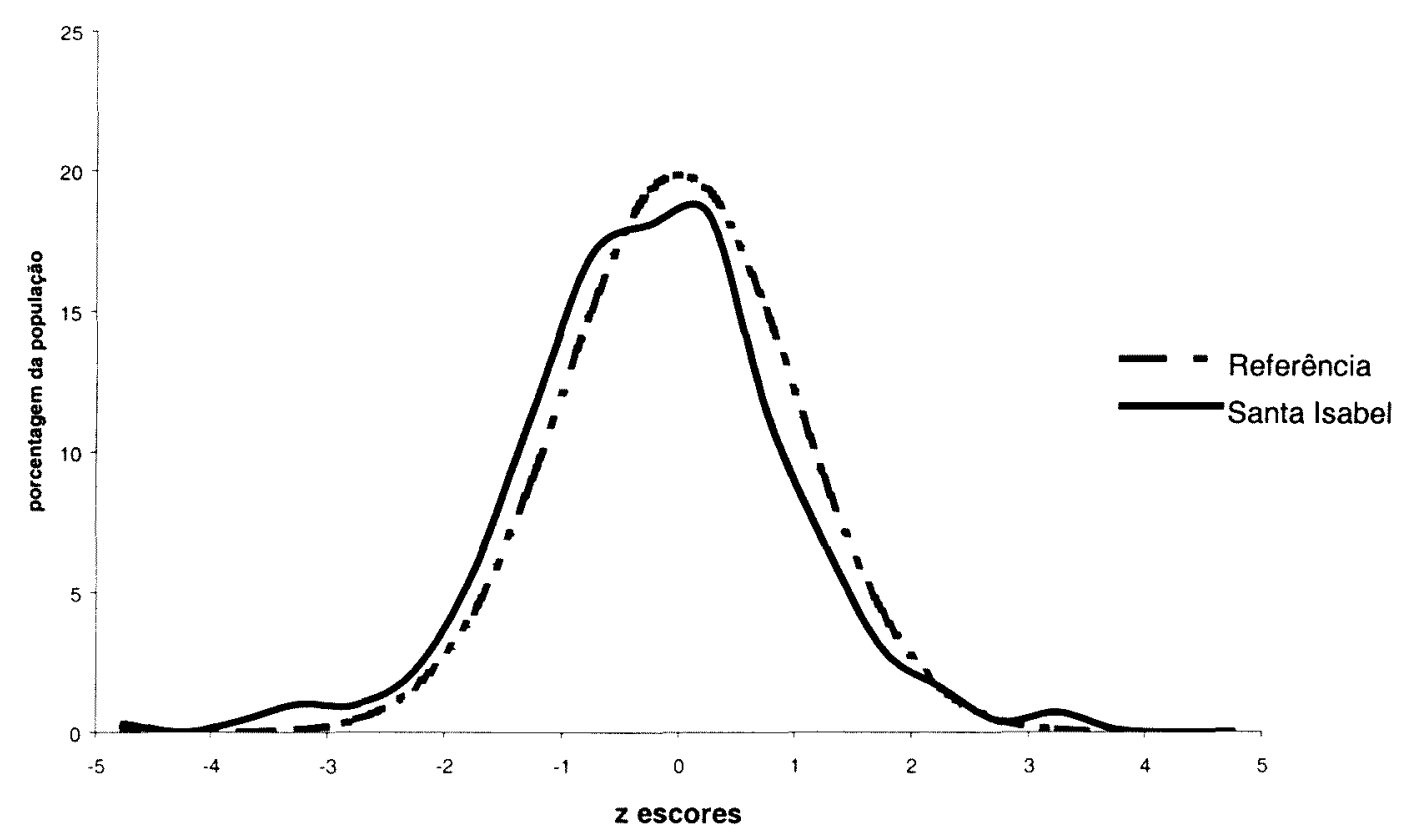

Gráfico 1- Curvas de distribuição do índice de Altura para Idade da população de referência (NCHS) e da população estudada de Santa Isabel.

A distribuição da população estudada em relação a distribuição de referência do NCHS, para o índice de altura para idade, mostra que a curva está minimamente deslocada para esquerda. Esta distribuição possui uma média de $-0,25$, porém esta diferença não é estatisticamente significante $(p=0,80)$.

A curva de peso/altura das crianças do estudo em relação a população de referência (NCHS), apresenta um desvio à esquerda da curva da população de estudo em relação à da população de referência. A média de distribuição do peso/altura da população de estudo é de $-0,20$, e também não difere estatisticamente da curva padrão $(p=0,84)$. 


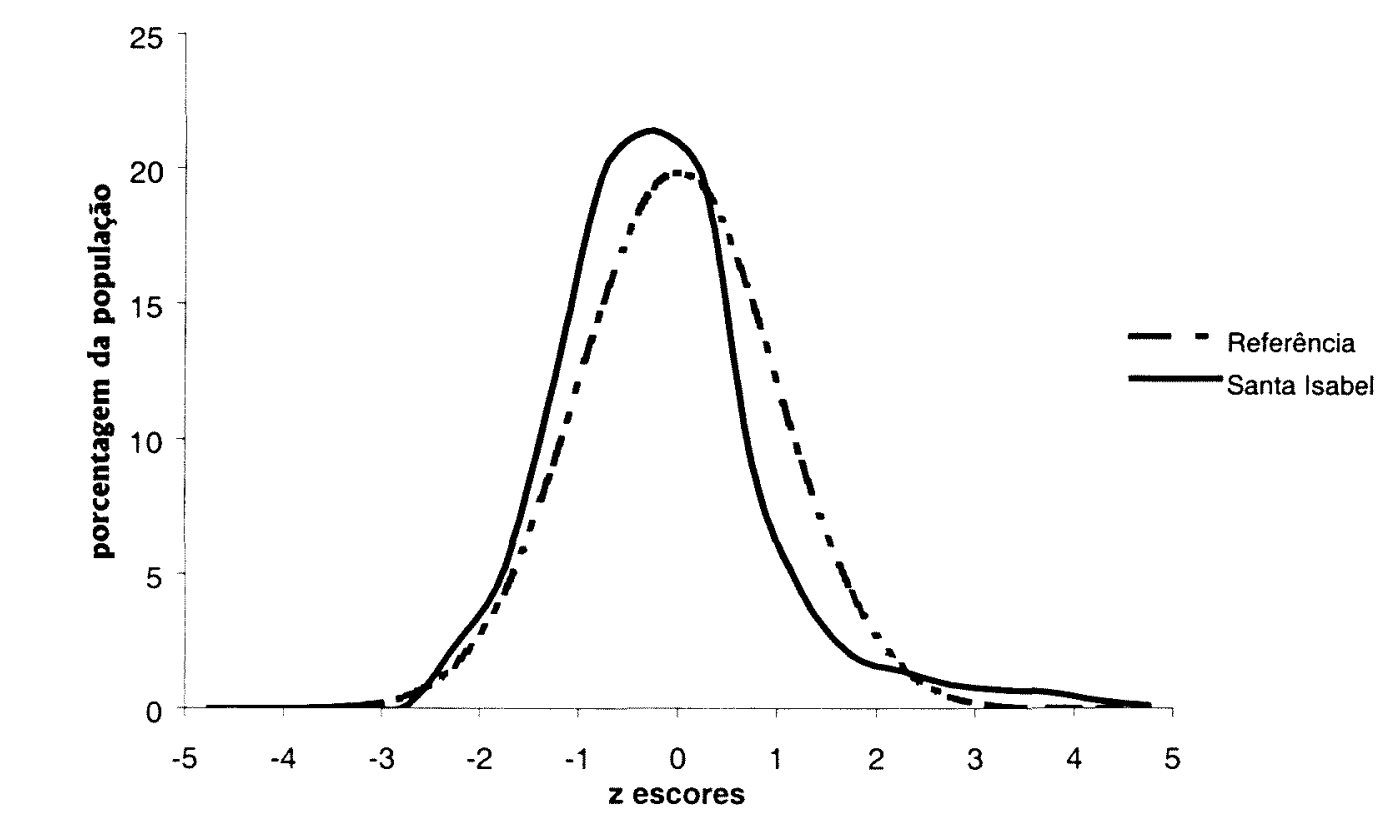

Gráfico 2 - Curvas de distribuição de peso para altura da população de referência (NCHS) e da população estudada em Santa Isabel.

Intuitivamente a classificação do estado nutricional pode variar no tempo para cada criança, principalmente quando se refere ao déficit de peso. No transcorrer do estudo, observou-se que tais variações compensaram-se ao longo do ano para esta população, isto é, 7 crianças classificadas inicialmente com déficit de peso para altura mudaram para eutróficas, em contrapartida outras 6 crianças que foram classificadas inicialmente como eutróficas apresentaram déficit de peso para altura.

\section{Prevalência de Morbidade Referida}

Para analisar os dados referentes às fichas individuais aplicadas em todas as crianças durante o período de estudo, resolvemos caracterizar os eventos relacionados a internações hospitalares, bem como episódios de diarréia e doenças 
respiratórias, uma vez que estas situações representam as maiores causas de morbidade entre as crianças, podendo inclusive afetar o seu estado nutricional. É importante ressaltar que todos estes eventos foram relatados pelas mães, não havendo, da nossa parte, nenhuma comprovação clínica, hospitalar ou laboratorial.

\section{Internações hospitalares}

Tivemos $30(4 \%)$ crianças internadas ao longo do estudo, sendo que destas $10(30 \%)$ foram motivadas por causas respiratórias, principalmente por pneumonias e bronquites. Tivemos 2 crianças que foram internadas mais de uma vez neste período, sendo que destas, uma era desnutrida e a causa de internação foi hidratação por vômitos. Esta criança permaneceu com exame negativo para parasitas durante todo o estudo.

\section{Diarréias}

O objetivo de analisar os dados colhidos sobre os episódios de diarréia mencionados pelas mães, foi o de se afastar a possibilidade de erro de avaliação do estado nutricional das crianças. Tivemos várias crianças desnutridas com diarréia, porém todas foram classificadas como desnutridas crônicas e não apresentaram mudança de classificação ao longo do estudo.

Os resultados dos dados referentes aos episódios de diarréia durante o período de estudo, encontram-se na tabela 6. 
Tabela 6 - Número total e o número de crianças desnutridas que tiveram episódios de diarréia durante o período de Outubro de 1997 a Outubro de 1998, em crianças de 1 a 10 anos em três bairros de Santa Isabel, SP.

\begin{tabular}{c|c|c}
\hline Período de avaliação & $\begin{array}{c}\text { Total de crianças com } \\
\text { diarréias }\end{array}$ & $\begin{array}{c}\text { Desnutridas com } \\
\text { diarréias }\end{array}$ \\
\hline Outubro/nov. 97 & $95(12 \%)$ & $14(22 \%)$ \\
Janeiro 98 & $80(11 \%)$ & $06(8,5 \%)$ \\
Março/abril 98 & $65(11 \%)$ & $04(8,5 \%)$ \\
Junho 98 & $40(9 \%)$ & $05(13 \%)$ \\
Agosto 98 & $28(7 \%)$ & $02(6 \%)$ \\
Outubro 98 & $30(8 \%)$ & $02(6 \%)$ \\
\hline
\end{tabular}

Analisando-se os dados de diarréia e de desnutrição encontramos uma associação positiva apenas no início do estudo, ou seja, em Outubro/Novembro de 1997, com odds ratio de $2,20(1,11-4,33), x^{2}=6,17$ e $p=0,0129$.

\section{Doenças Respiratórias}

Para analisarmos os dados sobre doenças respiratórias, foram considerados todos os eventos mencionados pelas as mães como tosses, resfriados, laringites, faringites e gripes. A tabela 7 apresenta o total de crianças e o número de crianças desnutridas, que as mães referiram os eventos. 
Tabela 7 - Número total de crianças e número de desnutridos com eventos de doenças respiratórias, durante o período de estudo (1997-1998), em três bairros de Santa Isabel, SP.

\begin{tabular}{c|c|c}
\hline Período de avaliação & Total de crianças & Desnutridos \\
\hline Outubro/nov. 97 & $300(39 \%)$ & $24(38 \%)$ \\
Janeiro 98 & $153(21 \%)$ & $14(22 \%)$ \\
Março/abril 98 & $179(30 \%)$ & $18(38 \%)$ \\
Junho 98 & $242(54 \%)$ & $19(50 \%)$ \\
Agosto 98 & $162(40 \%)$ & $12(35 \%)$ \\
Outubro 98 & $134(38 \%)$ & $13(41 \%)$ \\
\hline
\end{tabular}

Não foi encontrada diferença entre os eutróficos e desnutridos neste tópico.

Nota-se uma certa sazonalidade nestas doenças, com maior ocorrência nos meses frios.

\section{Prevalência das parasitoses intestinais}

A prevalência de parasitas encontrada no início do estudo foi de 44,3\% (336), sendo a prevalência de helmintos de 33,6\% (255) e a de protozoários (Giardia lamblia e E. Histolytica) de $20 \%$ (153).

A tabela 8 apresenta a prevalência inicial dos parasitas (por espécie) na população estudada. 
Tabela 8 - Distribuição da freqüência por espécie de parasitas em crianças de 1 a 10 anos residentes em 3 localidades de Santa Isabel - SP, 1997.

\begin{tabular}{c|cc} 
Parasita & Freqüência & Porcentagem(\%) \\
\hline Giardia lamblia & 144 & 19,0 \\
Entamoeba histolytica & 09 & 1,2 \\
Trichuris trichiura & 128 & 16,9 \\
Ascaris lumbricoides & 143 & 18,9 \\
Enterobius vermicularis & 59 & 7,8 \\
Ancylostoma duodenale & 09 & 1,2 \\
Hymenolepis nana & 06 & 0,8 \\
Strongyloides stercoralis & 06 & 0,8 \\
\hline
\end{tabular}

A distribuição da frequiência de parasitas nas crianças ocorreu de forma múltipla, ou seja, muitas delas possuíam mais de um parasita. Os parasitas mais prevalentes foram: Giardia lamblia 19\% (144) e Ascaris lumbricoides 18,9\% (143), e Trichuris trichiura $16,9 \%$ (128)

A prevalência da infecção por parasitas intestinais desta população é bem menor do que a encontrada em 1994 em crianças de 1 a 12 anos residentes em 3 bairros rurais de São Miguel Arcanjo: Giardia lamblia 44,5\% e Ascaris lumbricoides 41\%, e Trichuris trichiura 40\% (Saldiva e col.,1999).

Neste estudo, o principal interesse ficou voltado para a infecção por helmintos, uma vez que em estudo anterior, foi encontrado uma associação entre desnutrição e presença de helmintos, principalmente a associação entre Ascaris lumbricoides e Trichuris trichiura (Saldiva e col., 1999).

A proporção de eutróficos infectados por helmintos foi de $32,3 \%$ (228) enquanto que a mesma proporção para os desnutridos foi de $44,3 \%$ (27). A análise pelo teste do Qui-quadrado apresentou um odds ratio de 1,64 e intervalo 
de confiança entre 0,93 a $2,87, x^{2}=3,38 p=0,06$. Este resultado sugere que a desnutrição representa um fator de risco para infecção por helmintos.

A infecção concomitante de Ascaris e Trichuris foi observada em 26\% (11) dos desnutridos, mostrando uma associação positiva com odds ratio de 4,45 $(1,98-9,03), x^{2}=18,3 p<0,00001$, confirmando os resultados anteriores do nosso grupo (Saldiva e col., 1999).

Os resultados apresentados a seguir foram extraídos dos exames nos quais foi possível realizar o método de Kato Katz das amostras de fezes positivas para Ascaris lumbricoides e Trichuris trichiura para a contagem de ovos, e assim conhecermos a intensidade de infecção na nossa população de estudo.

Na tabela 9 encontram-se os resultados obtidos sobre a intensidade de infecção por Ascaris lumbricoides e Trichuris trichiura entre as crianças classificadas de acordo com o seu estado nutricional na seleção dos casos em novembro de 1997.

Tabela 9 - Prevalência da intensidade de infecção nas crianças desnutridas e eutróficas de Santa Isabel, SP, novembro de 1997.

\begin{tabular}{c|cc|cc}
\hline $\begin{array}{c}\text { Intensidade de } \\
\text { Infecção }\end{array}$ & \multicolumn{2}{|c|}{ Ascaris lumbricoides } & \multicolumn{2}{c}{ Trichuris trichiura } \\
Desnutrida & Eutrófica & Desnutrida & Eutrófica \\
\hline Leve & $35 \%(6)$ & $39 \%(34)$ & $27 \%(3)$ & $64 \%(53)$ \\
Moderada & $24 \%(4)$ & $39 \%(34)$ & $55 \%(6)$ & $30 \%(25)$ \\
Intensa & $41 \%(7)$ & $22 \%(19)$ & $18 \%(2)$ & $6 \%(5)$ \\
\hline
\end{tabular}

A intensidade de infecção está associada marginalmente com o estado nutricional na infecção por Trichuris $x^{2}=5,87 p=0,0532$ com 2 graus de 
liberdade enquanto que para o Ascaris não houve associação $x^{2}=3,12 p=0,20$ para 2 graus de liberdade.

Em todas as etapas de estudo foi realizada a contagem de ovos para se conhecer a intensidade de infecção após a quimioterapia de massa. Em 10\% das crianças com exames positivos para Ascaris e Trichuris não foi possível ser feita a contagem de ovos por serem inadequadas.

É importante se destacar que na primeira etapa do estudo póstratamento em janeiro de $1998,82 \%$ das infecções foram de Trichuris trichiura e nenhuma de Ascaris lumbricoides. Foram contabilizadas todas as crianças que se infectaram durante o período do estudo (janeiro a outubro de 1998). Estes resultados estão na tabela 10 .

Tabela 10 - Proporção da intensidade de infecção do Ascaris lumbricoides e Trichuris trichiura, em crianças desnutridas e eutróficas que se infectaram durante no período de janeiro a outubro de 1998, Santa Isabel, SP.

\begin{tabular}{c|cc|cc}
\hline \multirow{2}{*}{$\begin{array}{c}\text { Intensidade de } \\
\text { Infecção }\end{array}$} & \multicolumn{2}{|c|}{ Ascaris lumbricoides } & \multicolumn{2}{c}{ Trichuris trichiura } \\
& Desnutrido & Eutrófico & Desnutrido & Eutrófico \\
\hline Leve & $33 \%(1)$ & $69 \%(33)$ & $89 \%(8)$ & $92 \%(35)$ \\
Moderada & $67 \%(2)$ & $21 \%(10)$ & $0 \%$ & $8 \%(3)$ \\
Intensa & $0 \%$ & $10 \%(5)$ & $11 \%(1)$ & $0 \%$ \\
\hline
\end{tabular}

Esta tabela demonstra que houve modificação na intensidade de infecção a partir do tratamento, porém o número de crianças é muito pequeno e não se pode tirar muitas conclusões.

Os dados apresentados abaixo referem-se aos métodos de Faust, Rugai e Hoffman de identificação dos ovos encontrados nas fezes da população de 
estudo, focalizando a infecção por helmintos encontrados nas várias etapas do trabalho após o tratamento quimioterápico. A tabela 11 apresenta o número de crianças infectadas por helmintos de acordo com o seu estado nutricional.

Tabela 11 - Número de crianças infectadas por helmintos (n) e a sua respectiva proporção (p), classificadas de acordo com seu estado nutricional, na etapa de seleção de casos e nas 5 etapas do estudo, Santa Isabel, SP, 1998.

\begin{tabular}{|c|c|c|c|c|c|c|c|c|c|c|c|c|}
\hline \multirow[t]{2}{*}{$\begin{array}{c}\text { Estado } \\
\text { Nutricional }\end{array}$} & \multicolumn{2}{|c|}{$\begin{array}{c}\text { Outubro/97 } \\
\text { T0 }\end{array}$} & \multicolumn{2}{|c|}{$\begin{array}{c}\text { Janeiro/98 } \\
\text { T1 }\end{array}$} & \multicolumn{2}{|c|}{$\begin{array}{c}\text { Março } \\
\text { T2 }\end{array}$} & \multicolumn{2}{|c|}{$\begin{array}{c}\text { Junho } \\
\text { T3 }\end{array}$} & \multicolumn{2}{|c|}{$\begin{array}{c}\text { Agosto } \\
\text { T4 }\end{array}$} & \multicolumn{2}{|c|}{$\begin{array}{c}\text { Outubro } \\
\text { T5 }\end{array}$} \\
\hline & $\mathrm{n}$ & $\%$ & $\mathrm{n}$ & $\%$ & $n$ & $\%$ & $n$ & $\%$ & $n$ & $\%$ & $n$ & $\%$ \\
\hline Eutrófico & 228 & 32,3 & 25 & 4 & 45 & 9,1 & 21 & 5,1 & 17 & 4,8 & 9 & 2,9 \\
\hline Desnutrido & 27 & 44 & 8 & 12 & 5 & 10,6 & 3 & 7,7 & 1 & 2,9 & 1 & 3,4 \\
\hline Total & 255 & 33,5 & 33 & 4,8 & 50 & 9,3 & 24 & 5,3 & 18 & 4,6 & 10 & 3,0 \\
\hline
\end{tabular}

Esta tabela mostra que as crianças desnutridas infectaram-se por helmintos numa proporção maior que as eutróficas, uma vez que em janeiro $12 \%$ (8) das desnutridas tinham se infectado contra $4 \%$ (25) das eutróficas. O risco relativo de infecção neste período foi 2,95 vezes maior para os desnutridos, com um $x^{2}=9,85$, um nível de significância $p=0,0017$, e odds ratio $=3,57$ (intervalo de confiança compreendido entre 1,41 a 8,83 ). A partir desta fase, a proporção de infecção entre os dois grupos não apresentou diferença significativa a nível de $5 \%$.

Conforme foi descrito na seção de métodos as crianças infectadas nas etapas de estudo (134) correspondem a todas aquelas que apresentaram resultado positivo para helmintos. Quando analisamos a infecção pós tratamento, do ponto de vista específico ou seja, para cada criança, temos um sub-grupo de crianças que se reinfectaram (91), e as crianças que tiveram uma infecção "nova" (43). O fato de haver infecção mostra que o ambiente não foi descontaminado. Como o 
objetivo deste estudo era garantir somente o tratamento antiparasitário para crianças, houve provavelmente a permanência de outros indivíduos infectados no ambiente. Embora a manutenção de indivíduos potencialmente infectados (não tratados) na comunidade não tenha sido proposital, os mesmos podem ter atuado como "reservatórios" de helmintos, que permitiram estudar as infecções ou reinfecções na população tratada num espaço de tempo relativamente curto.

O gráfico 3 apresenta o número de crianças que se reinfectaram e as crianças com infecção "nova" ao longo das 5 etapas de estudo.

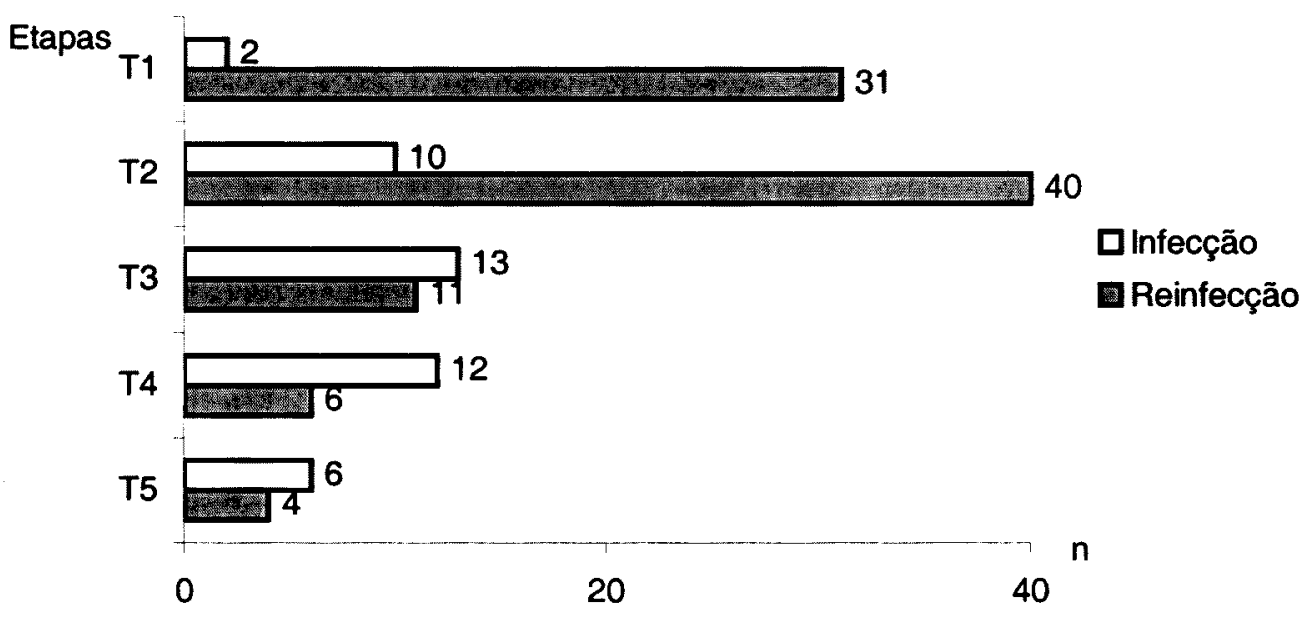

\section{Gráfico 3 - Número de crianças com reinfecção e infecção "nova” nas 5 etapas de estudo em 3 bairros do Município de Santa Isabel, SP, 1998.}

Conforme podemos observar no gráfico 3 o número de crianças com reinfecção é maior do que aquelas com infecção "nova". Notamos ainda, que a evolução temporal dos dois grupos também é distinta, dado que a reinfecção atinge seu pico mais precocemente. 
A análise realizada em uma amostra da população $(n=378)$ que continha informações sobre o nível sócio - econômico e educacional das famílias, mostrou uma associação significativa entre a infecção por helmintos pós tratamento quimioterápico e o fato da mãe não saber ler com um odds ratio de 3,15 (intervalo de confiança entre 1,59 e $6,24, x^{2}=13,38$ ) e um nível de significância de 0,000025 . Também foi encontrado uma associação significativa entre infecção pós tratamento e a renda per capita inferior a 85,00 reais com um odds ratio de 2,56 (intervalo de confiança entre 1,46 e $4,49, x^{2}=12,61$ ) e um nível de significância $p=0,00038$. Vale a pena ressaltar, porém que não houve associação estatística entre a infecção pós tratamento com a escolaridade do chefe da família, ou ainda com o local de residência.

\section{Consumo Alimentar}

A análise do consumo alimentar da amostra coletada entre 121 crianças apresentou os seguintes resultados:

A mediana de adequação do consumo de calorias foi de $100,5 \%$ com uma adequação mínima de $27,7 \%$ e máxima de $219 \%$.

A mediana de adequação do consumo de proteínas foi de $195 \%$ variando entre $28,4 \%$ a $750 \%$.

Entre as crianças desnutridas tivemos $59,3 \%$ (32) com consumo de calorias abaixo de $100 \%$ de adequação $\left(x^{2}=4,3\right.$ e $\left.p=0,03\right)$ e $25,9 \%$ (14) com consumo protéico abaixo de $100 \%$ de adequação $\left(x^{2}=11,4\right.$ e $\left.p=0,0007\right)$. 
Foram realizadas análises univariadas levando em consideração a adequação do consumo de calorias e proteínas como variável dependente e alguns dos parâmetros estudados: estado nutricional, sexo e bairro $(n=121)$.

As análises de associação entre adequação do consumo calórico e as variáveis acima demonstraram não haver associação estatística significante entre elas. Já as análises de associação entre o consumo protéico mostrou-se significante em algumas situações, e o resultado desta análise encontra-se na tabela 12.

Tabela 12 - Valores do $\boldsymbol{x}^{2}$ (Yates ), e o $\boldsymbol{p}$ ( nível de significância), odds ratio e o (IC) Intervalo de Confiança ao nível de $95 \%$, das associações entre a adequação do consumo protéico e as variáveis: estado nutricional, Eldorado, Novo Éden, Acácias e Sexo de crianças residentes em 3 localidades do Município de Santa Isabel, SP, 1998.

\begin{tabular}{c|c|c|c|c|c}
\hline Variáveis & $\boldsymbol{X}^{\mathbf{2}}$ & $\boldsymbol{P}$ & O.Ratio & $\boldsymbol{I C}$ (inf.) & $\boldsymbol{I C}$ (sup.) \\
\hline Estado nutricional & 9,68 & 0,001 & 7,47 & 1,84 & 35,09 \\
Eldorado & 7,10 & 0,007 & 5,20 & 1,44 & 20,48 \\
Novo Éden & 3,12 & 0,07 & 0,31 & 0,08 & 1,11 \\
Sexo & 0,56 & 0,46 & 1,76 & 0,52 & 6,23 \\
\hline
\end{tabular}

Esta tabela mostra que existe uma associação estatisticamente significante entre o consumo inadequado de proteínas e o estado nutricional da criança, e ao fato dela residir no bairro Jardim Eldorado. A associação da desnutrição com consumo protéico inadequado é semelhante ao achado em São Miguel Arcanjo em 1994 (Saldiva e col., 1999). 


\section{Resultado das análises de sobrevida (Modelo de Cox)}

Para o avaliarmos comportamento da infecção por helmintos entre os dois grupos de crianças classificadas de acordo com o seu estado nutricional ao longo de 12 meses após o tratamento inicial, foram elaborados modelos de riscos proporcionais de Cox, sendo considerados diferentes especificações de variáveis preditivas.

O modelo desenvolvido partiu da amostra total da população estudada (759 crianças), no qual foram considerados os seguintes parâmetros: tempo de permanência da criança no estudo (em dias), seu status ( infectado (134 crianças) ou censurado por perda e por não infecção (541)), estado nutricional (eutrófico ou desnutrido), os locais de residência definidos como moradores ou não do Bairro Eldorado, e a idade (em meses).

Neste modelo o Bairro Eldorado foi considerado como uma variável categórica importante, por considerarmos que neste bairro as condições sociais e ambientais eram piores do que nos outros dois locais estudados. Vale a pena ressaltar porém, que não houve diferença estatística para desnutrição entre os três bairros. 
Tabela 13 - Resultado da análise de "sobrevida" através do Modelo de Cox, com os valores do Coeficiente da exposição a infecção $(\boldsymbol{B})$, erro padrão da exposição $(S E)$, risco $(B)$ e o nível de significância $(P)$, em crianças de 3 localidades do município de Santa Isabel. $\left(X^{2}=\right.$ $18,62, p=0,0003), 1999$.

\begin{tabular}{c|c|c|c|c}
\hline Variáveis & Coeficiente $(\boldsymbol{B})$ & Erro padrão(SE) & Risco $(\boldsymbol{B})$ & $\boldsymbol{P}$ \\
\hline Idade em meses & 0,0066 & 0,0026 & 1,006 & 0,0106 \\
Desnutrição & 0,5459 & 0,2554 & 1,726 & 0,0326 \\
Eldorado & 0,4012 & 0,1767 & 1,493 & 0,0232 \\
\hline
\end{tabular}

De acordo com os resultados da análise temos que o risco de infecção por helmintos pós tratamento está associado à desnutrição $(\boldsymbol{R} \boldsymbol{R}=1,726$ e $\boldsymbol{p}=$ 0,0326), mesmo controlando para idade e local de moradia. O risco de infecção aumenta com a idade da criança, e com o fato dela morar no bairro Eldorado.

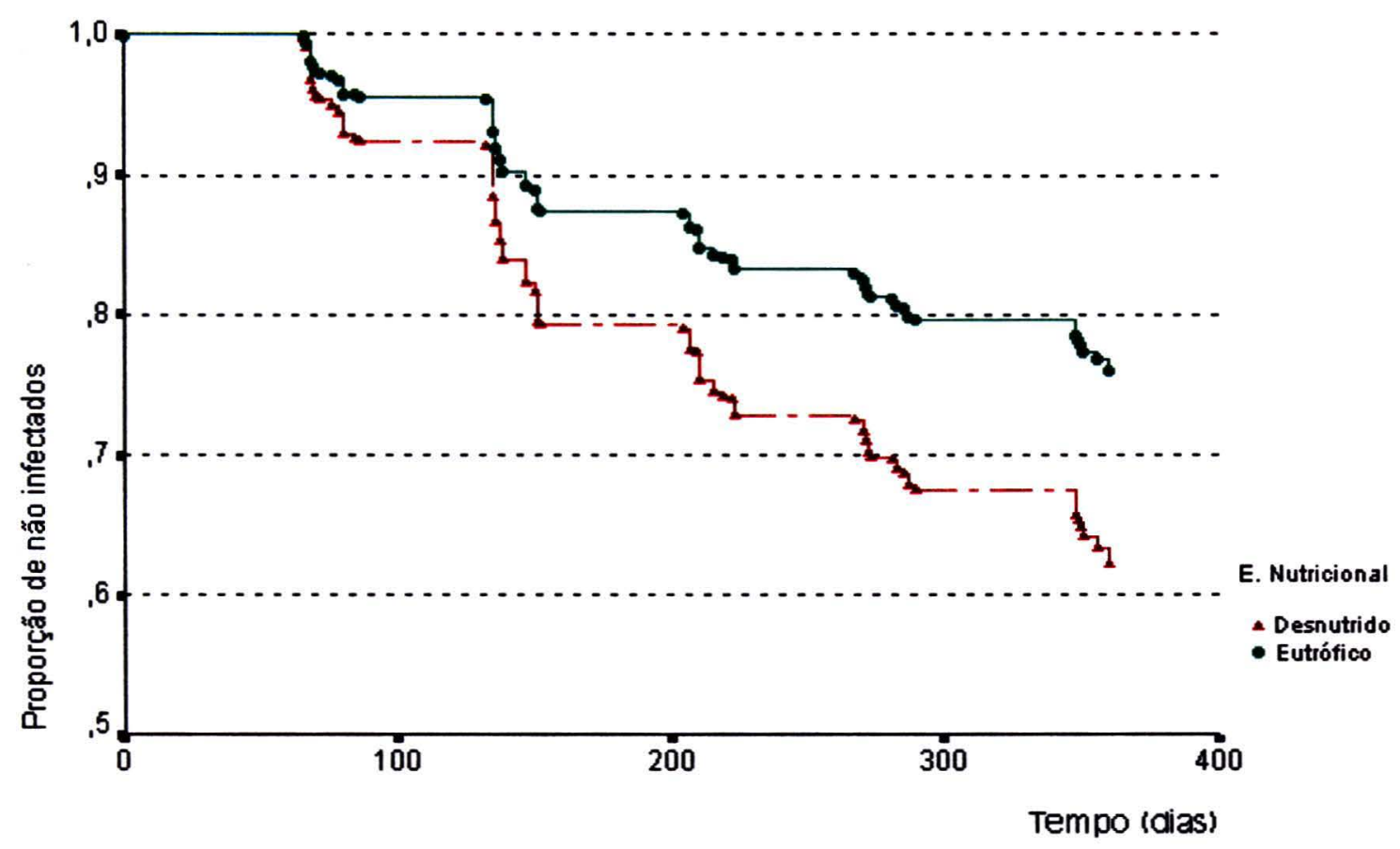

Gráfico 4 - Curvas do modelo de Cox das crianças de 1 a 10 anos de idade (675) classificadas segundo seu estado nutricional, residentes em Santa Isabel, SP. 


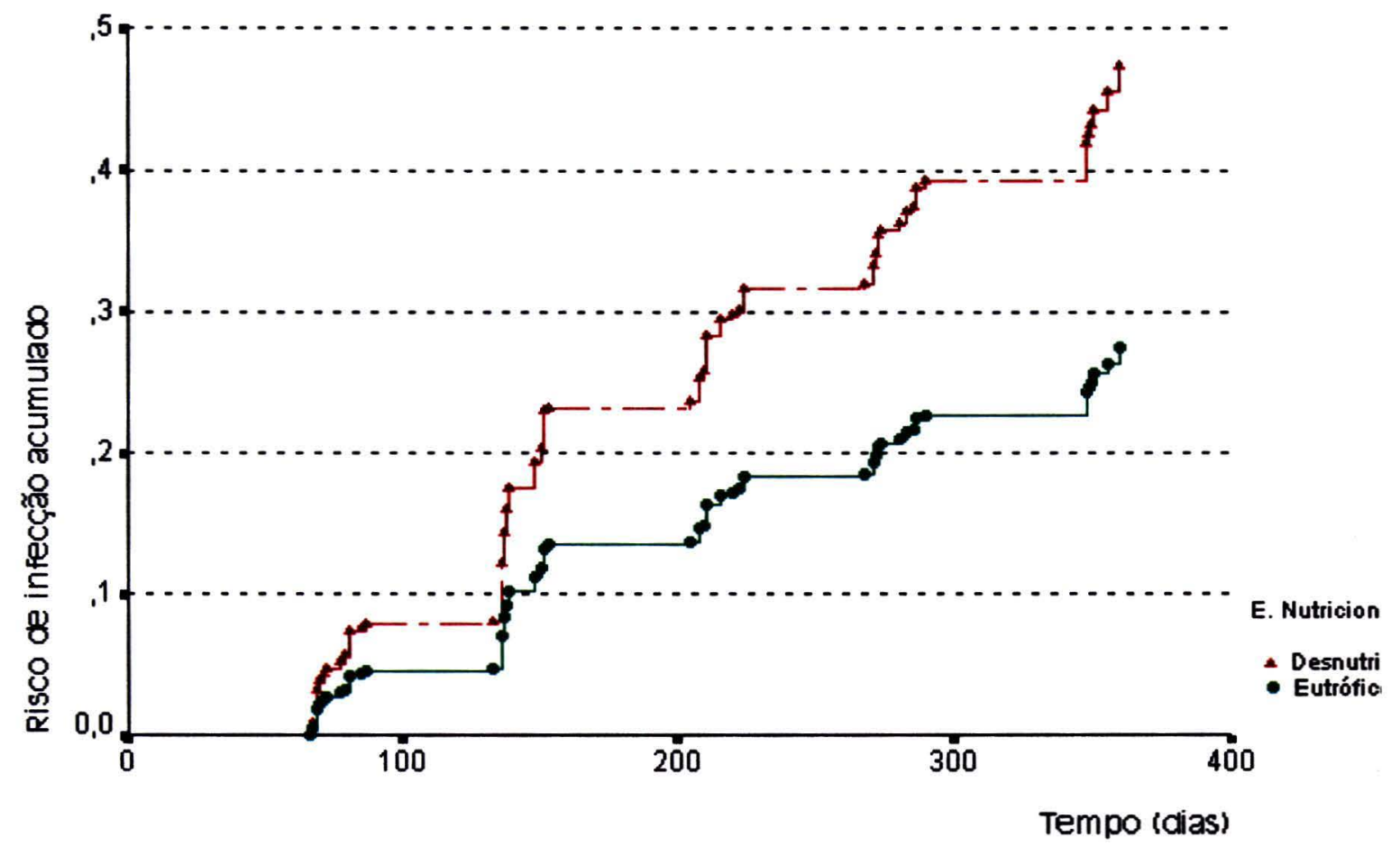

\section{Gráfico 5 - Curvas referentes ao risco de infecção do modelo de Cox para as crianças de 1 a 10 anos (675) classificadas segundo seu estado nutricional, residentes em Santa Isabel, SP.}

As curvas acima demonstram a diferença entre as crianças desnutridas e eutróficas em relação à infecção de helmintos pós tratamento quimioterápico. As curvas de "sobrevida" do modelo de Cox (gráfico 4) mostra que aproximadamente $62 \%$ das crianças desnutridas permanecem no estado não infectado contra aproximadamente $75 \%$ das crianças eutróficas, e esta diferença é estatisticamente significativa $\boldsymbol{p}=0,0326$. A curva de risco de aquisição de infecção por helmintos após o tratamento também é diferente entre os dois grupos, ou seja os desnutridos têm aproximadamente $48 \%$ mais de chance de adquirir infecção, ao passo que nos eutróficos esta chance é estimada em aproximadamente $28 \%$.

Em decorrência dos resultados encontrados na análise univariada sobre o comportamento da reinfecção por helmintos foi elaborado um modelo de 
riscos proporcionais de Cox, para relacionar a influência do estado nutricional na reinfecção de helmintos, controlando para variáveis preditivas descritas acima como as de maior relevância no conjunto de dados estudados.

Neste modelo foi estudada a amostra total da população (759 crianças), no qual foram considerados os seguintes parâmetros: tempo de permanência da criança no estudo (em dias), seu "status" (reinfecção (91 crianças)) ou censurado por perda e por não reinfecção(589)), estado nutricional (eutrófico ou desnutrido), os locais de residência definidos como moradores ou não do Bairro Eldorado, e a idade (em meses).

A tabela 14 apresenta os resultados encontrados do modelo desenvolvido para o estudo da reinfecção por helmintos.

Tabela 14 - Resultado da análise através do Modelo de Cox, com os valores do Coeficiente da exposição a reinfecção $(\boldsymbol{B})$, erro padrão da exposição $(\boldsymbol{S E})$, risco $(\boldsymbol{B})$ e o nível de significância $(\boldsymbol{P})$, em crianças de 3 localidades do município de Santa Isabel. $\left(X^{2}=28,57\right.$, $p=0,000), 1999$.

\begin{tabular}{c|c|c|c|c}
\hline Variáveis & Coeficiente $(\boldsymbol{B})$ & Erro padrão $(\boldsymbol{S E})$ & Risco $(\boldsymbol{B})$ & $\boldsymbol{P}$ \\
\hline Idade em meses & 0,0101 & 0,0032 & 1,0101 & 0,0016 \\
Desnutrição & 0,8295 & 0,2784 & 2,2921 & 0,0029 \\
Eldorado & 0,4896 & 0,2126 & 1,6316 & 0,0213 \\
\hline
\end{tabular}

Os resultados deste modelo demonstram que o risco de reinfecção por helmintos está associado à desnutrição $(\boldsymbol{R} R=2,2921$ e $\boldsymbol{p}=0,0029)$, mesmo quando são considerados simultâneamente na análise a idade da criança e o local de moradia. 
Os gráficos 6 e 7 apresentam os resultados das curvas estimadas pelo modelo de Cox e de risco de reinfecção descrito acima.

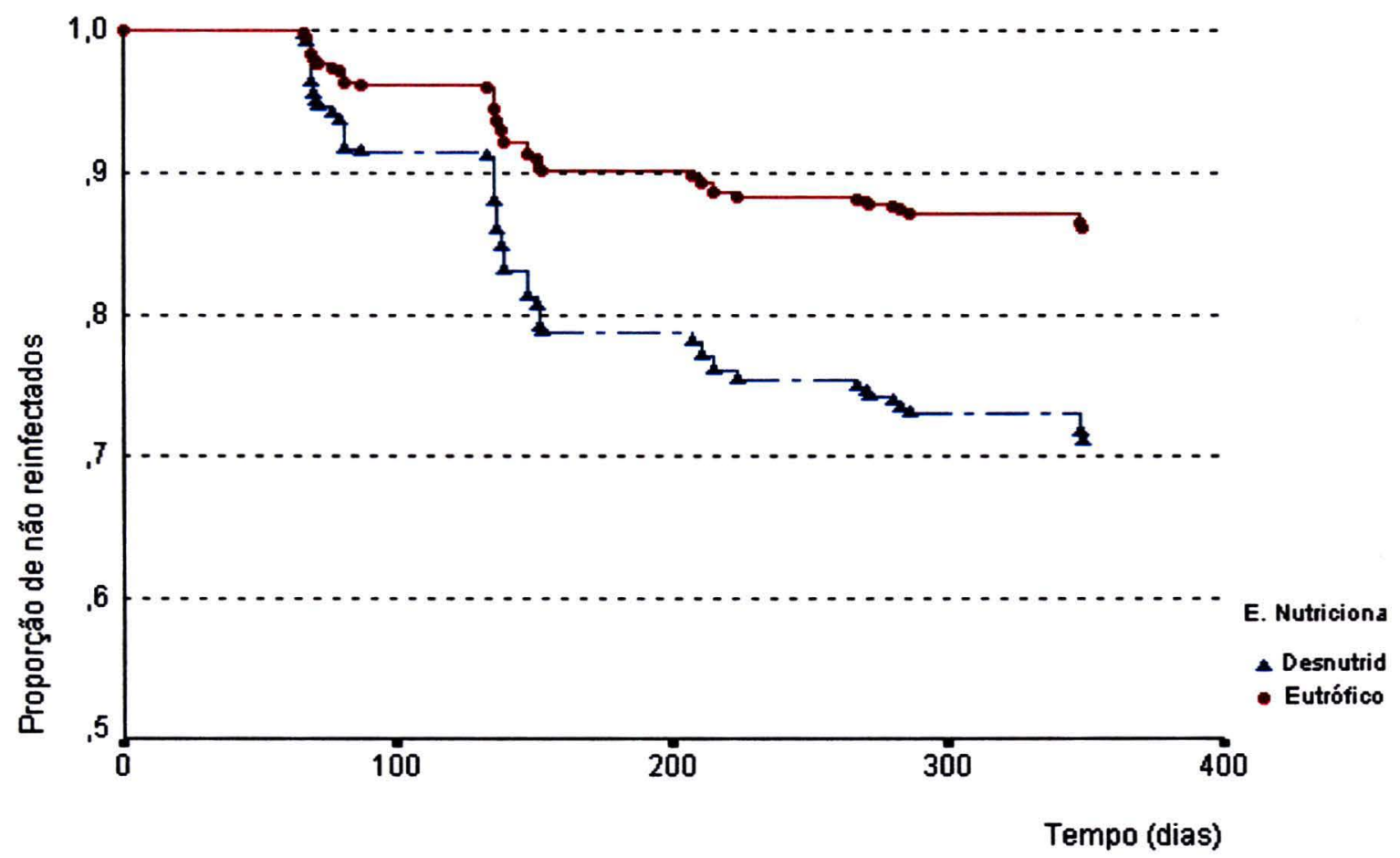

Gráfico 6- Curvas de proporção de não infectados derivadas do modelo de Cox sobre reinfecção por helmintos em crianças de 1 a 10 anos de idade (675) classificadas segundo seu estado nutricional, residentes em Santa Isabel, SP.

As curvas referentes a reinfecção por helmintos também demonstram a diferença entre as crianças eutróficas e desnutridas. A curva de sobrevida deste novo modelo mostra que aproximadamente $87 \%$ das crianças eutróficas permanecem na condição "não reinfectada", enquanto que $72 \%$ das crianças desnutridas permanecem nesta mesma condição. Em relação ao risco de reinfecção por helmintos a curva também é diferente entre os dois grupos, mostrando que os desnutridos têm aproximadamente $33 \%$ de chance de adquirir reinfecção enquanto que os eutróficos têm aproximadamente $15 \%$ de chance. 


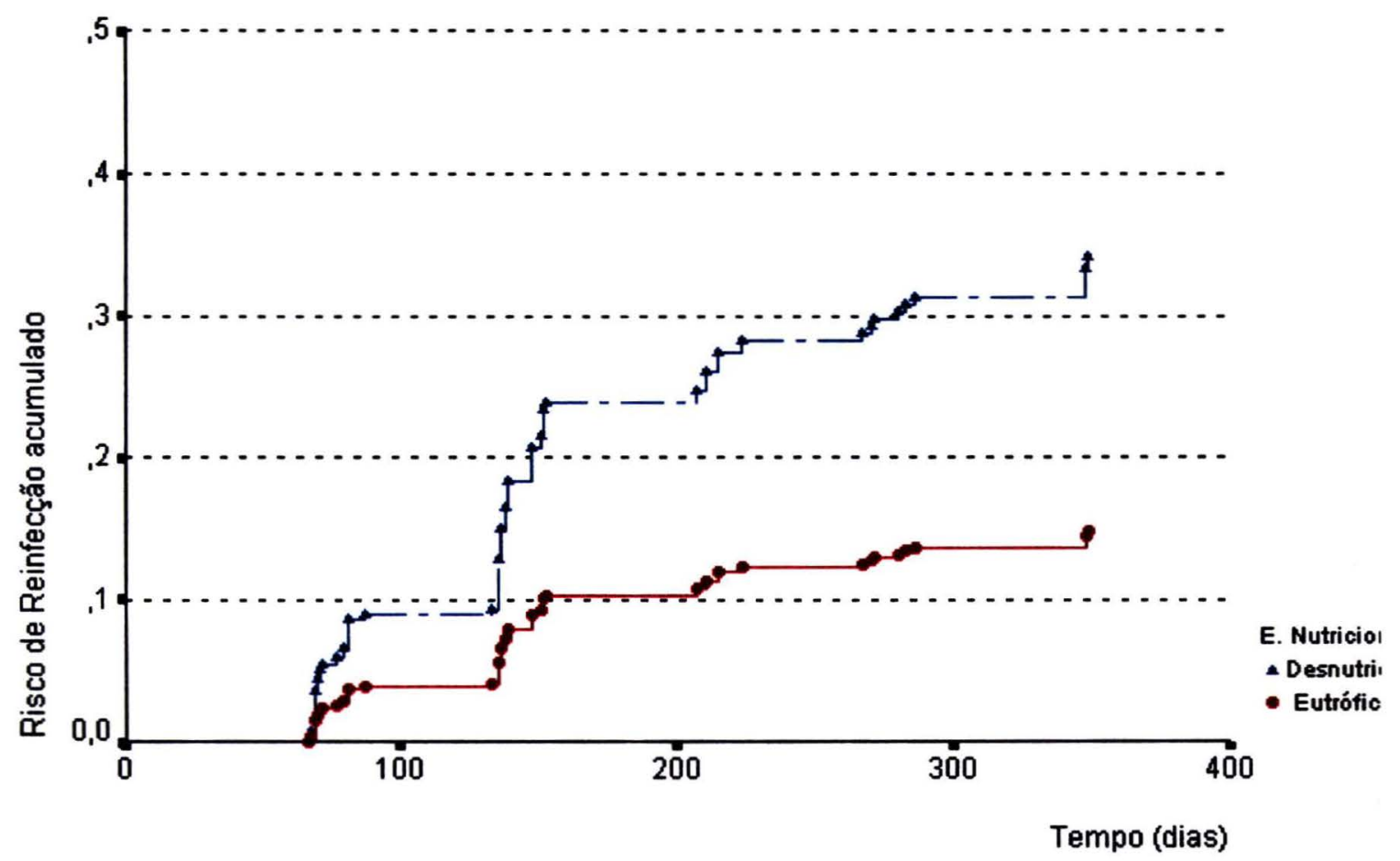

Gráfico 7 - Curvas referentes ao risco de reinfecção do modelo de Cox para as crianças de 1 a 10 anos (675) classificadas segundo seu estado nutricional, residentes em Santa Isabel, SP. 
Este estudo foi desenvolvido com o intuito de se avaliar, de forma objetiva, algumas das relações entre parasitas intestinais e desnutrição infantil em uma localidade de baixa renda do Estado de São Paulo. Na realidade, este trabalho representa uma continuidade de estudo anterior, onde foi verificado que a infecção por parasitas intestinal, principalmente a associação de Ascaris e Trichuris, mostrava uma associação positiva com a desnutrição. Diferentemente do estudo anterior, o planejamento do presente trabalho foi feito tendo por objetivo o tratamento de massa de toda a população infantil das áreas de estudo, tornando-a livre de parasitas. Após isto, foi feito o acompanhamento desta população visando analisar a reinfecção por parasitas. A hipótese a ser testada no estudo foi a de que crianças desnutridas não somente teriam maior prevalência de parasitismo mas também que, após tratadas, teriam uma taxa de reinfecção maior.

O estudo do impacto das infecções por helmintos na nutrição humana não é novo, visto existir há mais de dez anos publicações extensas sobre o assunto (Stephenson, 1987). A maior parte das evidências que relacionam desnutrição e parasitismo provém de estudos que demonstraram haver melhora dos indicadores nutricionais após o tratamento antiparasitário (Gupta e col. (1977), Willet e col. (1979), Thein-Hlaind e col. (1991), Stephenson e col. (1993), Oberhelman, 1998). A despeito da grande massa de conhecimentos presentes, o efeito da desnutrição como agente predisponente da infecção é muito menos estabelecido do que a situação oposta, ou seja, as infecções por parasitas como causadoras de desnutrição. Isto posto, o presente estudo visa fornecer informações sobre a primeira situação. Antes de se iniciar a discussão específica dos resultados 
relacionados à hipótese principal do trabalho, serão feitas algumas considerações sobre a escolha da população de estudo e sobre os métodos empregados em campo.

A escolha de Santa Isabel para sediar o estudo deu-se em função da localização ser próxima a São Paulo, por ser um município relativamente pobre com uma economia baseada em hortifrutigranjeiros, possuir uma migração populacional pequena, e ainda ao interesse da Secretaria da Saúde do Município de Santa Isabel, em viabilizar o projeto junto a Prefeitura e a População. Foi montada no Centro de Saúde Hilário Dassie toda nossa estrutura de treinamento de pessoal, estoque de material, medicamentos e equipamentos, assim como, uma secretaria com computador e impressora para o cadastramento das crianças e a confecção das listas de endereços a serem visitados quando da entrega de material para exame. Foi também estabelecido que os pediatras desta Unidade atenderiam as crianças que estivessem participando do estudo em que fosse detectada qualquer ocorrência de doenças. Porém na prática, isto não aconteceu, pois as mães na sua maioria já possuíam um pediatra de sua preferência. Os casos detectados de desnutrição foram encaminhados para o Secretário da Saúde para que se pudessem tomar as providências médicas e de assistência social. Recentemente foi inaugurado no Jardim Eldorado um Centro de Saúde (Jåneiro/99) para atender a população do Eldorado e Acácias e outro no Jardim Novo Éden está para ser inaugurado em Novembro/99.

Quando se trabalha com desnutrição infantil e verminoses focaliza-se um segmento da população, onde as condições sociais e ambientais são 
desfavoráveis, onde predominam a pobreza, a falta de recursos de saúde, higiene e sociais. Isto representa um aspecto de uma estrutura mais complexa de interrelações entre as variáveis econômicas e as relacionadas à saúde e nutrição. Conhecendo estas condições, foi estudada a população infantil residente em bairros periféricos do município de Santa Isabel, onde as condições sócioseconômicas e do ambiente favoreciam esta investigação.

Partiu-se do pressuposto que tanto as crianças eutróficas quanto as desnutridas conviviam num mesmo ambiente e por vezes até na mesma família. Tais condições permitem supor que estas crianças tivessem um perfil sócioeconômico, microambiental e sanitário semelhantes, fazendo com que a sua influência sobre os resultados fosse minimizada.

Os resultados obtidos através dos questionários aplicados em uma amostra da população apresentam alguns aspectos da realidade vivida por esta população.

As análises a respeito das variáveis sócio-econômicas foram realizadas somente com o intuito de se traçar o perfil econômico da população, sem nenhuma pretensão de se traçar uma classificação de pobreza. Os resultados mostraram que a população estudada possuía uma renda familiar média per capita em torno de $\mathrm{R} \$ 110$, que o nível de desemprego entre os chefes de família era em torno de $14 \%$, e o analfabetismo estava presente em $13 \%$.

$\mathrm{O}$ ambiente a que estas crianças estavam expostas também fornece uma idéia da precariedade do local estudado, uma vez que em $60 \%$ dos domicílios o destino dos dejetos eram inadequados, em $25 \%$ o abastecimento de água era 
feita através de poços artesianos ou caminhões pipa, e $64 \%$ deles estavam localizados em ruas e calçadas sem pavimentação. Neste sentido no final do estudo em setembro de 1998, as ruas tanto do Jardim Eldorado quanto do Jardim das Acácias já estavam sendo trabalhadas no sentido de se colocar manta asfáltica nas vias principais. Isto talvez traga para estes bairros além da melhoria de acesso, serviços tanto de saúde quanto de saneamento. Nenhum dos 3 bairros estudados possuía uma Unidade de Saúde, todos eles tinham suas emergências direcionadas para a Santa Casa ou a Unidade de Saúde localizados no centro urbano. O centro urbano dista do Jardim Novo Éden cerca de $5 \mathrm{Km}$, o Jardim Eldorado cerca de 8 Km e o Jardim das Acácias cerca de $10 \mathrm{Km}$.

A interação direta com as famílias, ainda mais no contexto da administração de um medicamento, poderia gerar expectativas de prestação de outro tipo de assistência médica que não aquela prevista pelo protocolo, este aspecto foi discutido no planejamento do estudo mas não ocorreu durante a sua execução, mostrando que a linguagem no consentimento pós-informado foi adequada ao descrever os objetivos do estudo.

Dentre os fatores de perda de seguimento os mais importantes foram aqueles resultantes da falta da entrega de amostras de fezes. Diferentes eventos ocorreram: dificuldade das crianças defecaram nos dias esperados, dificuldade das mães em colher as amostras adequadamente, ausências eventuais dos pais ou responsáveis nas visitas, não aderência a um protocolo que solicita a entrega de repetidas amostras de fezes, o que desagrada muitas vezes as mães ou as crianças, 
entre outros. Para minimizar estas perdas foram feitas repetidas visitas de reforço e incentivo, sem, no entanto, ultrapassar os limites do constrangimento.

Foi encontrada uma proporção maior de diarréia nas crianças desnutridas $(22 \%)$ em relação às eutróficas $(12 \%)$ no período de seleção de casos em novembro de 1997 (tabela 6). Não obstante, as crianças desnutridas mantiveram-se como tal ao longo do período de estudo, mesmo quando a frequêência de diarréia foi reduzida após o tratamento, provavelmente devido ao fato de que a sua deficiência era predominantemente de altura, caracterizando uma desnutrição crônica.

A equipe de entrevistadores foi composta por estudantes do segundo grau. Esta não foi a primeira escolha quando do planejamento do estudo, que objetivava ter como entrevistadores professores do primeiro grau, no entanto a opção dos professores se mostrou inviável. O perfil etário dos entrevistadores fez com que o treinamento e a supervisão do trabalho durante o projeto tivesse que ser mais intensivo, necessitando de vários remanejamentos internos. Apesar das dificuldades, a experiência do trabalho com estes jovens foi positiva, mostrando ser possível considerar esta força de trabalho em projetos futuros, norteada por disciplina e motivação adequada.

Quando analisado o perfil nutricional desta população deparou-se com uma prevalência de desnutrição de $8 \%$ para todas as faixas etárias, sendo que para as crianças até 5 anos a prevalência foi de $10 \%$. Apenas com o intuito de avaliar a magnitude do problema, comparou-se este achado com a prevalência descrita por Monteiro e col. (1995), referente ao inquérito nacional realizado em 1989 
(PNSN). Neste inquérito a prevalência de desnutrição infantil para as crianças menores de 5 anos, para todo o território nacional era de $7.1 \%$ e, para a região sudeste de $4.1 \%$.

Vale a pena ressaltar que neste inquérito nacional, o índice estudado foi o peso para idade, e na nossa população foram estudados os índices de peso para altura (WHZ) e altura para a idade (HAZ). Embora possam existir diferenças entre os índices acima citados, é lícito supor que os mesmos representam um indicador da desnutrição que permita algumas comparações. A prevalência de desnutrição da população deste estudo - $10 \%$ para menores de 5 anos - representa 2 vezes a encontrada na região Sudeste relatada por Monteiro e col. (1995), somente igualando-se com a região Norte do Pais $(10,6 \%)$.

Na sub-amostra analisada $(n=378)$ não foram encontradas associações estatísticas entre desnutrição e as variáveis de renda per capita, escolaridade da mãe e local de residência. Estas variáveis costumam contribuir como fatores de viés no estudo dos efeitos da desnutrição, porém nesta população isto não ocorreu. Outras variáveis referentes ao comportamento da mãe tais como: desenvoltura no cuidado da criança, aspectos relacionados com sua saúde física e mental, tanto temporária quanto definitiva, entre outros, podem estar associados à desnutrição e que não foram investigadas no presente estudo. Dada a extensão adquirida pelo o trabalho, a medida destas variáveis mais complexas da relação materno infantil deverá ser objeto de investigações futuras.

Como estamos falando de uma população com baixa renda, com uma prevalência de desnutrição relativamente alta, foi também importante conhecer o 
consumo alimentar destas crianças. O método escolhido foi o Recordatório 24 horas, por ser de fácil aplicação em estudos populacionais, porém ele é um método que requer muito treinamento do entrevistador para que não haja interferência nas respostas das mães e que ele contenha os dados mais fidedignos possíveis do que a criança consumiu naquele período. Além disso, requer no mínimo meia hora de entrevista com a mãe, e isto se torna muito demorado quando a mesma possui mais de uma criança, e todos os afazeres domésticos. Em vista destas limitações foi sorteada uma amostra da população.

A amostra escolhida para a aplicação do Recordatório 24 horas foi constituída de desnutridos e eutróficos pareados de acordo com o sexo e idade. Importante ressaltar, que foi realizada apenas uma medida, o que fragiliza os resultados obtidos, limitando com isso a sua interpretação. Os resultados mostraram que $49 \%$ das crianças tiveram consumo abaixo de $100 \%$ de adequação para calorias e $14 \%$ para proteínas. Houve uma associação significante entre o consumo protéico abaixo de $100 \%$ e desnutrição com $x^{2}=11,4$ e $p=0,0007$. Este resultado é similar ao encontrado em São Miguel Arcanjo (Saldiva e col., 1999).

Os dados da pesquisa do IBGE/ENDEF - 74/75 e IBGE/POF - 87/88 sobre o consumo alimentar da população das áreas metropolitanas mostraram que, de maneira geral, houve redução da quantidade e na porcentagem de adequação de calorias e proteínas. Para o período de 1990/95 existem poucas informações diretas e medidas do consumo alimentar. Apesar da alta produção agrícola dos anos de 1993/94 e 1994/95 a produção de arroz e feijão, base da alimentação de uma grande maioria de brasileiros e que são excelentes fontes de calorias e 
proteínas, não aumentou. Embora em menor ritmo houve aumento da população, portanto, imagina-se que os pobres estão consumindo menos esses alimentos básicos (Dutra e col., 1996).

Mondini e Monteiro (1995), em estudo sobre o padrão de alimentação dos brasileiros nas décadas de 70 e de 80 , mostraram uma redução do consumo de cereais e derivados, feijão, raízes e tubérculos, um aumento no consumo de ovos, leite e derivados, a substituição da banha, toucinho e manteiga por óleos vegetais e margarinas e aumento do consumo de carnes. As modificações observadas neste mesmo estudo mostraram uma tendência generalizada de menor contribuição dos carboidratos no consumo calórico total e sua substituição por gorduras, e ainda que a participação das proteínas na dieta pouco se alterou ao longo do período estudado.

A prevalência de parasitas intestinais no início da investigação apresentada na tabela 7 , foi semelhante a do estudo descrito por Ferreira e col. em 1994, em uma população residente em favelas de São Paulo mostrando $23.8 \%$ de Ascaris e $17.2 \%$ de Trichuris. Apesar da prevalência encontrada neste estudo ser bem menor à encontrada em outro estudo realizado em 1994 em São Miguel Arcanjo (Saldiva e col.,1999) com crianças da mesma faixa etária. O presente conjunto de dados encontra também associações positivas entre a presença de parasitas e desnutrição, reproduzindo-se o mesmo efeito encontrado anteriormente.

Na amostra estudada de domicílios (378 crianças), foi possível verificar o efeito altamente significativo das variáveis renda familiar per capita, e 
grau de instrução materna com a prevalência de infecção de helmintos $\left(x^{2}=12,61\right.$ $p=0,0003$ e $x^{2}=13,38 p=0,00002$ respectivamente). Este efeito já foi relatado em vários estudos que apontam para esta associação (Ismail e col., 1989). Mais recentemente, estudo realizado em Sri Lanka, (De Silva e col., 1996) mostrou haver associação entre o nível educacional da mãe ou responsável pelo cuidado da criança e a prevalência de infecções por helmintos, ou seja, quanto pior o nível educacional maior a prevalência de infecções. Foi também relatado que com a melhora do nível sócio-econômico diminuía a prevalência de infecções por helmintos. Kightlinger e col., 1998 em outro estudo, no sudeste de Madagascar mostrou haver uma associação entre intensidade de infecção por Ascaris lumbricoides e a exposição de crianças a fatores ambientais e comportamentais. Não foram encontradas associações estatísticas com o grau de instrução do chefe de família, e com as variáveis ambientais medidas nesta sub-amostra da população.

Neste estudo foi realizada a avaliação quantitativa dos ovos dos parasitas Ascaris lumbricoides e Trichuris trichiura, visando avaliar a intensidade de infecção. Este tipo de abordagem é controverso, visto que Croll e col.(1982), e Bundy e col. (1985) relatam que a postura de ovos pelo parasitas é influenciada pela sua densidade no trato intestinal. Em outras palavras situações de extrema infestação levariam a uma redução da oviposição, fato este que invalidaria a contagem de ovos como instrumento para avaliação da intensidade de infecção. Contrario a este conceito Elkins e col. (1988), e Forrester e Scott (1990) encontraram uma boa correlação entre a contagem de ovos de Ascaris lumbricoides e a intensidade de infecção por este parasita. Neste estudo foi 
observado que as crianças desnutridas apresentavam uma maior densidade de ovos nas fezes (Tabela 8).

Uma das premissas básicas do presente estudo era que a prevalência dos helmintos fosse reduzida a zero. Este tipo de abordagem foi utilizado previamente por outros autores tais como, por exemplo, Soeripto (1991), Chan e col. (1992), Holland e col. (1992), Henry e col. (1993), Kighltlinger e col. (1998). Em relação ao protocolo de tratamento e o acompanhamento da infecção/reinfecção, a diferença entre os estudos acima citados e este estudo é que aqui o período de avaliação e a frequiência foram mais curtos, visando determinar as fases mais precoces da história natural da infecção/reinfecção pós tratamento antiparasitário.

A população foi tratada com Mebendazol, por não haver contraindicação de uso, pela sua comprovada eficácia uma vez que para Ascaris lumbricoides é igual ou acima de $90 \%$ de cura, e para Trichuris trichiura entre 60 a $89 \%$ de cura (WHO,1985 e 1987), ser bem tolerado pelas crianças. Foi administrado na quantidade de $600 \mathrm{mg}$ em 2 doses diárias durante 3 dias consecutivos, este tratamento foi repetido após 15 dias para dar maior segurança de erradicação dos helmintos. Passados 10 dias do último tratamento foi realizado um novo exame de fezes.

Para o tratamento das giardíases e amebíases foi escolhido o Secnidal (secnidazol), por ser administrado em dose única e por ser de melhor sabor para a ingestão por crianças. Os medicamentos Cestox (praziquantel) e Thiaben 
(tiabendazol) foram utilizados pela sua alta eficácia em casos de Himenolepíases e Estrongilodíases respectivamente.

A estratégia do tratamento baseou-se no controle efetivo da administração dos medicamentos anti-parasitários. Este tipo de procedimento - o controle estrito da tratamento - demandou uma energia substancial por parte da equipe de campo. No entanto, dado o perfil sócio-cultural das famílias envolvidas no estudo e a demora natural para o estabelecimento de vínculos de confiança entre a equipe e as famílias, preferiu-se despender este esforço em benefício de um tratamento adequado.

O protocolo acima descrito permitiu verificar a eficácia do tratamento num curto espaço de tempo, visto que, é pouco provável uma nova infecção neste intervalo. Mesmo com 2 tratamentos a eficácia obtida não foi absoluta: 4 crianças que eram positivas para Ascaris lumbricoides e Trichuris trichiuris no início do estudo, permaneceram positivas para Trichuris trichiura, confirmando a relativa resistência deste parasita ao tratamento com Mebendazol (WHO,1985).

Devido ao pequeno número de crianças que foi resistente ao tratamento não foi possível determinar nenhuma característica peculiar que explicasse a razão deste comportamento. Visando uma maior precisão do estudo, as mesmas foram retiradas da amostra, para que o modelo de riscos proporcionais levasse em conta no momento zero apenas as crianças com exame de fezes negativo.

Após a quimioterapia pode-se acompanhar a história natural da reinfecção da população. Passado um mês da negativação dos exames, a avaliação 
seguinte já revelava a presença de infecção, na sua maioria por Trichuris trichiura. A ocorrência de infecção por Trichuris num espaço de tempo tão reduzido contraria os preceitos tradicionais que prescrevem que a presença de ovos de Trichuris nas fezes ocorrem somente após 70 a 90 dias da ingestão de ovos (WHO, 1987). No entanto, os resultados deste estudo são coerentes com aqueles relatados por Zaman, (1978) e Shiddo e col. (1990) que mostram a presença de ovos nas fezes em períodos tão curtos quanto 15 dias. Nas análises de fezes subsequientes não se observou nenhuma dominância por qualquer parasita.

Quando analisamos os dados da infecção pós quimioterapia, apresentados na tabela 10 , pode-se verificar que os desnutridos apresentam uma infecção mais precoce que os eutróficos como observado a partir da análise univariada realizada após um mês de tratamento. O risco relativo neste período para os desnutridos foi de $2,95 \operatorname{com} x^{2}=9,85$ e $p=0,0017$. Nas fases posteriores do estudo não houve diferença entre os dois grupos na proporção de infecção a nível de 5\% de significância.

As crianças que se reinfectaram representam $68 \%$ das crianças infectadas após o tratamento, sendo que a maioria das reinfecções $(78 \%)$ ocorrem logo nos primeiros 120 dias (gráfico 3). Este efeito mostra que existe um segmento da população que está mais susceptível a reinfecção. A existência de um segmento da população com maior susceptibilidade foi também observada em outros estudos como os Kightlinger e col. (1998) e Peng e col. (1998). Nestes estudos diversos fatores foram relacionados à predisposição para a reinfecção por helmintos, principalmente aqueles relativos a higiene, educação e hábitos 
sanitários da população, sendo que o papel do estado nutricional não foi especificamente investigado.

Foram observadas nesta população associações entre infecção por helmintos pós tratamento com o analfabetismo da mãe $(O R=3,15$ IC95\% 1,59 $6,24)$ e com a renda per capita inferior a $\mathrm{R} \$ 85,00(O R=2,56$ IC95\% $1,46-4,49)$. Estes resultados mostram a importância tanto do nível educacional da mãe, quanto da renda per capita na perpetuação da infecção por helmintos, e o quanto a mãe analfabeta não possui percepção adequada no cuidado da criança. Este achado é concordante com a literatura, onde tanto a infecção por helmintos quanto a desnutrição têm em comum a pobreza e baixa escolaridade dos pais. Observa-se porém, que neste estudo a associação existente com a infecção não ocorreu para a desnutrição infantil.

Embora o resultado acima seja significativo e suporte a hipótese de trabalho apresentada quando do planejamento do estudo, é necessário que se considere que outros fatores predisponentes para a infecção por parasitas possam estar contribuindo para o maior risco de infecção por parasitas na população de desnutridos, os quais não são considerados na análise univariada. Por exemplo, é possível que condições adversas de saneamento básico contribuam para o resultado observado. É importante ressaltar, por exemplo, que no bairro de Eldorado, as condições sociais e ambientais são mais precárias. Por outro lado, a idade da criança pode funcionar como um fator modulador da infecção parasitária, visto que crianças mais velhas apresentam um comportamento sanitário de maior 
risco, ou seja a maior exposição ao solo, fezes e objetos contaminados (Chan e col., 1994).

Com a finalidade de se controlar para estes fatores de confusão, eventualmente responsáveis por um erro do tipo I (associação não causal), foram elaborados modelos multivariados de riscos proporcionais, utilizando-se a técnica de Cox. Quando do cálculo dos coeficientes nos modelos de Cox, as variáveis explicativas local de moradia expressa como variável categórica e a idade da criança em meses foram consideradas simultaneamente ao estado nutricional. Como observado na tabela 13 o bairro do Eldorado, assim como a idade da criança apresentaram um risco relativo significativo para a infecção de parasitas. Porém, a inclusão destas novas variáveis independentes não afeta a significância da associação entre desnutrição e risco para a infecção por helmintos, mostrando que esta associação é robusta e não dependente de fatores etários ou das condições de urbanização.

Existem indicações de que a desnutrição de fato aumenta a susceptibilidade a infecção parasitária. Entretanto a análise realizada em uma subamostra da população $(\mathrm{n}=378)$ demonstrou que a renda per capita quando incluída no modelo de Cox reduz o efeito do estado nutricional como determinante da susceptibilidade da infecção. Assim sendo, é possível que o fator renda seja uma variável de confusão causando tanto desnutrição quanto aumento de susceptibilidade à infecção por razões de higiene, ou outros fatores ambientais. Tendo em vista estes aspectos, não se pode afastar a influência da pobreza sobre o déficit nutricional tomando-se por base medidas antropométricas 
Outro modelo foi elaborado no intuito de se avaliar a reinfecção por helmintos, neste modelo as variáveis preditivas foram as mesmas do modelo geral de infecção pós tratamento (idade, estado nutricional, local de moradia), e os resultados mostraram mais uma vez que as crianças desnutridas apresentam um risco de reinfecção de $R=2,29$ e $p=0,0016$, mesmo quando se controla este risco com a idade da criança e o local de moradia (tabela 13).

A reinfeç̧ão por helmintos apresenta um vasto campo de investigação, onde vários fatores estão envolvidos, tanto aqueles referentes ao meio ambiente como aqueles inerentes ao indivíduo, ou seja, fatores genéticos, imunológicos e comportamentais.

Este estudo aponta para a susceptibilidade das crianças desnutridas na infecção e reinfecção por parasitas intestinais, reforçando o conceito de que estas crianças merecem uma atenção diferenciada não só no tratamento das helmintíases, como também na implementação de medidas estruturais de maior amplitude, envolvendo educação e suporte nutricional, para evitar o efeito prejudicial do círculo vicioso representado pelo binômio desnutrição enteroparsitoses. Somente com estas medidas poder-se-á assegurar de forma mínima as condições para o desenvolvimento adequado de crianças pertencentes aos segmentos mais desfavorecidos da sociedade, permitindo-lhes a oportunidade de progredir, e com o seu progresso, assegurar o desenvolvimento do País. 


\section{Conclusões}


1. A prevalência de infecção por Ascaris lumbricoides e Trichuris trichiura em Santa Isabel é de $18,9 \%$ e $16,9 \%$, indicando que as enteroparasitoses são bastante prevalentes neste município próximo à Cidade de São Paulo.

2. A intensidade de infecção determinada pela técnica de contagem de ovos, no início do estudo, mostrou que a infecção intensa de Ascaris lumbricoides estava presente em $41 \%(7)$ dos desnutridos e $22 \%$ (19) dos eutróficos. Para Trichuris trichiura a infecção intensa era de $18 \%(6)$ nos desnutridos e $6 \%(5)$ nos eutróficos.

3. A prevalência da desnutrição infantil foi de $8 \%$, revelando que este problema no município de Santa Isabel têm uma magnitude maior que a encontrada no PNSN, 1989 para população urbana da região sudeste do país $(3,7 \%)$

4. O consumo alimentar mostrou que $48,8 \%$ das crianças estudadas apresentam consumo inadequado de calorias e $14 \%$ consumo inadequado de proteínas.

5. A reinfecção por helmintos após a quimioterapia ocorre de maneira distinta entre as crianças eutróficas e desnutridas.

6. A taxa de reinfecção para os eutróficos foi de $13 \%$ ano, enquanto que para os desnutridos foi de $28 \% /$ ano.

7. O risco relativo de reinfecção para as crianças desnutridas em relação às eutróficas foi de $\boldsymbol{R} \boldsymbol{R}=2,29$, considerando as variáveis medidas no estudo. 


\section{REFERÊNCIAS}


Albonico M, Smith PG, Ercole E, Hall A, Chwaya HM, Alawi KS, Savioli L. Rate of reinfection with intestinal nematodes after treatment of children with mebendazole or albendazole in a highly endemic area. Trans R Soc Trop Med Hyg 1995; 89: 538-41.

Amato NetoV, Corrêa LL. Exame parasitológico das fezes. $5^{\mathrm{a}}$ ed. São Paulo: Sarvier; 1991.

Anderson RM, May RM. Population dynamics of human helminth infections: control by chemotherapy.Nature 1982; 297:557-63.

Anderson RM, May RM. Helminth infections of humans: mathematical models, population dynamics and control. Adv Parasitol.1985; 24:1-101.

Anderson RM, Medley GF. Community control of helminth infections in man by mass and selective chemotherapy. Parasitology 1985; 90: 629-60.

Anderson RM. The population dynamics and epidemiology of intestinal nematode infections. Trans R Soc Trop Med Hyg1986; 80: 686-96.

Batista Filho M, Barbosa NP. Pró-memória: alimentação e nutrição 1974/85. Brasília: Ministério da Saúde/Instituto Nacional de Alimentação e Nutrição;1985.

Bloemberg BPM, Kromhout GL, Obermann de Boer GL, Van Kampen-Donker $M$. The reproducibility of dietary intake data assessed with the cross-check dietary history method. Am J Epidemiol 1989; 130: 1047-56.

Blumenthal DS, Schultz MC. Effect of Ascaris infection on nutritional status in children. Am J Trop Med Hyg 1976; 25:682-90.

Bundy DAP, Thompson DE, Cooper ES, Golden MHN, Anderson RM. Population dynamics and chemotherapeutic control Trichuris trichiura infection of children in Jamaica and St. Lucia. Trans R Soc Trop Med Hyg $1985 ; 79: 759-64$.

Bundy DAP, Cooper ES, Thompson PE, Anderson RM, Didier-Blanchard JM. Age-related changes in the prevalence and intensity of Trichuris-trichiura in a St. Lucia community. Trans R Soc Trop Med Hyg 1987; 81: 85-94. 
Bundy DAP, Hall A, Medley GF, Savioli L. Evaluating measures to control intestinal parasitic infections World Health Stat Q1992; 45: 168-79.

Bundy DAP, Silva NR. Can we deworm this wormy world? Br Med Bull 1998;54: 421-32.

Callender JEM, McGregor SM, Walker S, Cooper ES. Trichuris infection and mental development in children Lancet 1992; 339: 181.

Centers for Disease Control and Prevention. EPI INFO: a word processing, database and statistics program for public health. version $6.04 \mathrm{~b}$ [computer program] Atlanta:CDC; 1997.

Chan L, Kan SP, Bundy DAP. The effect of repeated chemotherapy on age-related predisposition to Ascaris lumbricoides and Trichuris trichiura. Parasitology 1992, 104:371-7.

Chan MS, Medley GF, Jamison D, Bundy DAP. The evaluation of potential global mortality attributable to intestinal nematode infections. Parasitology 1994a; 109: 373-387.

Chan MS, Guyatt HL, Bundy DAP, Medley GF. The development and validation of an age-structured model for the evalution of disease control strategies for intestinal helminths. Parasitology 1994b; 109: 389-96.

Chandra RK, Newberne PM. Nutrition, immunity and infection: mechanisms of interactions. New York: Plenum; 1977.

Chen LC, Alauddin-Chowdhury AKM, Huffman SL. Anthropometric assessment of energy-protein malnutrition and subsequent risk of mortality among preschool-aged children. Am J Clin Nutr. 1980; 33: 1836-45.

Chieffi PP, Waldman EA, Waldman CCS, Sakata EE, Gerbi LJ, Rocha AB, Aguiar PR. Aspectos epidemiológicos das enteroparasitoses no Estado de São Paulo Brasil Rev Paul Med 1982; 99(3):34-6.

Cook GC. Gastrointestinal helminth infections. The clinical significance of gastrointestinal helminths - a review. Trans R Soc Trop Med Hyg 1986; 80: 675-85. 
Crompton DWT, Whitehead RR. Hookworm infections and human iron metabolism. Parasitology 1993; 107: S137-45.

Croll NA, Anderson RM, Gyorkos TW, Ghadirian E. The population biology and control of Ascaris lumbricoides in a rural community in Iran. Trans R Soc Trop Med Hyg 1982; 76:187-97.

Davis A. Justifications for control and optimal deployment of chemotherapeutic tactics. In: Crompton DWT et al. Ascariasis and its prevention and control London: Taylor \& Francis; 1989. p. 45-69.

De Silva NR, Chan MS, Bundy DAP. Morbidity and mortalidy due to ascariasis: re-estimation and sensitivity analysis of global numbers at risk. Trop Med Int Health 1997a; 2 519-28.

De Silva NR, Guyatt H, Bundy DAP. Anthelmintics: a comparative review of their clinical pharmacology. Drugs 1997b; 53: 769-88.

De Silva NR, Jayapani VP, De Silva HJ. Socioeconomic and behavioral factors affecting the prevalence of geohelminths in preschool children. Southeast Asian J Trop Med Public Health 1996; 27: 36-42.

Dibley MJ, Goldsby JB, Staehling NW, Trowbridge FL. Development of normalized curves for the international growth reference: historical and technical considerations. Am J Clin Nutr 1987a; 46: 738-48.

Dibley MJ, Staehling NW, Nieburg P, Trowbrige FL. Interpretation of z-score anthropometric indicators derived from the internacional growth reference. Am J Clin Nutr 1987b; 46:749-62.

Dupont HL, Pickering LK. Infections of the gastrointestinal tract: microbiology, pathophysiology and clinical features. New York: Plenum; 1980 .

Dutra JEO, Cunha SFC, Marchini JS. A desnutrição dos pobres e dos ricos: dados sobre a alimentação no Brasil. São Paulo: Sarvier;1996.

Elkins DB, Haswell-Elkins M, Anderson RM. The importance of host age and sex to patterns of reinfection with Ascaris lumbricoides following mass anthelmintic treatment in South Indian fishing community. Parasitology 1988; 96:171-84. 
Forrester JE, Scott ME. Measurement of Ascaris lumbricoides infections intensity and the dynamics of expulsion following treatment with mebendazole. Parasitology 1990; 100:303-8.

FAO/WHO/UNO. Expert consultation on energy and protein requirements: Geneva: World Health Organization; 1985 (WHO Technical Report Series, 724).

Faust EC, Sawistz W, Tobie J, Odom V, Peres C, Lincicome D.R. Comparative efficiency of various technics for the diagnosis of protozoa and helminths in feces. J Parasitol 1939; 25: 241-62.

Fundação IBGE. Censo demográfico 1996. Rio de Janeiro; 1996.v. IV.

Fundação IBGE. Censo agropecuário 1995-1996. Rio de Janeiro; 199619 , p. 213.

Fundação Prefeito Faria Lima (CEPAM).Censo cultural São Paulo 1990: interior e capital.São Paulo: Secretaria de Estado da Cultura; 1991.

Fundação SEADE Anuário estatístico do Estado de São Paulo: 1997.São Paulo; 1997.

Gordon CC, Chumlea WC, Roche AF. Stature, Recumbent length, and weight. In: Lohman TG, Roche AF, Martorell R. Anthropometric standardization reference manual. Champaign, Illinois: Human Kinetcs Books; 1988.

Gupta MC, Arora KL, Mithal S, Tandon BN. Effect of periodic deworming on nutritional status of Ascarisinfested preschool children receiving supplementary food. Lancet $1977 ; 2: 108-10$.

Gupta MC. Intestinal parasitic infections and malnutrition. Indian J Pediatr 1980; 47: 503-9.

Gupta MC, Urrutia JJ. Effect of periodic anti-Ascaris and anti-Giardia treatment upon nutritional status of preschool children. Am J Clin Nutr 1982; 36: 79 86.

Gupta MC. Effect of ascariasis upon nutritional status of children. J Trop Pediatr 1990; 36: 189-91. 
Hall A, Anwar KS, Tomkins AM. Intensity of reinfection with Ascaris lumbricoides and its implications for parasite control. Lancet 1992; 339: 23, 1253-57.

Hamill PUU, Drizo TA, Johnson CL, Reed RB, Roche AF, Moore WM. Phisical Growth : NCHS percentiles. Am J Clin Nutr 1979; 32:607-29.

Henry FI, Huttly SRA, Ahmed MU, Alam A. Effect of chemotherapy on helminth reinfection in slums and villages in Bangladesh. Southeast Asian J Trop Med Public Health 1993; 24: 307-12.

Hoffman WA, Pons JÁ, Janer JL. The sedimentation concentration method in schistosomiasis mansoni: Puerto Rico J Public Health 1934; 9: 281-98.

Holland CV, Crompton DWT, Asaolu SO, Crichton WB, Torimiro SEA, Walters DE. A possibel genetic factor influencing protection from infection with Ascaris lumbricoides in Nigerian children. J Parasitol 1992; 78: 915-6.

Ismail MM, Rajapakse AL, Suraweera MGW, Weerasuriya K, Amarasinghe DKC. Some Socio-economic and health-related factors and soil-transmitted Nematode infections: 1. Relationship to prevalence and intensity of infection. In: Asian Parasite Control Organization Research Group. Collected Paper on the Control of Soil-transmitted Helminthiases.Tokio, 1989.v. 4. p. 23-38.

Katz NAC, Pellegrino J. A simple defice for quantitative stool thick-smear technique in schistosomiasis mansoni. Rev Inst Med Trop São Paulo 1972; 14: $397-400$

Kightlinger LK, Seed JR, Kightlinger MB. Ascaris lumbricoides aggregation in relation to child growth status, delayed cutaneous hypersensitivity, and plant anthelmintic use in Madagascar. J Parasitol 1996; 82: 25-33.

Kightlinger LK, Seed JR, Kightlinger MB. Ascaris lumbricoides intensity in relation to environmental, socioeconomic, and behavioral determinants of exposure to infection in children from southeast Madagascar. J Parasitol 1998; 84: 480-4.

Kleinbaum DG. Survival analysis: a self learning text. New York: SpringerVerlag; 1996.

Lunn PG, Northrop-Clewes CA . Symposium on Parasitism and protein and energy metabolism in man and animals. Proce Nutri Soc. 1993; 52: 101-11. 
Mata LJ. The children of Santa Maria Cauqué: a prospective field study of health and growth. Cambridge: MIT Press; 1978.

Miranda ECBM, Souza OS, Oliveira CS. Helmintíases intestinais. In: Leão RNQ, Doenças infecciosas e parasitárias: enfoque amazônico. Bélem-Pa: Editora Cejup; 1997 p.701-16.

Medlin C, Skinner J. Individual dietary intake methodology: a 50-year review of progress. J Am Diet Assoc 1988; 88:1250-7.

Mondini L, Monteiro CA. Mudanças no padrão de alimentação.In: Monteiro CA, organizador. Velhos e novos males da saúde no Brasil: a evolução do país e de suas doenças. São Paulo: Hucitec/Nupens/USP;1995 p.79-89.

Monteiro CA, Benicio MHD'A, Iunes RF, Gouveia NC, Cardoso, MAA. Evolução da Desnutrição Infantil. In: Monteiro CA organizador. Velhos e novos males da saúde no Brasil: a evolução do país e de suas doenças. São Paulo: Hucitec/Nupens/USP,1995. p. 93-114.

Muller R. Worms and disease. London: William Heinemann Medical Books, 1975.

Murray MJ, Murray AB. Starvation suppression and refeeding activation of infection. Lancet 1977; 123-5.

National Research Council. Recommended dietary allowances. 10th ed. Washington DC: National Academy Press; 1989.

Nokes C, Grantham-McGregor SM, Sawyer AW, Cooper ES, Robinson BA, Bundy DAP. Moderate to heavy infections of Trichuris trichiura affect cognitive function in Jamaican school children. Parasitology 1992; 104: 53947.

Oberhelman RA, Guerrero ES, Fernandez ML, Silio M, Mercato D, Comiskey N, et al. Correlations between intestinal parasitosis, physical growth, and psychomotor development among infants and children from rural Nicaragua. Am J Trop Med Hyg 1998; 58:470-5.

Organizacion Mundial de la Salud. Medicion del cambio del estado nutricional: diretrices para evaluar el efecto nutricional de programas de 
alimentacion suplementaria destinados a grupos vulnerables. Ginebra; 1983.

Partnership for Child Development. Better health, nutrition and education for the school-aged child. Trans R Soc Trop Med Hyg 1997; 91: 1-2.

Peng W, Zhou X, Cui X, Crompton DWT, Whitehead RR, Xiong $\mathrm{J}$ et al. Transmission and natural regulation of infection with Ascaris lumbricoides in a rural community in China. J Parasitol 1998; 84: 252-8.

Philippi ST, Szarfarc SC, Latterza AR. Virtual Nutri. sistema de análise nutricional, Versão 1.0 for windows. São Paulo; 1996.

Ruiz A, Ocampo G, Soto A, Jose MV. Degree of aggregation of Ascaris lumbricoides according to age groups after a massive antihelminthic intervention. Salud Publica Mex 1996; 38:249-56.

Rugai E, Mattos TG, Brisola A. Nova técnica par isolar larvas de nematóides das fezes - Modificação do método de Baermann. Rev Inst Adolfo Lutz 1954; 14: $5-8$.

Saldiva SRM. Enteroparasitoses: indicadores antropométricos e inquérito alimentar em crianças de uma localidade rural do Estado de São Paulo. São Paulo; 1995. [Dissertação de Mestrado - Faculdade de Saúde Pública da USP].

Saldiva SRDM, Silveira ASB, Phillipi ST, Torres MAGV, Mangini ACS, Dias $\mathrm{RM}$ et al. Ascaris-Trichuris association and malnutrition in Brazilian children. Paediatr Perinat Epidemiol 1999; 13: 89-98.

Simeon DT, Granthan-Mc Gregor SM, Callender JE, Wong MS. Treatment of Trichuris Trichiura infection improves growth, spelling scores and school attendance in some children. J Nutr 1995; 125:1875-83.

Scrimshaw NS, Taylor CE, Gordon JE. Interactions of nutrition and infection. Am J Med Sci 1959; 237: 367-403.

Shiddo S, Ilardi I, Mussa C, Mohamud MA, Aceti A, Leone F et al. Reinfection of Somali children with Trichuris trichiura after chemotherapy: relevance of immunostimulation. Trans R Soc Trop Med Hyg 1990; 84: 832-6. 
Shrimpton R. Ecologia da desnutrição na infância, análise da evidência das relações entre as variáveis sócio-econômicas e estado nutricional. Brasília: Centro Nacional de Recursos Humanos do IPEA/ UNICEF; 1986.

Soeripto N. Reinfection and infection rates of soil-transmitted helminths in Kemiri Sewu, Yogyakarta, Indonesia. Southeast Asian J Trop Med Public Health 1991; 22:216-21.

SPSS Inc. SPSS 9.0 for windows. [computer program].Chigago; 1999.

Stephenson LS, Holland C. Impact of helminth infections on human nutrition. London: Taylor \& Francis; 1987.

Stephenson LS, Latham MC, Adams EJ, Kinoti SN, Pertet A. Weight gain of Kenyan school children infected with hookworm, Trichuris trichiura and Ascaris lumbricoides is improved following once- or twice yearly treatment with albendazole. J Nutri 1993a; 123: 656-65.

Stephenson L, Latham M, Adams E, Kinoti S, Pertet A. Physical fitness, growth and apetite of Kenyan schoolboys with hookworm, Trichuris trichiura and Ascaris lumbricoides infections are improved four months after a single dose of albendazole. J Nutri 1993b; 123: 1036-46.

Targett GAT. Malnutrition and immunity to protozoa parasites. In: Isliker $\mathrm{H}$, Schurch $B$, editors. The impact of malnutrition on immune defense in parasitic infestation. Bern: Has Huber; 1980. p. 158-179.

Thein-Hlaing, Thane-Toe, Than-Saw, Myat-Lay-Kyn, Myint-Lwin. A controlled chemotherapeutic intervention trial on the relationship between Ascaris lumbricoides infection and malnutrition in children. Trans R Soc Trop Med Hyg 1991; 85: 523-8.

Waldman EA, Silva LJ, Monteiro CA. Trajetória das doenças infecciosas: da eliminação da poliomelite à reintrodução da coléra. In: Monteiro CA, editor. Velhos e novos males da saúde no Brasil: a evolução do país e de suas doenças. São Paulo: HUCITEC; 1995, 195-244.

Watkins WE, Pollitt E. "Stupidity or worms": do intestinal worms impair mental performance? Psychol Bull 1997; 121: 171-91. 
Whitfield PJ. Parasitic Helminths. In: Coxn FEG. Modern Parasitology: a textbook of parasitology. $2^{\text {th }}$ ed.Oxford: Blackwell Science; 1996, p.24-52.

Weisell RC, Francois PJ. Reference weight for height standards: an easier approach for computerization. Food Nutr 1982; 8:12-8.

Willet WC, Kilama WL, Kihamia CM. Ascaris and growth rates: a randomized trial of treatment. Am J Public Health 1979; 69:987-91.

World Health Organization. Soil transmited helmints: report. Geneva; 1964. (WHO Technical Report Series, 277).

World Health Organization. Control of ascariasis: report Geneva; 1967. (WHOTechnical Report Series, 379)

World Health Organization. Intestinal protozoan and helminthic infections: report Geneva; 1981. (WHO - Technical Report Series, 666).

World Health Organization. The use of essential drugs: report. Geneva; 1985.(WHO-Technical Report Series 722).

World Health Organization. Use and interpretation of anthropometric indicators of nutritional status. Bull World Health Organ 1986; 64:929-41.

World Health Organization. Prevention and control of intestinal parasitic infections: report. Geneva; 1987. (WHO Technical Report Series, 749).

Zaman V. Intestinal nematodes of man. Drugs 1978; 15 suppl.1:63-9. 
Anexo 1 


\section{HOSPITAL DAS CLÍNICAS \\ DA}

FACULDADE DE MEDICINA DA UNIVERSIDADE DE SÃO PAULO

TERMO DE CONSENTIMENTO PÓS -INFORMAÇÃO

(Obrigatório Para Pesquisas Científicas em Seres Humanos - Resolução No 01 de 13_6_1988 - CNS)

\section{I - DADOS DE IDENTIFICAÇÃO DO PACIENTE OU RESPONSÁVEL LEGAL.}

1. RESPONSÁVEL LEGAL:

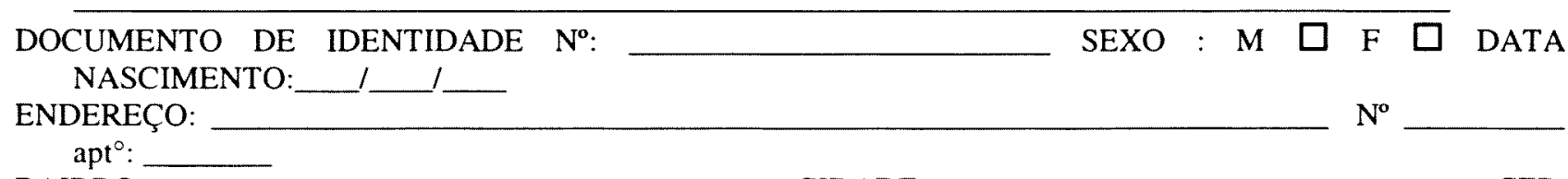

BAIRRO:

TELEFONE:(_LH_L_L

CIDADE:

CEP:

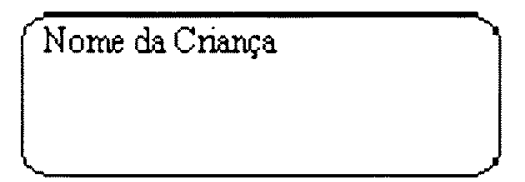

Nome da Criança

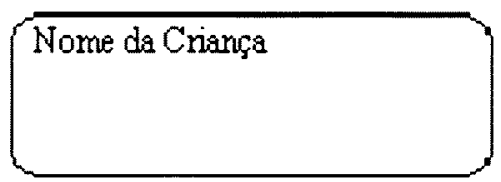

Nome da Criança

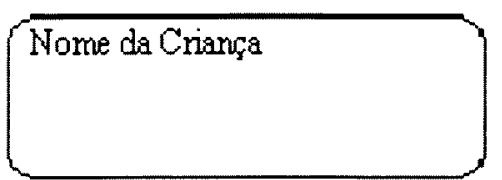

Nome da Criança (2)

II - DADOS SOBRE A PESQUISA CIENTÍFICA.

1. TÍTULO DO PROTOCOLO DE PESQUISA: O Papel do Estado Nutricional na Reinfeccão Pós-Tratamento Anti. $\underline{\text { Parasitário no }}$

Município de Santa Isabel, São Paulo.

2. PESQUISADOR: Prof. Dr. Eduardo Massad. $\quad$ CARGO/FUNÇÃO: Médico. $\quad$ INSCRIÇÃO CONSELHO REGIONAL No 40158

UNIDADE DO HCFMUSP: Patologia - Disciplina de Informática Médica da USP - LIM 01.

3. AVALIAÇÃO DO RISCO DA PESQUISA: (probabilidade de que o indivíduo sofra algum dano como consequência imediata ou tardia do estudo)

凶 SEM RISCO

$\square$ RISCO MINIMO

RISCO MÉDIO

RISCO MAIOR

4. APROVAÇÃO DO PROTOCOLO DE PESQUISA PELA COMISSÃO DE ÉTICA PARA ANÁliSE DE PROJETOS DE PESQUISA EM: $1 \mathbf{1 7 / 0 7 / 9 7}$

5. DURAÇÃO DA PESQUISA : $\underline{01}$ ano.

\section{III - CONSENTIMENTO PÓS-ESCLARECIDO.}

Declaro, após ter sido convenientemente esclarecido pelo pesquisador, conforme registro nos itens 1 a 11 , do inciso IV denominado "Explicações do Pesquisador ao Paciente ou seu Representante Legal" em meu poder, meu consentimento em participar do presente Projeto de Pesquisa.

São Paulo, de de 19

ASSINATURA DO RESPONSÁVEL LEGAL

(NOME LEGÍvEL POR EXTENSO)
Prof. Dr. Eduardo Massad ASSINATURA DO PESQUISADOR QUE OBTEVE O CONSENTIMENTO (CARIMBo OU NOME LEGÍvel) 


\section{Projeto de Pesquisa FAPESP N 96/1126-0 - "O PAPEl do Estado Nutricional na Reinfecção Pós-Tratamento Anti-Parasitário no Município de Santa ISAbel, São PAUlO."}

(Para quaisquer esclarecimentos entrar em contato com Prof. Dr. Eduardo Massad no tel: (011) 881.77.17)

\section{IV - EXPLICAÇÕES dO PESQUISADOR AO PACIENTE OU SEU REPRESENTANTE LEGAL.}

1. JUSTIFICATIVA E OS OBJETIVOS DA PESQUISA. (explicitar)

O Projeto de Pequisa FAPESP N ${ }^{\circ}$ 96/1126-0 “O Papel do Estado Nutricional na Reinfecção Pós-Tratamento Anti-Parasitário no Município de Santa Isabel, São Paulo", visa estabelecer os níveis de prevalência de parasitas intestinais e de desnutrição em crianças de 01 a 10 anos de idade, assim como a intensidade e grau de reinfecção após quimioterapia de massa.

2. PROCEDIMENTOS QUE SERÃO UTILIZADOS E PROPÓSITOS, INCLUINDO A IDENTIFICAÇÃO DOS PROCEDIMENTOS QUE SÃO EXPERIMENTAIS. (explicitar)

Serão aplicados questionários que abordam fatores sócio-econômicos, tais como: moradia, saúde e alimentação. Será também colhido amostras de fezes de cada participante do estudo, com finalidade diagnóstica e avaliação do nível endêmico das verminoses, seguindo-se tratamento individual e orientado.

3. DESCONFORTOS E RISCOS ESPERADOS. (explicitar)

Tempo disponivel para responder à aplicação do questionário.

4. BENEFÍCIOS QUE PODERÃO SER OBTIDOS: (explicitar)

Todas as crianças terão medicamento gratuito para o tratamento das verminoses diagnosticadas.

5. PROCEDIMENTOS ALTERNATIVOS QUE POSSAM SER VANTAJOSOS PARA O INDIVÍDUO. (explicitar)

Orientação sobre a alimentação da criança, controle de peso e encaminhamento ao Serviço de Saúde, quando detectado algum distúrbio de saúde.

6. ESCLARECIMENTO SOBRE A GARANTIA DE RECEBER RESPOSTA A QUALQUER PERGUNTA OU ESCLARECIMENTO, A QUALQUER DÚVIDA ACERCA DOS PROCEDIMENTOS, RISCOS, BENEFÍ́CIOS E OUTROS ASSUNTOS RELACIONADOS COM A PESQUISA E O TRATAMENTO DO INDIVÍDUO.
冈 Sim
$\square$ Não

7. ESCLARECIMENTO SOBRE A LIBERDADE DE RETIRAR SEU CONSENTIMENTO A QUALQUER MOMENTO E DEIXAR DE PARTICIPAR NO ESTUDO, SEM QUE ISTO TRAGA PREJUÍZO À CONTINUAÇÃO DO SEU CUIDADO E TRATAMENTO.
囚 Sim
$\square$ Não

8. COMPROMISSO SOBRE A SEGURANÇA DE QUE NÃo SE IDENTIFICARÁ O INDIVÍdUO E QUE SE MANTERÁ O CARÁTER CONFIDENCIAL DA INFORMAÇÃO RELACIONADA COM A SUA PRIVACIDADE.
囚 $\operatorname{Sim}$
$\square$ Não

9. COMPROMISSO DE PROPORCIONAR INFORMAÇÃO ATUALIZADA OBTIDA DURANTE O ESTUDO, AINDA QUE ESTA POSSA AFETAR A VONTADE DO INDIVÍDUO EM CONTINUAR PARTICIPANDO.
冈 Sim
$\square$ Não

10. DISPONIBILIDADE DE ASSISTÊNCIA NO HCFMUSP.
$\square \operatorname{Sim}$
凶 Não

11. OBSERVAÇÕES COMPLEMENTARES: Nada a declarar.

Prof. Dr. Eduardo Massad 
ANeXo 2 


\section{Ficha Individual}

\section{Identificação da criança: \\ número \\ da \\ criança: \\ Data:................... \\ Qc1. Nome completo da criança:}

\section{Qc2. Sexo}

1.[ ]masculino

2. [

Jfeminino

\section{Qc3. Data de nascimento}

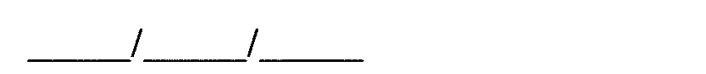

Seção 1- Suplementação

Alimentar

Qc4. A criança frequienta creche ou escola?

1.[ ]não $\rightarrow($ siga 7)

2.[ ] $\operatorname{sim}$

Qc5. Quanto tempo fica?

1.[ ]meio período

2.[ ]período integral
Qc6. A instituição oferece alguma refeição?

1.[ ]não

2.[ ] ]sim, 1 refeição

3.[ ]2 refeições

4.[ ]3 ou mais refeições

Qc7. A criança está matriculada em alguma instituição que distribui alimentos para levar para casa?

1.[ ]não (siga 10)

2.[ ] $\operatorname{sim} \Rightarrow$ Qual:

Qc8. Classificação da Instituição

1.[ ]centro/posto de saúde

2.[ ]entidade filantrópica

3.[ ]outra $\Rightarrow$ Qual:

Qc9. Estes alimentos são suficientes para quanto tempo?

1. [ ] menos de uma semana

2. [ ] 1 semana

3. [ ] 2 semanas

4. [ ] mês todo 
Qc10. Recebeu leite em pó de alguma Instituição?
1.[ ]não
2.[ ] $\operatorname{sim}$

Qc11. Recebeu leite de saquinho do Centro de Saúde?

1.[ ]não

2.[ ] $\operatorname{sim}$

Seção 2-Saúde da criança

Qc12. No último mês a criança foi internada alguma vez em Hospital?
1.[ ] $\operatorname{sim}$
2.[ ] não $\rightarrow$ (siga 14)

Qc13. Quantas vezes?

internações.

Pergunte e anote no quadro a causa de cada internação.

\begin{tabular}{|l|l|}
\hline Causas(s) & Dias \\
\hline
\end{tabular}

\begin{tabular}{|l|l|}
\hline & \\
\hline & \\
\hline & \\
\hline & \\
\hline
\end{tabular}

Qc14. No último mês a criança teve algum episódio de diarréia?
1.[ ] $\operatorname{sim}$
2.[ ]não $\Rightarrow$ (siga19)

\section{Qc15. Quantos episódios?}

episódios de diarréia.

Qc16. Tomou soro?
1.[ ] $\operatorname{sim}$
2.[ ]não

Qc17. Diminuiu o apetite?
1.[ ] $\operatorname{sim}$
2.[ ]não

Qc18. Procurou o Serviço de Saúde?
1.[ ] sim
2.[ ]não

Qc19. No último mês a criança teve Resfriado, Bronquite, Tosse, Dor de ouvido ou Chiado no Peito?
1.[ ] $\operatorname{sim}$
2.[ ]não(siga 24)

Qc20. Quantas vezes?

Qc21. Tomou remédio?
1.[ ] $\operatorname{sim}$
2.[ ]não

Qc22. Diminuiu o apetite?
1.[ ] $\operatorname{sim}$
2.[ ]não

Qc23. Procurou o Serviço de Saúde?

1.[ ] $\operatorname{sim}$

2.[ ]não 
Qc24. A criança tem alguma outra doença além daquelas que perguntamos?

1.[ ]não

2.[ ] $\operatorname{sim} \rightarrow$ Qual:.

\section{Seção 3- Alimentação}

Qc25. Na última semana o apetite da criança esteve:

1.[ ]diminuído

2.[ ]normal

3.[ ]aumentado

4.[ ]não sabe/não informou

Qc26. A sra. procurou oferecer alimentos à criança mais vezes do que o habitual?

1.[ ]não 2.[ ]sim

Qc27. A sra. deu algum remédio ou vitamina para abrir o apetite da criança?

1.[ ]não 2.[ ]sim $\Rightarrow$ Qual.
Seção 4 - Exame Antropométrico

Examinador:
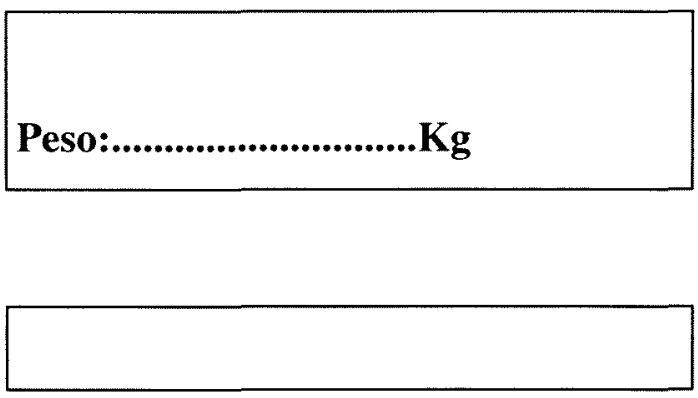

Altura:.........................cm 
ANEXo 3 


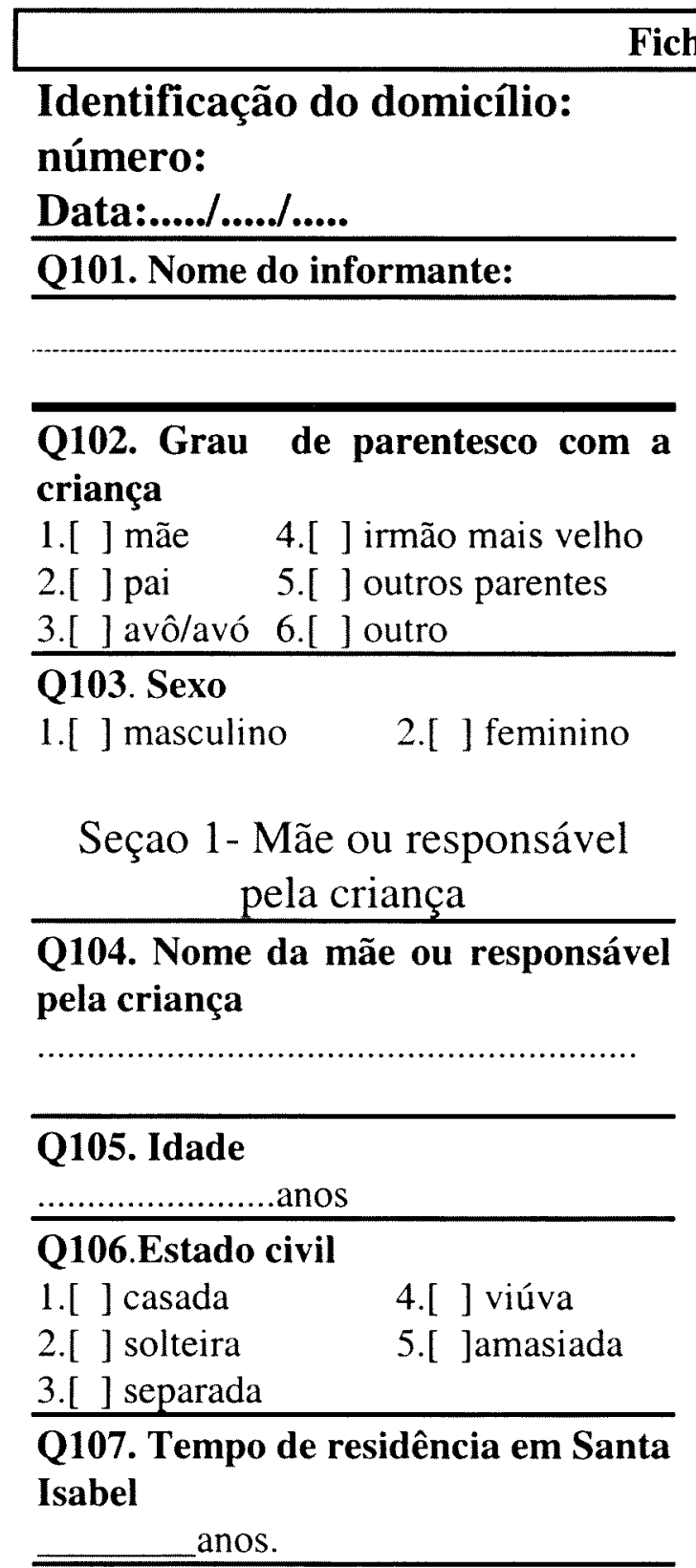

\begin{tabular}{|c|c|}
\hline $\begin{array}{l}\text { Q108. Sabe Ler? } \\
\text { 1.[ ] não }\end{array}$ & 2.[ ] $\mathrm{sim}$ \\
\hline Q109. Sabe Escreve & \\
\hline 1.[ ] não & 2.[ ] sim \\
\hline $\begin{array}{l}\text { Q110. Frequientou } \\
\text { 1.[ ] não (siga } 113 \text { ) }\end{array}$ & cola? \\
\hline
\end{tabular}


SEÇÃO 2- Chefe da Família

Se o Chefe for a "Mãe ou

Responsável” $\Rightarrow$ Siga Seção3.

Q21. Nome do Chefe do Domicílio

Q22. Sexo

1.[ ] masculino

2.[ ] feminino

Q23. Idade

anos

Q24. Tempo de residência em Santa Isabel

anos.

Q25. O Chefe sabe ler?

1.[ ]não

2.[ ] $\mathrm{sim}$

Q26. O Chefe sabe escrever?

1.[ ]não 2.[ ] $\operatorname{sim}$

Q27. Chefe freqüentou escola?

1.[ ] não (siga 210)

2.[ ] sim

Q28. Até que série/ano cursou? série/ano (completos)

Q29. De que grau?

1.[ ] $1^{0}$ grau incompl(ou antigo primário)

2.[ ] $1^{0}$ grau completo (ou antigo ginásio)

3.[ ] $2^{0}$ grau incompl.(ou antigo científico)

4.[ ] $2^{\circ}$ grau compl.(ou antigo científico)

7.[ ] outro - Qual:..

Q210. O Chefe está trabalhando no momento?

$\begin{array}{ll}\text { 1.[ ] não } & \text { 2.[ ] sim }\end{array}$

Q211. O Chefe trabalhou no último mês?

\begin{tabular}{llll} 
1.[ ] não & 2.[ ] $\operatorname{sim} \approx($ siga 214$)$ \\
\hline Q212. Por que não está
\end{tabular} trabalhando?

1.[ ] está desempregado

2.[ ] é aposentado/pensionista

3.[ ] está de licença/afastado

4.[ ] outros motivos

$\rightarrow$ Quais:.................

Q213. Há quantos meses o Chefe não trabalha?
Q214. Relação de trabalho do Chefe

1. [ ] empregado com vínculo

2. [ ] empregador

3. [ ]conta própria com estabelecimento

4. [ ] conta própria em casa de clientes

5. [ ] ]outra $\rightarrow$ Qual:..............................

Questões 215 e 216 apenas para

Chefes que são assalariados e que trabalharam no último mês.

Q215. A empresa onde o Chefe da Família trabalha oferece: (marque mais de um " $X$ "se necessário).

1. [ ] cesta básica

2. [ ] vale refeição

3. [ ] vale alimentação

9. [ ]nenhuma das anteriores

Q216. A cesta é suficiente para quanto tempo?

1. [ ] menos de uma semana

2. [ ] 1 semana

3. [ ] 2 semanas

4. [ ] mês todo

Q217. A Família recebe Cesta Básica de alguma Instituição Social?

1. [ ] não $\Rightarrow$ ( siga seção 3 )

2. [ ] sim, regularmente (todo mês)

3. [ ] sim, irregularmente ( pelo menos 1 vez nos últimos 12 meses)

Q218. A cesta é suficiente para quanto tempo?

1. [ ] menos de uma semana

2. [ ] 1 semana

3. [ ] 2 semanas

4. [ ] mês todo 
SEÇÃO 3- Renda Familiar

\begin{tabular}{l}
\hline $\begin{array}{l}\text { Q31. Número de pessoas no } \\
\text { domicílio } \\
\text { pessoas }\end{array}$ \\
\hline
\end{tabular}

Q32. Número de pessoas com renda própria pessoas

Q33. Perguntar a Renda Mensal de cada morador com renda própria. Anotar a renda em Reais informada.

$\begin{array}{ll}\text { 1.Chefe de família } & \mathrm{R} \$ \\ \text { 2. } & \mathrm{R} \$ \\ \text { 3. } & \mathrm{R} \$ \\ \text { 4. } & \mathrm{R} \$ \\ \text { 5. } & \mathrm{R} \$ \\ 6 . & \mathrm{R} \$ \\ \text { Total } & \end{array}$

Q34. A família tem outras fontes de renda? (aluguel, pensão, etc.)

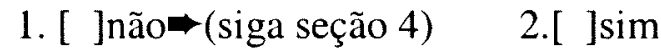
9. [ ]não sabe

Q35. Valor total de outras rendas $\mathrm{R} \$$

9. [ ]não sabe

SEÇÃO 4 - Características do Domicílio.

\begin{tabular}{llllll}
\hline As & questões & 41 & a & 44 & serão
\end{tabular} preenchidas a partir da observação da vizinhança do domicílio.

Q41. Área na vizinhança do
domicílio

1. [ ] área residencial

2. [ ]área de cortiço

3. [ ] área rural

4. [ ]área comercial

5. [ ]outra
Q42. Pavimentação

1. [ ]rua e calçada pavimentadas

2. [ ]somente a rua pavimentada

3. [ ]somente a calçada pavimentada

4. [ ]rua e calçada sem pavimentação

Q43. Esgoto a céu aberto?

1. [ ] não

1.[ ] $\mathrm{sim}$

Q44. Terreno baldio com lixo?

1. [ ] não

1.[ ] sim

Q45. Tipo de domicílio

1. [ ] casa

2. [ ] quarto ou cômodo

3. [ ]outro Qual:...

Q46. Tipo de parede predominante no domicílio

1. [ ] alvenaria com revestimento

2. [ ] alvenaria sem revestimento

3. [ ] madeira aparelhada

4. [ ] madeira aproveitada, latas, etc.

5. [ ] barro, pau-a-pique

6. [ ] outra $\Rightarrow$ Qual:.

Q47. Tipo de piso predominante

1.[ ] tacos/madeira

2.[ ] carpete

3.[ ] cimento ou tijolo

4.[ ] cerâmica

5.[ ] terra 6.[ ]outro $\rightarrow$ Qual:.........

Q48. Total de cômodos no domicílio

1.[ ]Um 4.[ ]Quatro ou mais

2.[ ]Dois

3.[ ]Três

Q49. Total de dormitórios

1.[ ]Um

3.[ ]Três

2.[ ]Dois

4. [ ] 4 ou mais.

Q410. Cozinha exclusiva?

1.[ ] $\operatorname{sim}$

2.[ ]não

Q411. Água utilizada no domicílio

1.[ ] SAE canalizada

2.[ ] SAE ponto único

3.[ ]Poço/mina canalizada

4.[ ]Poço/mina não canalizada

Q412. Costuma faltar água?

$\begin{array}{ll}\text { 1.[ ]não } & \text { 2.[ ]sim }\end{array}$

Q413. Água Encanada na cozinha

1.[ ] não tem

2.[ ] caixa d'água ligada a rede pública

3.[ ] caixa d'água ligada direto ao poço 


\section{Q414. Existência de chuveiro}

1.[ ]não tem

2.[ ]individual

3.[ ]coletivo

\begin{tabular}{l}
\hline Q415. Existência de privada ou \\
latrina \\
1.[ ] não tem \\
2.[ ]individual com água canalizada \\
3.[ ]coletiva com água canalizada \\
4.[ ]individual sem água canalizada \\
5.[ ]coletiva sem água canalizada \\
\hline Q416. Destino do Esgoto \\
1.[ ]rede pública de esgoto \\
2.[ ]fossa séptica \\
3.[ ]fossa rudimentar(fossa negra) \\
4.[ ] vala/céu aberto \\
5.[ ]não tem instalação sanitária \\
9.[ ]não sabe
\end{tabular}

Q417. Destino do lixo(marcar mais de uma resposta se necessário)

1.[ ]coleta pública regular(pelo menos 2 $x$ por semana)

2.[ ]coleta pública irregular(containers)

3.[ ]queimado

4.[ ]enterrado

5.[ ]colocado em terreno baldio

6.[ ]córrego/rio

7.[ ]outro

$\rightarrow$ Qual:
SEÇÃO 5-Cômodo das Crianças

As questões seguintes referem ao cômodo onde dormem as crianças

Q51. Quantas pessoas dormem no cômodo?

1.[ ]dois 2.[ ]três

3.[ ]quatro 4.[ ]5 ou mais

Q52. As crianças dormem na mesma cama?

$\begin{array}{ll}\text { 1.[ ]não 2.[ ]sim } & \text { 2. }\end{array}$

Q53. Tipo de Piso

1.[ ] tacos/madeira 4.[ ] cerâmica

2.[ ] carpete 5.[ ] terra

3.[ ] cimento/tijolo 6.[ ]outro

$\rightarrow$ qual:.........

Q55. Umidade "permanente" nas paredes

1.[ ]não $\quad$ 2.[ ] ]sim 
ANexo 4 


\section{Recordatório 24 horas}

número da criança:

data

Examinador:

Nome do entrevistado:

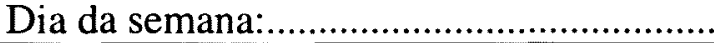

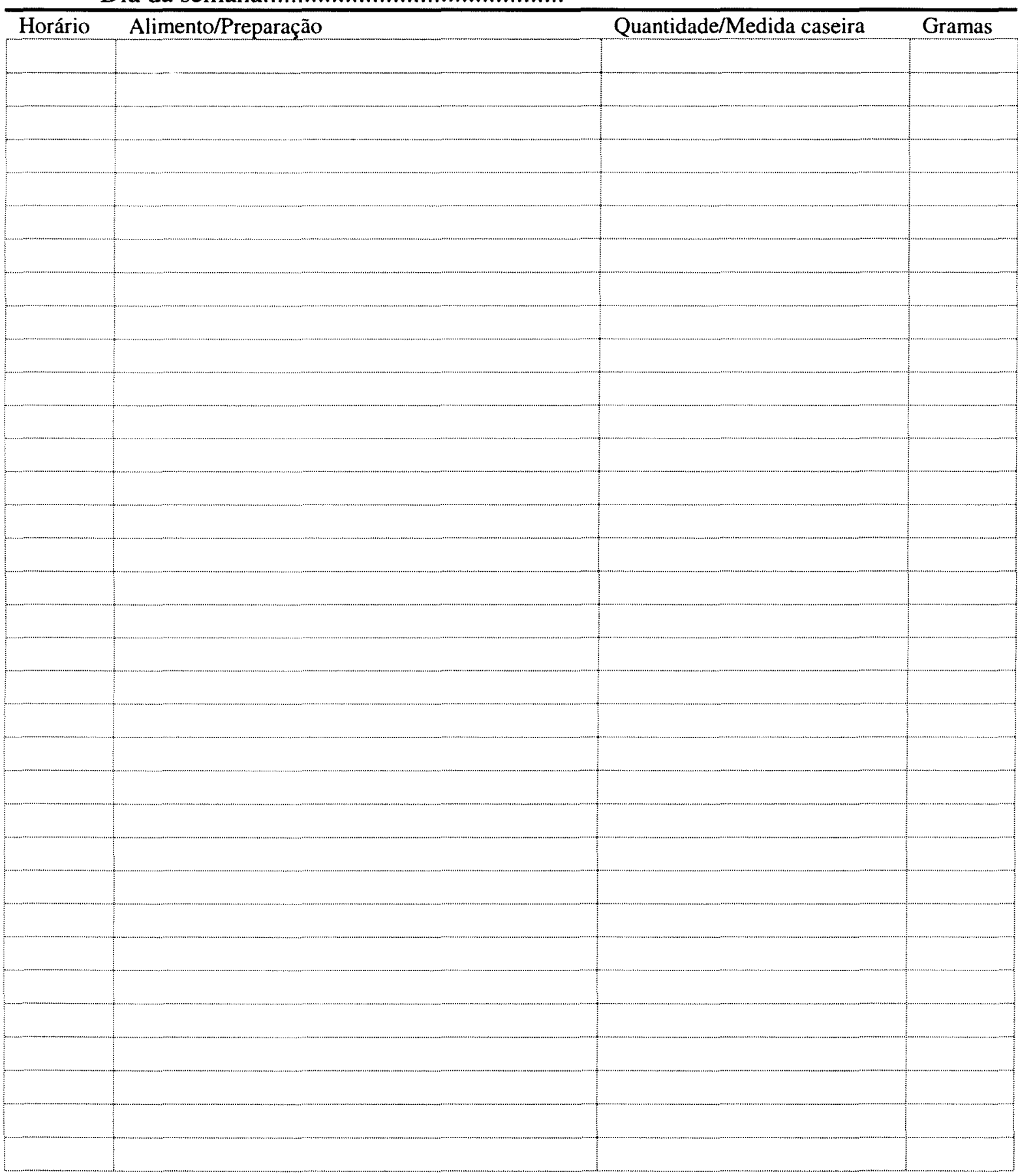

Obs.: Caso necessário, anotar no verso a receita das preparações. 